\title{
REVIEW
}

\section{¿Comparison of Rainfall Products over Sub-Saharan Africa}

\author{
CAMILle Le COZ AND Nick VAN DE GIESEN \\ Department of Water Resources Management, Delft University of Technology, Delft, Netherlands
}

(Manuscript received 17 January 2019, in final form 1 November 2019)

\begin{abstract}
An ever-increasing number of rainfall estimates is available. They are used in many important applications such as flood/drought monitoring, water management, or climate monitoring. Such data are especially valuable in sub-Saharan Africa, where rainfall has considerable socioeconomic impacts and the gauge and radar networks are sparse. The choice of a rainfall product can significantly influence the performance of such applications. This study reviews previous works, evaluating or comparing rainfall products over different parts of sub-Saharan Africa. Three types of rainfall products are considered: the gauge-only, the satellite-based, and the reanalysis ones. In addition to the global rainfall products, we included three regional ones specifically developed for Africa: the African Rainfall Climatology version 2 (ARC2), the Rainfall Estimate version 2 (RFE2), and the Tropical Applications of Meteorology Using Satellite Data and Ground-Based Observations (TAMSAT) African Rainfall Climatology and Time Series (TARCAT). The gauge density, the orography, and the rainfall regime, which vary with the climate and the season, influence the performance of the rainfall products. This review does not focus on comparing results, as many other publications doing so are already available. Instead, we propose this review as a guide through the different rainfall products available over Africa, and the factors influencing their performances. With this review, the reader can make informed decisions about which products serve their specific purpose best.
\end{abstract}

\section{Introduction}

Knowledge about precipitation is very important in sub-Saharan Africa, since $95 \%$ of the agriculture there is rain-fed (FAO 2016), making farmers vulnerable to climate change and extreme weather. Rainfall is a difficult variable to estimate accurately due to its large spatial variability, and even more so in Africa, since rainfall there is mainly generated by convective rainstorms, which can be very localized in time and space.

There are different types of precipitation data available in Africa. In situ measurements from gauges can be accurate, but reporting weather stations are especially sparse over Africa. Their number is often under the minimum recommended by World Meteorological Organization (WMO) and has been decreasing. The national meteorological agencies are often underfunded,

¿ Denotes content that is immediately available upon publication as open access.

Corresponding author: Camille Le Coz, c.m.1.lecoz-1@tudelft.nl and so cannot maintain or upgrade their station network; for example, some manual stations might still work but are not reporting to the global systems such as the Global Telecommunication System (GTS). Another possible source of data is satellite estimates, which cover a large area, but are more indirect. They derive precipitation rates from other measurements such as cloud properties (e.g., cloud-top temperature and radiation scattering by ice particles). There also have been efforts to use lightning observations ( $\mathrm{Xu}$ et al. 2013, 2014) or satellite soil moisture data (Brocca et al. 2013, 2014). A third possibility is precipitation fields from numerical weather models. They can be used to estimate both past (reanalysis) and future (forecast) precipitation, or to better understand the mechanism of the monsoon. They can cover the entire globe for long periods or focus on a region with high temporal and spatial resolution. These three different

This article is licensed under a Creative Commons Attribution 4.0 license (http://creativecommons.org/ licenses/by/4.0/) 
sources of data have different advantages and limitations. Rainfall products can be based on one or several sources to combine the advantages and cancel out limitations.

Different global rainfall products are available at different spatial and temporal scales. Some regional rainfall products have been developed and calibrated especially for Africa or a specific region. These various products use very different approaches to derive rainfall estimates. They can be divided into three categories: 1) reanalyses, based on a numerical weather prediction models and on data assimilation;2) gauge-only products, derived only from gauge data; and 3) satellitebased products, based only or partially on satellite data. Most of the latter ones use gauges for calibration or bias adjustment and a few (e.g., CMAP and CHIRPS; see appendix A for a list of acronyms) also use data from models. Tables 1-3 give a comprehensive list of rainfall products available over Africa for these three categories, respectively. The algorithms of the most used satellitebased products are described in appendix B, along with a review of their performances over Africa from various evaluation studies.

All these products differ in various ways. They have different advantages and weaknesses. Moreover, precipitation data are used for different purposes, such as hydrological applications, climatology studies, flood or drought early warning systems, or water management and planning. Depending on the application, the relevant characteristics are not the same. For instance, for drought monitoring one is interested in the good representation of small rainfall amounts (Maidment et al. 2014), while for climatology, consistency of the product's performance in time is more important, for example, no changes in the bias due to a new input data. In a recent review, Sun et al. (2018) described 30 datasets (including gauge-based, satellite-related, and reanalysis data), and examined the discrepancies between them at different time scales. They found large differences in northern Africa (among other regions). This means that the choice of a precipitation product can have a large impact on one's application. It is difficult to know which rainfall product, among the many existing ones, is the best to use according to the region of interest and the application considered, but also to know why and to which extent it is reliable. It is important to compare them with each other and be aware of their advantages, limits, and relative performances.

The International Precipitation Working Group (IPWG) supports the intercomparison of rainfall products (http:// www.isac.cnr.it/ ipwg/). They maintain a list of publicly available, quasi-operational, and quasi-global products, and are conducting some verification/validation over selected regions (Australia, Europe, Japan, South Africa,

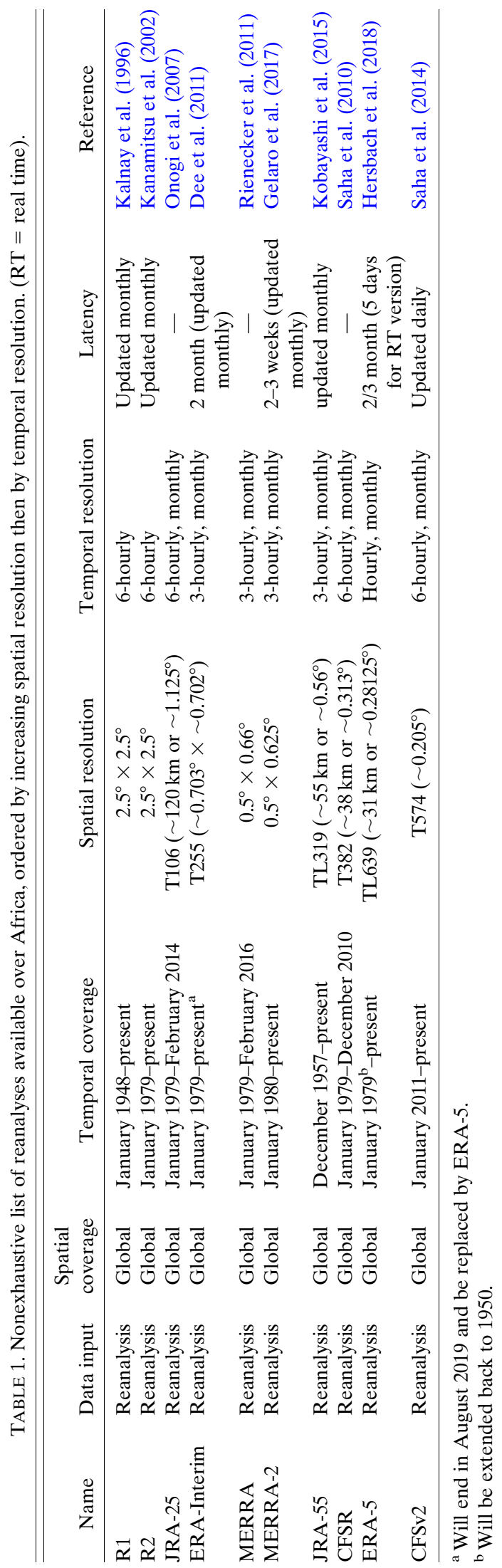


South America, and the United States) against groundbased radar and gauge networks. So far, they have not yet conducted any validation/comparison project over sub-Saharan Africa. The IPWG only takes into account the satellite and gauge products; they do not compare them with precipitation estimates derived from numerical weather prediction models or reanalysis. Several model intercomparison projects with focus on Africa (or West Africa) as well as a (global) reanalysis intercomparison project exist (see section 2). They take into account not only precipitation but also other atmospheric variables.

Many intercomparisons and validation studies of rainfall estimates have been done at a global and regional scale, as implied by the number of articles cited in the remainder of the article. One of the most comprehensive evaluations has been done by Beck et al. (2017b), who compared 22 rainfall products at a global scale. However, regional studies, even when using fewer products, are also very relevant. Global studies have access to fewer in situ measurements in sub-Saharan Africa than in other regions such as Europe or America, while regional ones often used additional gauge data from national meteorological agencies or other organizations [see, e.g., the reference data used in the global study of Beck et al. (2017b) and the reference data used in the regional comparison of Dinku et al. (2007)]. Moreover, regional rainfall products (such as TARCAT or RFE2) are not included in global intercomparisons. A literature review of intercomparison and validation works has already been done by Maggioni et al. (2016). They focused on seven global satellite-based products. In this paper, we focus on performance of rainfall products in subSaharan Africa and include more products, especially regional ones. In addition, we include rainfall estimates obtained from numerical models and from gauge-only products. The main target audiences are scientists and decision-makers who need rainfall products for a specific application and do not necessarily want to acquire in-depth knowledge of all products available.

In this paper, we review rainfall products and their performance over sub-Saharan Africa in existing literature. We first look at three types of precipitation estimates: those from models and reanalysis (section 2), satellite-based ones (section 3), and those based on gauge data only (section 4). The factors influencing the performance of these products are then discussed in section 5a. Finally, section $5 b$ focuses on seven use cases and their requirements in terms of rainfall data. Some recommendations are given with respect to these applications. The algorithm of a rainfall product is also important in order to understand what to expect from the product; its performance is linked to its algorithm.
The main addition of the present review to the extensive literature is that we guide the reader to the best product for a specific application and that we do this by explaining the underlying algorithm with their specific strengths and weaknesses. In appendix B, the algorithms of the most used products are shown using a uniform structure, making them easy to compare.

\section{Reanalysis and models}

The uncertainties of a reanalysis depend on the uncertainties of the numerical model and the uncertainties of the observations it uses. However, rainfall is difficult to simulate accurately with numerical models, since it results from a complex interaction of the different model physics. Thus, we will first look at precipitation estimates in global models before moving to reanalyses and then to dynamical downscaling. Another possible way of downscaling global reanalysis to smaller scales is to use a statistical model instead of a numerical one. This method is called statistical downscaling, and it has been applied to African rainfall as well (Nikulin et al. 2018; Gebrechorkos et al. 2019). However, in contrast to dynamic downscaling, it has not been the object of an extensive validation or intercomparison project. The reason why statistically downscaled datasets are less evaluated is that they are downscaled using the very observations needed for such evaluation. One would expect that, in general, statistically downscaled datasets already outperform dynamically downscaled datasets regarding statistics, although Nikulin et al. (2018) did not see this in their comparison between four dynamically and two statistically downscaled datasets. Statistical downscaling falls outside the scope of this review, and thus will not be addressed in the remainder of the article.

\section{a. Global circulation models (GCMs)}

Xue et al. (2010) and Hourdin et al. (2010) evaluated the ability of several GCMs (along regional models and other datasets) to represent the West African monsoon. They showed that GCMs, when they used specified sea surface temperature (SST), reproduce reasonably the main features of the West African monsoon, such as the migration of the intertropical convergence zone (ITCZ). However, large discrepancies remained between the GCMs and the other datasets. A possible reason of the GCMs' limitations could be their coarse resolution. However, Crétat et al. (2014) showed that a model with higher resolution is not necessarily better at representing daily intense events. Both Hourdin et al. (2010) and Crétat et al. (2014) pointed out the model's physics, and more specifically the convection parameterization, as an important factor influencing the GCM's performance. 


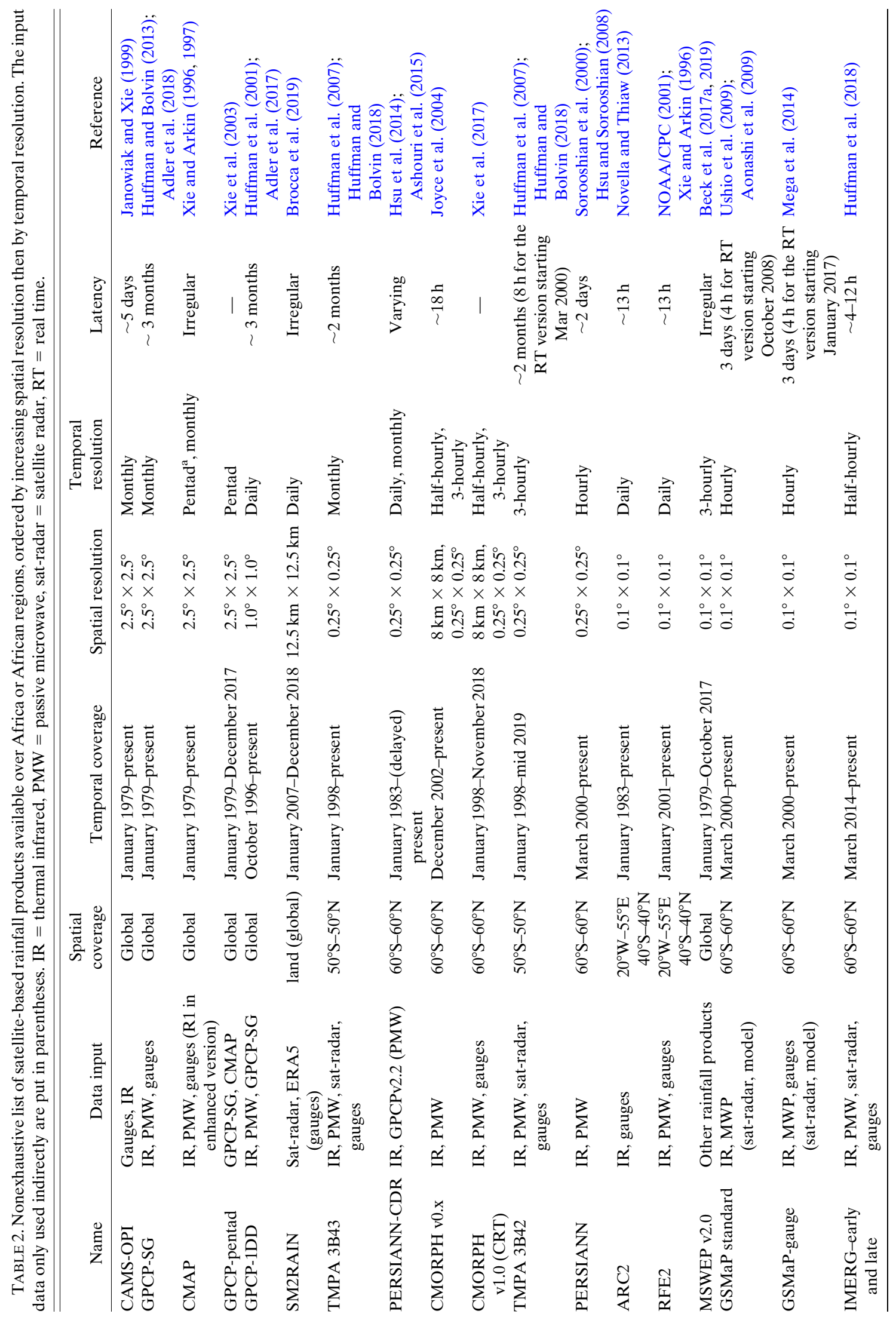


Intercomparison studies (Haiden et al. 2012; Ebert et al. 2007) at a global scale have shown that GCMs have poorer forecast skill in the tropics than in the extratropics. They explained that lower performance in the tropics by the difficulty of GCMs to predict convective precipitation. In general, the skill of models decreases when rainfall tends toward a convective regime.

\section{b. Reanalyses}

There is no regional reanalysis for Africa, however several global reanalyses are produced. A list of such reanalyses is given in Table 1 (see articles in reference column for detailed descriptions). An overview of the different reanalyses, including the observations used in the analysis, can be found in Fujiwara et al. (2017).

Global reanalyses are based on global models and thus suffer the same shortcomings as GCMs, despite improvements due to assimilation of observations. Like GCMs, reanalyses have lower performance in the tropics. Bosilovich et al. (2008) showed that the performance in reproducing precipitation of four wellknown reanalyses (viz., R1, R2, ERA-40, and JRA-25) was lower over South America and Africa compared to other regions, especially during the boreal summer, corresponding to the monsoon season. They gave two reasons for the poorer performance over the tropics: the difficulty to parameterize the land-atmosphere interaction and the difficult retrieval of satellite observation due to the cloudy conditions. Since conventional observations (ground stations, radiosonde, aircraft, etc.) were sparse over South America and Africa, the effects were more visible over these regions.

As for the GCMs, reanalyses are generally outperformed by satellite-based rainfall estimates (Maidment et al. 2013; Funk and Verdin 2003; Koutsouris et al. 2016), with some exceptions in sparsely gauged areas (Thiemig et al. 2012; Worqlul et al. 2014). The main results of these studies, with respect to reanalyses, are summarized in Table 4. Funk and Verdin (2003) explained the lower skill of reanalyses by the limitation of GCMs, such as the coarse grid and the physics, and by the few moisturerelated observations used in the data assimilation. It has to be noted that, since this study, new reanalyses have been created and they incorporate more moisturerelated observations. For example, ERA-Interim assimilates rain-affected satellite radiance, which was not used in ERA-40 (Dee et al. 2011). Most reanalyses do not assimilate precipitation observations directly. However, MERRA assimilates satellite rain rates over the oceans, but with a low weight, so they have a weak impact on the analysis (Rienecker et al. (2011)). The very recent reanalysis ERA-5 uses precipitation data from satellite and ground-based radar (Hennermann 2019). 


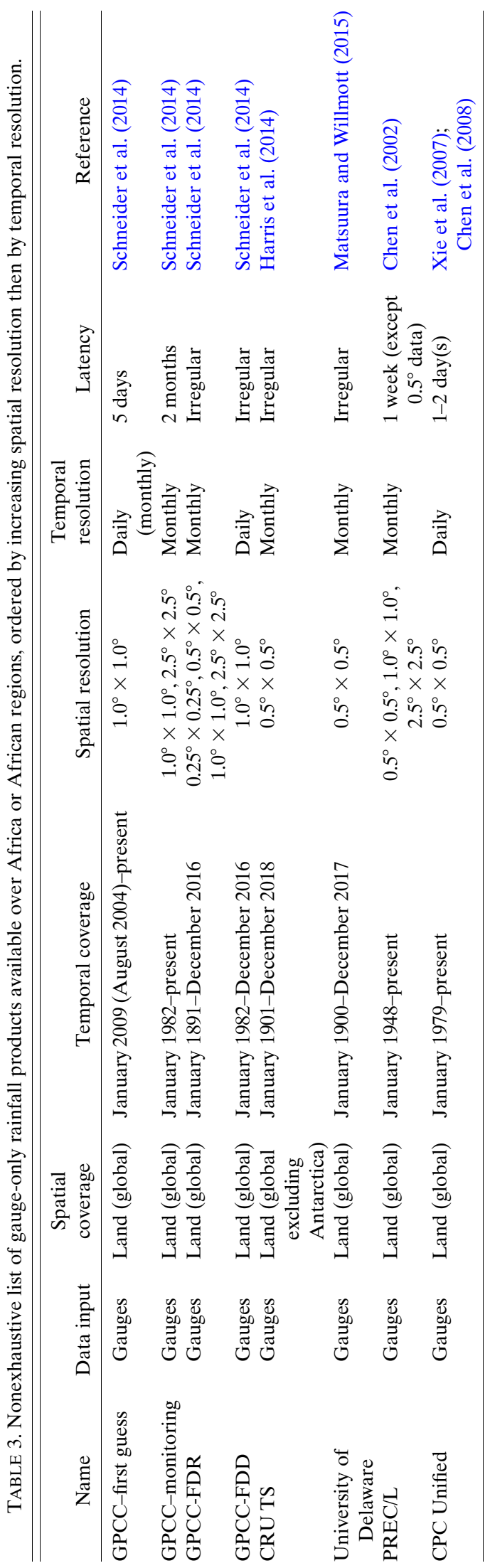

MERRA-2 and CFSR also use precipitation data for the forcing of the land surface model (Bosilovich et al. 2015; Saha et al. 2010).

The most recent reanalyses generally perform better than the older ones, due to improvements in both the model and the assimilation system (Kim and Alexander 2013; Bosilovich et al. 2008), but this not always the case (Bosilovich et al. 2008; Nkiaka et al. 2017; Koutsouris et al. 2016). Even more recent reanalyses are available, such as MERRA-2, JRA-55, and CFSv2. However, no comparison of their performance for precipitation has been found in literature yet. The StratosphereTroposphere Processes and Their Role in Climate (SPARC) Reanalysis Intercomparison Project (S-RIP) is comparing reanalyses, including the most recent ones, and will publish a report (planned for November 2020). This intercomparison project is described in Fujiwara et al. (2017), and more information is available on the S-RIP website (http://S-RIP.ees.hokudai.ac.jp).

\section{c. Dynamic downscaling}

Continuously running a GCM at a fine resolution would be too computationally expensive; thus, a possible solution is to dynamically downscale with a regional climate model (RCM). A lot of attention has been given to regional downscaling in recent decades and several projects have applied RCMs to obtain an ensemble of multimodel climate projections. Over West Africa, such projects include the Ensembles-Based Predictions of Climate Changes and Their Impacts (ENSEMBLES), African Monsoon Multidisciplinary Analyses (AMMA), the West African Monsoon Modeling and Evaluation project (WAMME) model intercomparison study (Xue et al. 2010; Druyan et al. 2010), and, more recently, the Coordinated Regional Climate Downscaling Experiment (CORDEX) that has a study region over all of Africa. The AMMA-Model Intercomparison Project (AMMAMIP; Hourdin et al. (2010)) has compared the ability of different models (both GCMs and RCMs) to reproduce the West African monsoon (WAM). Other studies comparing RCMs over Africa or West Africa include Sylla et al. (2013) and Crétat et al. (2014). They all agree on the added value of RCMs compared to GCMs.

The RCMs are able to reproduce more realistically the features of the monsoon (such as the interannual variability, the annual cycle, or the spatial patterns) than the GCMs and reanalyses. This shows the importance of regional forcing. The higher resolution of RCMs improves the simulation in several ways. It allows a better representation of the orography, an important regional forcing, which improves the simulation of orographic rainfall (Druyan et al. 2010). It also improves the representation of land surface properties (such as land cover) 


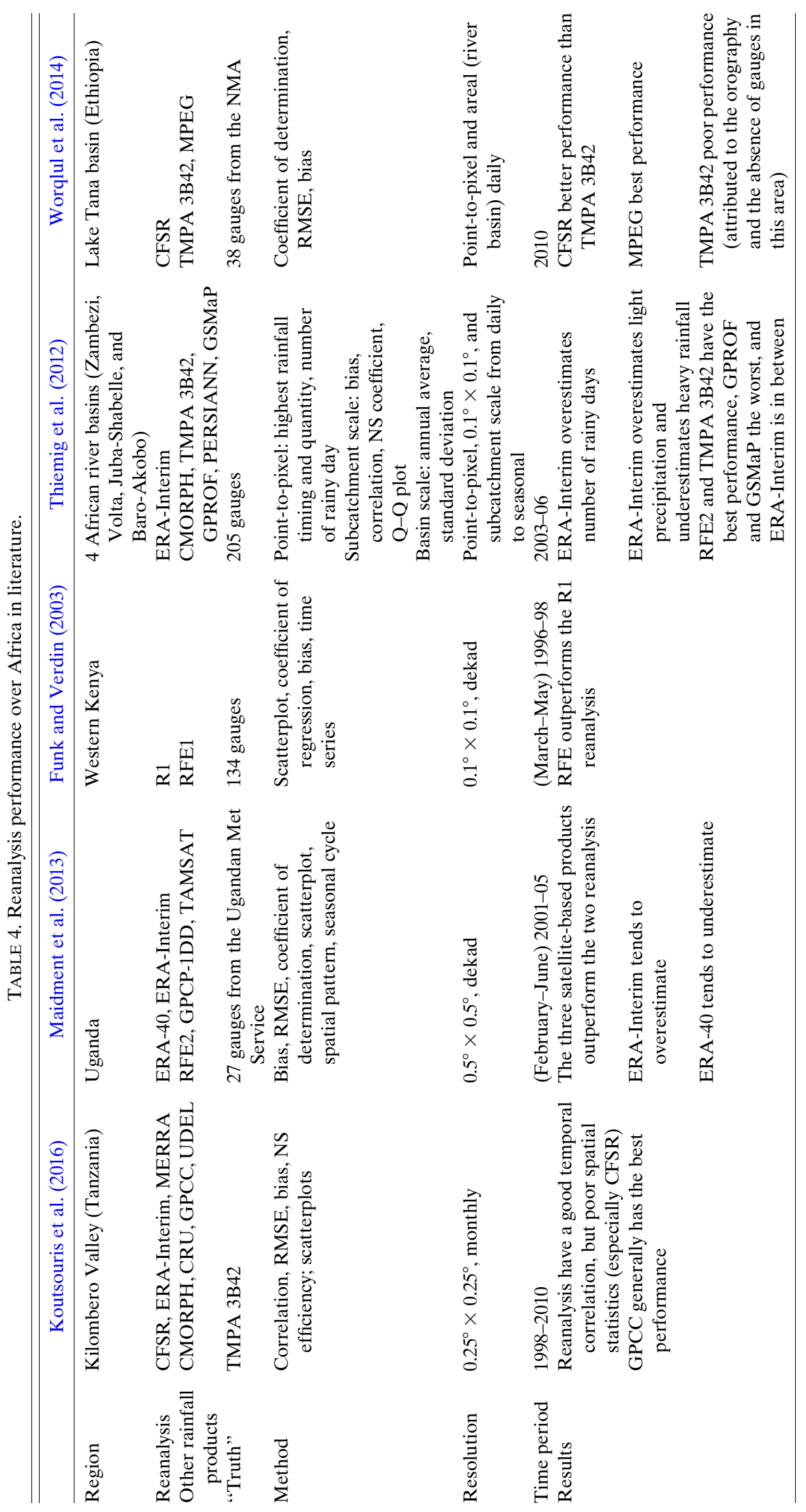




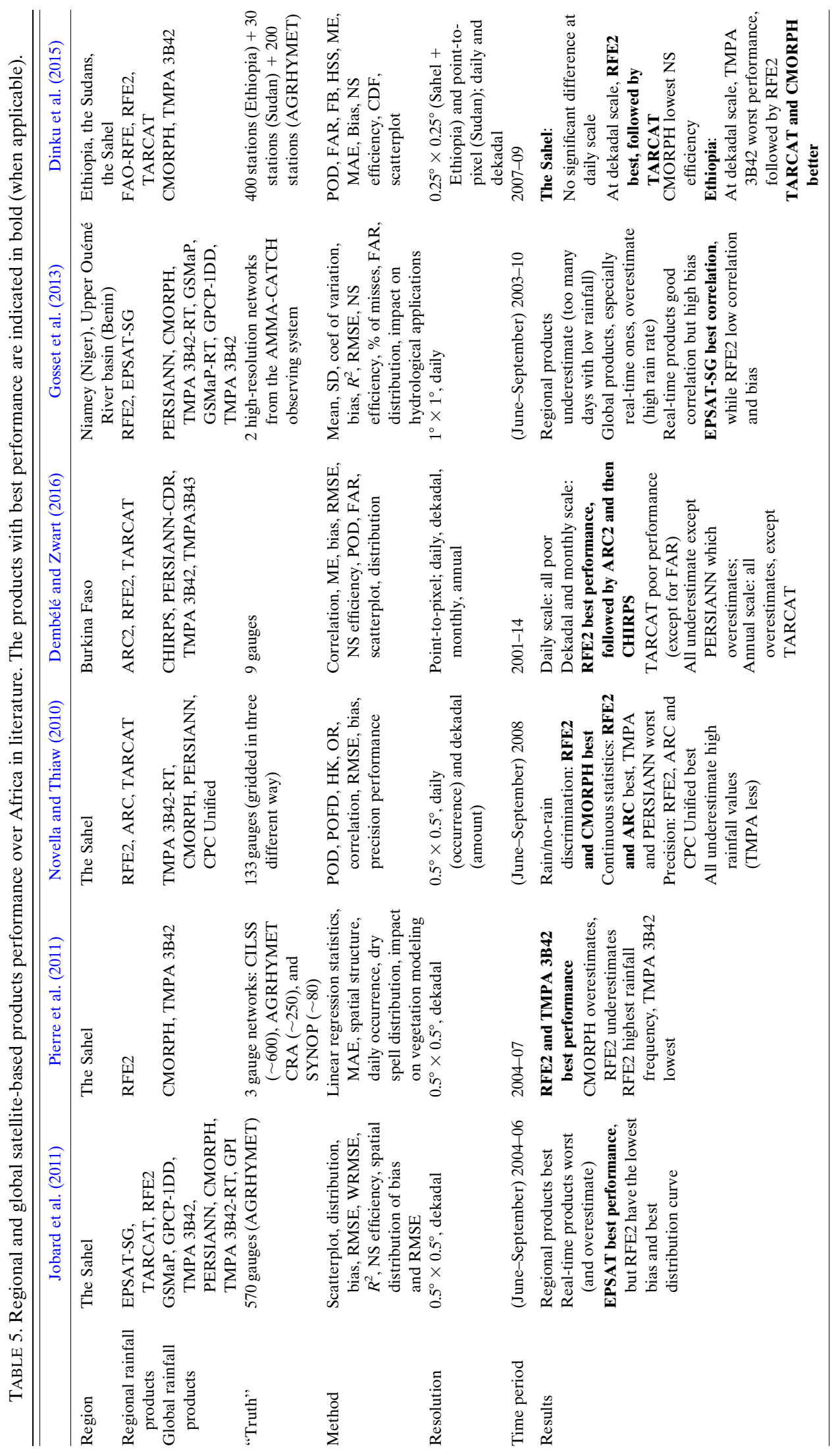




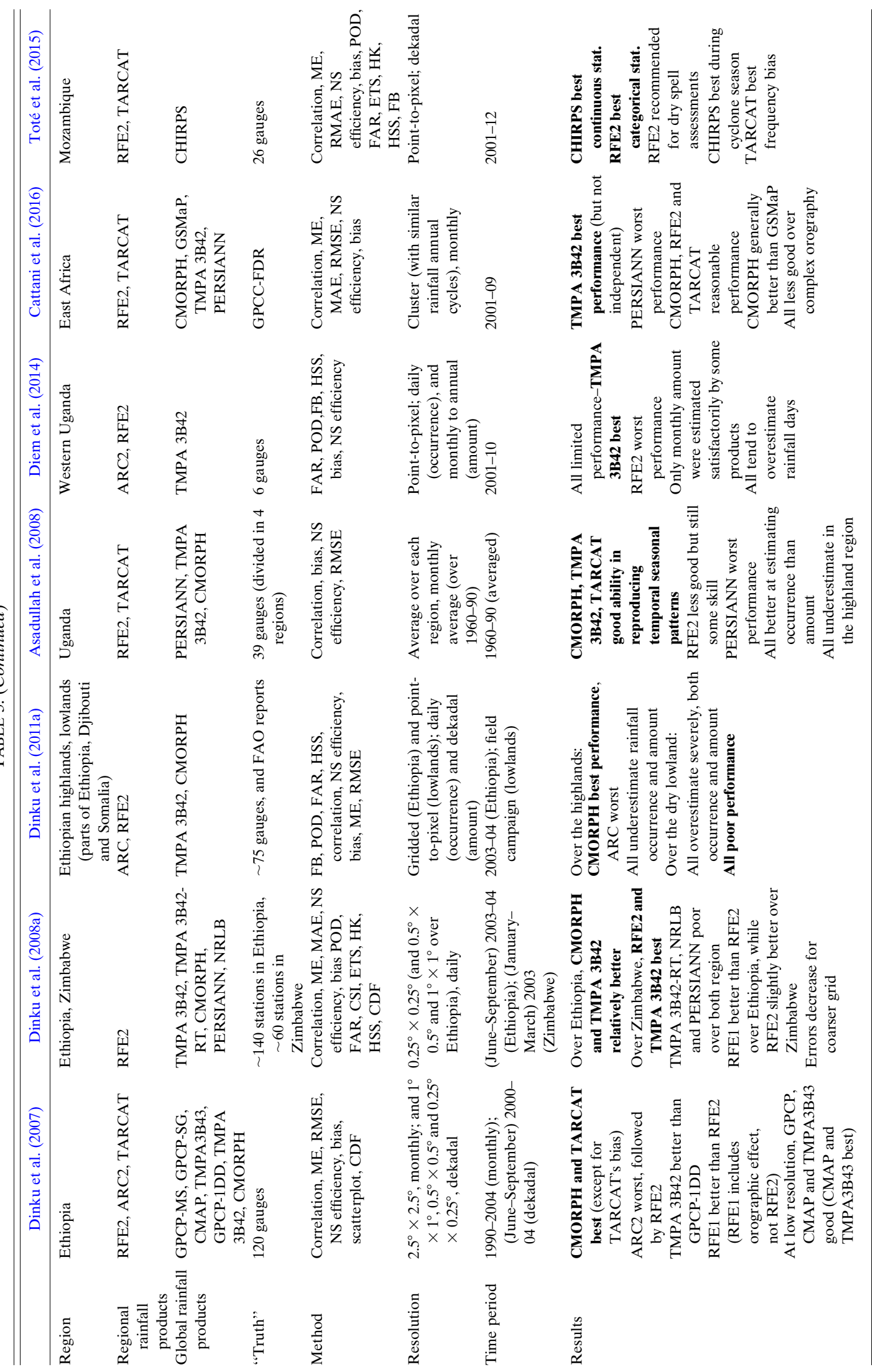


that play an important role in the WAM (Paeth et al. 2011; Sylla et al. 2013). However, RCMs, with horizontal resolution around $50 \mathrm{~km}$, still have difficulties in reproducing both the phase and the intensity of the diurnal cycle (Nikulin et al. 2012). An explanation could be the choice of the convection scheme to which the diurnal cycle is sensitive.

The outputs of the RCMs are influenced by the data (usually a reanalysis or a GCM) used for the initial and boundary forcing (Druyan et al. 2010; Druyan and Fulakeza 2013). However, RCMs driven by the same reanalysis can have very different accuracies, with bias varying considerably in space and time (Druyan et al. 2010; Paeth et al. 2011; Nikulin et al. 2012; Sylla et al. 2013). These differences highlight the importance of the dynamics and physics of each model. An advantage of RCMs compared to GCMs is that they give the possibility to choose physics more adapted to the region, and not to the entire globe. GCMs cover the entire globe and so have to represent a large variety of climates. On the contrary, RCMs focus on a smaller region, and so can choose physics parameterizations better suited for the particular climate of this region.

A review of RCM applications in West Africa can be found in Sylla et al. (2013), and a review of regional downscaling is given in Paeth et al. (2011).

\section{Satellite-based products}

\section{a. Satellite-based rainfall estimates}

The satellite-based products are based on data from different sensors and satellites. They can also include other data sources, such as ground radar, gauge networks, or forecasts from model or reanalysis. A list of satellite-based rainfall products, including the type of input they are using, is given in Table 2.

Satellites retrieve different types of observations from various sensors such as visible, infrared (IR), passive microwave (PMW), and radar measurements. IR measurements are used in many rainfall products. They have the advantage of being frequent and of covering large areas. However, precipitation is estimated through its relationship to cloud-top temperature (CTT) derived from thermal IR. This relationship is indirect and varies within and between rain events (Kidd and Levizzani 2011; Kidd and Huffman 2011). On the other hand, PMW measurements are less frequent [PMW sensors are only present on low-Earth-orbiting (LEO) satellites], but the relation to precipitation is more direct. PMW-based precipitation estimates are generally more accurate than IR-based ones, but have difficulties over snow-covered and desert areas
(Kidd and Levizzani 2011; Kidd and Huffman 2011). Satellite-radar measurements for precipitation retrieval are limited: only the Tropical Rainfall Measuring Mission (TRMM), the Global Precipitation Measurement (GPM), and the CloudSat missions have radars specifically designed to retrieve precipitation (Kidd and Levizzani 2011; Kidd and Huffman 2011). A rainfall product can combine different types of measurement to take advantage of their strengths and overcome their weaknesses. For example, many products combine IR measurements with the more accurate but less frequent PMW observations. TMPA and IMERG are the products using the most different types of measurements as input data: IR, PMW, satellite radar, and gauges. They are the only ones using satellite radar as input (CMORPH uses ground radar over the United States for adjustment), while CMAP and CHIRPS are the only ones using data from numerical models.

Other products with a very different approach (and not shown in the appendix figures) include SM2RAIN and MSWEP. SM2RAIN is based on soil moisture observations from satellites and ground measurements. It inverses the soil water balance equation to obtain precipitation estimates. MSWEP does not use satellite measurements directly; instead, it is based on other rainfall datasets (e.g., CMORPH, ERA-Interim, GPCCFDR). A long-term mean precipitation (from CHPclim; Funk et al. 2015a) is downscaled using precipitation anomalies obtained by a weighted average of different reanalyses and gauge and satellite products. Its goal is to take advantage of the strengths of different types of rainfall products.

Satellite-based products differ by the data (different types of measurement coming from different satellites/sensors) used as input and by their algorithms deriving the final precipitation estimates. As a consequence, the error of a satellite-based product is partially due to the error in the retrieval algorithm (i.e., estimating precipitation from the sensors measurements) and partially due to the merging algorithm (i.e., combining the different estimates in the final precipitation estimate).

\section{b. Regional versus global}

There exist several regional rainfall products developed especially for and only covering Africa. They have been compared to global products in various studies for different regions of Africa. Their results are summarized in Table 5 .

The performance of the regional products and their advantages with respect to the global products vary from region to region. Over the Sahel, both RFE2 and TARCAT perform well in rainfall detection and in estimating rainfall amounts, at least as well as the global 
products (Jobard et al. 2011; Pierre et al. 2011; Novella and Thiaw 2010; Dinku et al. 2015). However, over Burkina Faso, which is part of the Sahel, TARCAT has been shown to have very poor performance by Dembélé and Zwart (2016), while RFE2 and ARC2 outperformed TMPA. Gosset et al. (2013) showed that regional products (RFE2, EPSAT) tend to underestimate rainfall amounts while global and especially near-real-time ones overestimate it over the south of West Africa. Over East Africa, regional products do not perform as well, and TMPA and CMORPH tend to show the best performances. RFE2 has particularly poor performance over Ethiopia despite some skill for rainfall detection. It is outperformed by most of the global products over this region (Dinku et al. 2007, 2008a, 2011a). Over Ethiopia, TARCAT still shows some agreement with gauge data despite underestimating (Dinku et al. 2007). Over Uganda, TARCAT has a similar performance as CMORPH and TMPA, while ARC2 outperforms RFE2 (Asadullah et al. 2008; Diem et al. 2014). In general, over a large part of East Africa, TARCAT and RFE2 have relatively similar and reasonable performances. They outperform some global products (e.g., PERSIANN and GSMaP) while they are outperformed by others such as TMPA 3B42 (Cattani et al. 2016).

Regional products show very good results and perform as well as or better than the most-used global products. However, it cannot be concluded that the regional products outperform global ones as a general rule. For example, the algorithm of RFE2 is not suitable for regions with complicated orography such as Ethiopia. More information about the algorithms and the performance of the regional products is given in section $\mathrm{h}$ (for RFE2), section $\mathrm{i}$ (for $\mathrm{ARC} 2$ ), and section 1 (for TARCAT) of appendix B.

\section{c. Gauge data in satellite-based products}

Satellite-based rainfall products can also use data other than satellite data in their algorithms. For instance CMORPH uses ground-radar data to adjust the cloud motion vectors derived from IR data. Other products, such as GPCP-1DD or PERSIANN-CDR, use other rainfall products, namely, GPCP-SG. Many satellite-based products, which are listed in Table 6, use gauge data. Gauge data can be used in different ways.

The bias of a product varies depending on the region of interest, and is different from one product to another. For example, CMORPH tends to overestimate while GSMaP tends to underestimate over the Sahel (Jobard et al. 2011), and PERSIANN overestimates almost everywhere over Africa except over mountainous areas, over which it underestimates. Bias correction using gauge
TABLE 6. List of satellite-derived rainfall products using gauge data and how they are used in their algorithms.

\begin{tabular}{lccc}
\hline \hline & Calibration & Bias adjustment & Merged \\
\hline ARC2 & & & $\mathrm{x}$ \\
CAMS-OPI & $\mathrm{x}$ & $\mathrm{x}$ \\
CHIRPS & & $\mathrm{x}$ \\
CMAP & $\mathrm{x}$ & $\mathrm{x}$ \\
CMORPHv1.0 CRT & $\mathrm{x}$ & $\mathrm{x}$ \\
CMORPHv1.0 BLD & $\mathrm{x}$ & $\mathrm{x}$ \\
GPCP-SG & $\mathrm{x}$ & $\mathrm{x}$ \\
GPM & $\mathrm{x}$ & \\
GSMaP_gauge & & & $\mathrm{x}$ \\
RFE2 & & $\mathrm{x}$ & \\
TARCAT & $\mathrm{x}$ & $\mathrm{x}$ \\
TMPA & & & \\
\hline
\end{tabular}

data can reduce the bias significantly. It has been shown by Jobard et al. (2011) that near-real-time products that do not include bias adjustment have worse performance than the other global products over the Sahel; they especially have large bias. There are several methods to remove the bias using gauge data, such as scaling by the ratio of the gauge/satellite rainfall estimates (GPCP-SG and TMPA) or matching the probability density function of the satellite estimates with the one from the gauge data [CMORPH-Corrected (CRT)]. PERSIANN-CDR is also bias adjusted, using a monthly ratio method, but based on another satellite-based product.

Some products merged satellite estimates, after bias adjustment or not, with gauge estimates. There are several ways of doing so. Some use inverse error variance weighting (TMPA, IMERG, GPCP-SG) or other weighted average (CHIRPS), while other products use directly the gauge-only estimate when reliable, and a blended satellite-gauge estimate elsewhere (ARC2, RFE2, CMAP, CAMS-OPI).

Another way of using gauge data is for calibration, as in TARCAT. Indeed, the TARCAT algorithm is calibrated locally to historical gauge data and is then applied to recent IR data. TARCAT does not use gauge data for bias adjustment or merging, but has been shown to perform well over different parts of Africa despite a dry bias for the high-intensity rain rates. Over Ethiopia, Dinku et al. (2007) found that TARCAT performed better than some gauge-adjusted products such as TMPA 3B42, RFE2, and GPCP-1DD (except with respect to the bias). Jobard et al. (2011) showed that the regional products, including TARCAT, performed better than global bias-adjusted ones over the Sahel. A benefit of using historical data, as TARCAT does, is that it takes advantage of data from gauges that no longer exist. Similarly, CMORPH-CRT uses a twostep approach for the bias adjustment over land. It first 
removes the climatic bias using historical data and then adjusts to real-time data (Xie et al. 2017). This approach is particularly beneficial for areas with very sparse gauge coverage.

\section{Gauge-only products}

There exist various gridded gauge-only products (see Table 3). Some are updated regularly, from a few days to a few months latency, such as Climate Prediction Center (CPC) Unified, Precipitation Reconstruction over Land (PREC/L), Global Precipitation Climatology Centre (GPCC)-first guess, and GPCC-monitoring. Others are updated irregularly, such as GPCC-Full Data Reanalysis (GPCC-FDR), GPCC-Full Data Daily (GPCC-FDD), University of Delaware dataset (UDEL), and Climatic Research Unit Time series (CRU-TS), for which a new version is available every few years with reprocessed data for the entire period. They are produced at relatively coarse spatial and temporal resolutions compared to satellite-based rainfall products. Their spatial resolution ranges from $0.5^{\circ} \times 0.5^{\circ}$ to $2.5^{\circ} \times 2.5^{\circ}$, and they are available as monthly estimates except for CPC Unified, GPCC-first guess, and GPCC-FDD, which are available for daily totals.

\section{a. Factors influencing the performance of gauge-only products}

The gauge coverage in Africa, with the exception of a few regions such as South Africa, is sparse. Moreover, the number of recording stations (available for these products) varies over space and time, and has significantly decreased during the last decades. This decrease of available gauge records is shown in Lorenz and Kunstmann (2012, Figs. 3 and 4) for GPCC and CPC Unified datasets for the period 1989-2006, in Cattani et al. (2016, Fig. 8) for GPCC-FDR over East Africa between 2001 and 2009, in Maidment et al. (2014, Fig. 3d) for GPCC-FDR over Africa for the period 1983-2010 (a clear drop in gauges coverage is visible around 2009), and in Dinku et al. (2008b, Fig. 3) for three GPCC products, PREC/L, and CRU-TS over Ethiopia for the period 1981-2000, over which the number of gauges decreases sharply around 1985 . The decreasing number of recording stations in Africa is a known issue (van de Giesen et al. 2014) and is mainly due to a lack of funding for the maintenance and upgrading of the gauge network. With GPCC-FDR product being a reanalysis, the decrease of records used for the last years is also due to the time delay in obtaining data from national agencies.

The relation between the gauge coverage and the accuracy of gridded products has been observed by
Maidment et al. (2014). They compared TARCAT with various rainfall products over Africa for the period 1983-2010 and found less agreement between the three gauge-only products (CRU, GPCC-FDR, and PREC/L) during 2000-10, this period corresponding to a sharp decrease of recording gauges. Similar results were found by Dinku et al. (2008b) when comparing PREC/L, CRU-TS, GPCC-FDR, and GPCC-clim over Ethiopia for two different periods: 1981-85 and 1996-2000. Far fewer gauge records were available for the products during the second period, and this decrease had an impact on the products' accuracy. Indeed, more discrepancies in time series were observed during the second period than during the first one. Moreover, the correlation and Nash-Sutcliffe (NS) efficiency coefficients decreased between the first and the second period, while the mean average error increased for the four products.

Dinku et al. (2008b) studied the impact of the number as well as the quality of gauge records on product performance by comparing three GPCC monthly products (GPCC-monitoring, GPCC-FDR, and GPCC-clim) over the complex topography of Ethiopia at $2.5^{\circ} \times 2.5^{\circ}$ and $1.0^{\circ} \times 1.0^{\circ}$ resolution. These three products use the same interpolation method but a different number of gauges and different quality requirements. GPCC-monitoring uses reports received through GTS within a month after the observation month, while GPCC-FDR is produced irregularly and thus can also use non-real-time data and apply a higher quality check, so it includes more stations and those stations are of better quality than those in GPCC-monitoring. GPCC-clim uses fewer stations but of higher quality since it requires the stations to have a time series that is at least $90 \%$ complete. They all had similar performances, with GPCC-monitoring having a larger bias, GPCC-clim having higher random error, and GPCC-FDR having a relative better performance. The performances of gridded products vary in time and space depending on the gauge's coverage. It is recommended to interpret the gauge estimate with respect to the gauge's density information supplied with it.

The gauge coverage has an impact on the accuracy of the products; however the number of gauge records alone does not determine the performance of the products. When comparing four gauge-only products to the reference at three different spatial resolutions, Dinku et al. (2008b) showed that they all have good performance, with high correlation and NS efficiency and very low bias. However, despite using the largest number of stations and high quality check among the products, CRU-TS had overall the worst statistics, behind GPCC-clim using the least number of stations. 
So, its limitation comes from its interpolation method. A better gauge coverage does not always mean better accuracy; the interpolation method also has an impact on a product's performance.

To summarize, the accuracy of the estimates do not depend on the gauge coverage alone, but also on the quality check and the interpolation method used by the gauge-only product.

\section{b. Gauge-only versus satellite-based products}

The gauge-only products have been evaluated over Ethiopia by Dinku et al. (2008b), but not over other parts of Africa. However, gauge-only products have been compared to satellite-based product over different African regions. These studies are summarized in Table 7, and their main results with respect to the gaugeonly products are described below.

Ali et al. (2005) compared the gauge-only GPCC product and three satellite-based ones (CMAP, GPCP, and GPI) at monthly scale and $2.5^{\circ}$ over the Sahel. They concluded that CMAP had the best performance with, among others, the smallest root-mean-square error (RMSE) and bias and the highest coefficient of determination, followed closely by GPCC and GPCP, with GPI far behind.

Over Ethiopia, Dinku et al. (2011b) evaluated the performance of two gauge-only products (CRU-TS and GPCC-FDR) and two satellite-based products (GPCPv2 and CMAP), also monthly, at $2.5^{\circ}$ resolution. All products gave good results, with low bias and mean average error and high correlation and NS efficiency. The gauge-only products had no or lower bias but CRU-TS had a slightly larger random error. GPCC-FDR seemed to perform slightly better than the other ones. However, when GPCPv2 and GPCC-FDR are compared to GPCPv2.1, which includes GPCC-FDR in the algorithm, the latter outperformed them, except for the bias that remains lower for GPCC.

CPC Unified was evaluated over the Sahel at higher resolution, which is for dekadal estimates on a $0.5^{\circ}$ grid, along six satellite-based estimates by Novella and Thiaw (2010). In terms of rainfall detection, RFE and CMORPH outperformed the other products, including CPC Unified. In term of statistics, CPC Unified, RFE, ARC, and TARCAT had a low bias and RMSE, but RFE and ARC also had a higher correlation. They concluded that RFE and ARC had the overall best performances.

Gauge-only products have in general good performance with no or very low bias, but they do not significantly outperform satellite-based products over Africa.

\section{Discussion}

\section{a. Factors influencing the performance}

\section{1) Temporal And SPATIAL SCALE}

Performance of rainfall products is influenced by the temporal and spatial resolution at which they are evaluated. Performance improves for decreasing resolution, that is, for coarser grids. One should pay attention to the temporal and spatial resolution when looking at validation or intercomparison study of rainfall products.

Dembélé and Zwart (2016) compared seven satellitebased rainfall products over Burkina Faso at different temporal resolutions, namely, daily, dekadal, monthly, and annual scale (see Table 5 for more details on the comparison method). They showed that both the continuous and categorical statistics improved when the temporal resolution decreased. At monthly and annual scale, all the products, except TARCAT, have very good performance in terms of continuous and categorical statistics. At dekadal scale the products are in good agreement with the gauges (e.g., correlation coefficients equal or larger than 0.80 ), while at daily scale the performance of the products was very low (with, e.g., correlation coefficients smaller than 0.50 ). Similarly, Dinku et al. (2011b) compared several satellite-based and gauge-only products over Ethiopia at different temporal and spatial scales (see Table 7 for more details on the comparison method). On a $1.0^{\circ} \times 1.0^{\circ}$ grid, RFE2, TMPA 3B42, and CMORPH had reasonable performances in estimating rainfall amount at dekadal scale, but poor ones at daily scale despite still good detection skill. They also compared these three products at daily scale on three grids with different resolution and showed that both continuous and categorical statistics were getting better when the spatial resolution decreased. In Dinku et al. (2007), six satellite-based rainfall products were compared at dekadal scale over Ethiopia using three different grid sizes (see Table 5). A decrease in the product's performance was observed when the spatial resolution was increased. Similar results were found for the gauge-only products by Dinku et al. (2008b) (see Table 7). They evaluated five products over Ethiopia at three different spatial resolutions for monthly amount. Their performance decreased with increasing resolution, but still remained good.

\section{2) Gauges}

The gauge density varies in space and time, and so influences the performance of the gauge-only and satellite-based products. The reanalyses use groundstation measurements but no rain gauge data in their data assimilation process, so they are not directly impacted by 


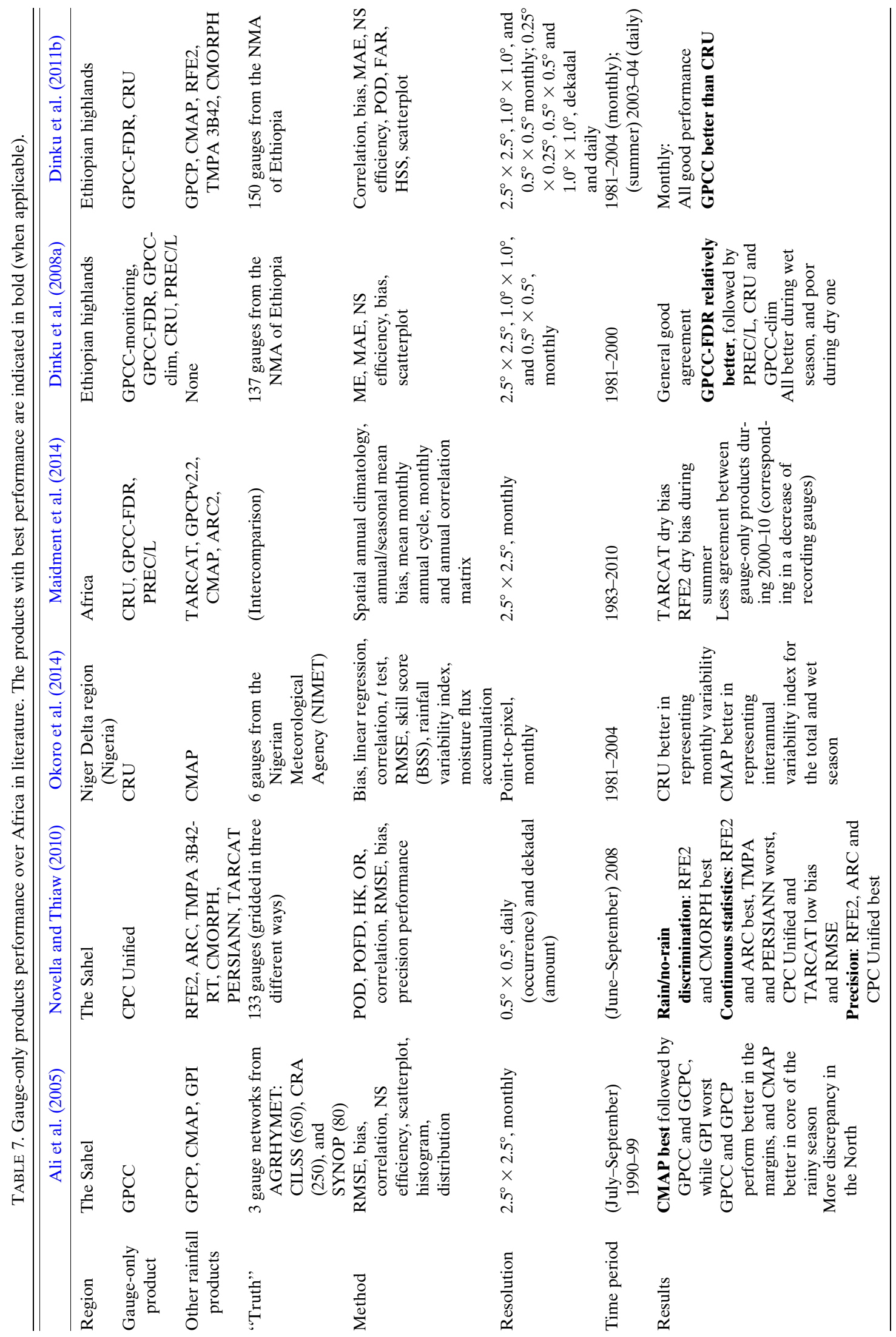




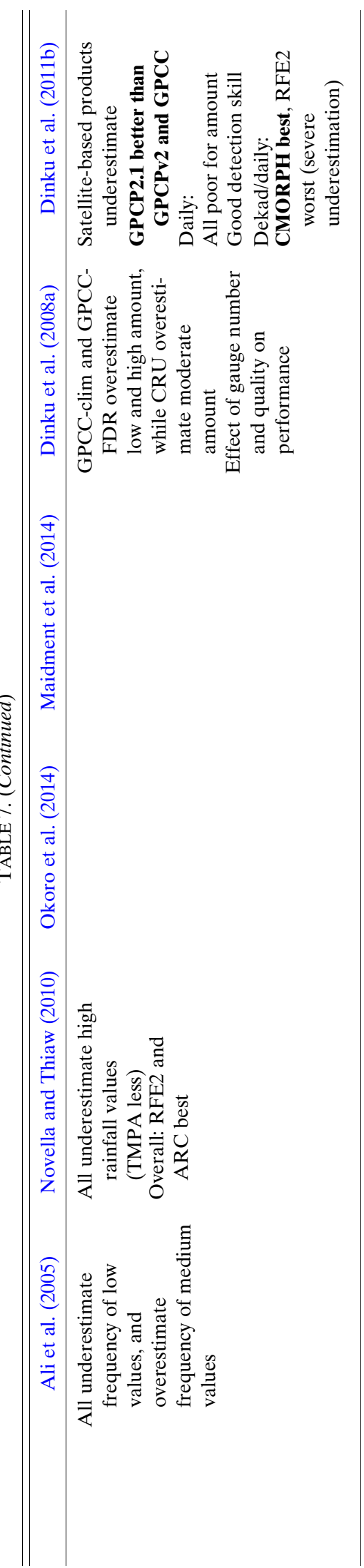

the gauge density. The exceptions are MERRA2, CFSR, and CFSv2. They use precipitation data (such as CMAP and CPC Unified) as part of their land surface forcing. However, MERRA2 uses CMAP and GPCPv2.1 over Africa (Bosilovich et al. 2015, Table 7.1), and CFSR favored CMAP over CPC Unified in the tropics (Saha et al. 2010). Thus, gauge data have a very limited influence on the reanalyses' precipitation.

The accuracy of gauge-only products depends strongly on the number of gauges available, which is why the gauge density is given along the rainfall estimates for these products. However, as seen in section 4a, the accuracy does not depend solely on gauge density. The quality of the data and the interpolation method also play an important role.

Many satellite-based products use gauge data (see section 3c). Thus, their performances are impacted by the availability of gauge data. For instance, the poor performance of TMPA 3B42 over Lake Tana has been attributed to the orography and the lack of available gauge data by Worqlul et al. (2014). Moreover, the gauge data used in satellite-based products are in general a small fraction of the gauge records available (e.g., gauge-only products use a much larger number of gauge records than satellitebased products). An exception is GPCP-SGv2.1 which uses GPCC, a gauge-only product, for bias adjustment and merging. Dinku et al. (2011b) showed the benefit of adding more gauge data by comparing GPCPSGv2.1 with its previous version GPCP-SGv2, which incorporated a smaller amount of gauge data, over the Ethiopian highlands. They found that the correlation improved from 0.96 to 0.99 , the NS efficiency from 0.92 to 0.99 , and that the random error became lower than the ones of both GPCP-SGv2 and GPCC.

\section{3) OROGRAPHY}

The orography has an impact on the atmospheric circulation, and so on the precipitation field. It is thus an important regional forcing in numerical weather model. The coarse resolution of reanalysis and GCMs does not allow them to represent accurately complex orography, limiting their performance in simulating orographic rainfall. A possibility to improve the representation of orography and orographic rainfall is to dynamically downscale the reanalysis using an RCM (Druyan et al. 2010).

Complex orography, and more generally warm-cloud processes, is a well-known challenge for satellite-based rainfall products (Serrat-Capdevila et al. 2014). IR-based estimates have difficulties in capturing warm-cloud precipitation over coastal and orographic regions. This is mainly due to the threshold they use to discriminate between raining and nonraining clouds, which is too cold 
for such processes (Dinku et al. 2007, 2008a, 2011a). Products including PMW data seem to perform better than the ones mainly based on IR (Dinku et al. 2007, 2011a). However, PMW-based precipitation estimates also have some limitations with respect to orographic rain. Indeed, PMW algorithms are mainly based on scattering by ice aloft, but orographic rainfall is a warm-cloud process that does not necessarily produce much ice, which can lead to underestimation. Moreover, ice on the mountains can be mistakenly considered as rainfall by such algorithms (Dinku et al. 2007, 2008a, 2011a).

Mountainous areas raise several difficulties for the gauge-only products too. There are few gauges at high elevations; most of the gauges are located at lower altitudes. The difficult access and remoteness of such locations make the installation and maintenance of weather stations complicated. At the same time, the variability of rainfall over mountainous regions is high. For example, Hirpa et al. (2010) showed the existence of an elevation dependence trend, that is the rainfall amounts increase with elevation. Hence, the gauge measurements at the bottom of a mountain are not representative of the rainfall at higher altitudes. Moreover, the high spatial variability is making the interpolation more difficult.

\section{4) RAINFALL REGIME}

The characteristics of the seasonal distribution of rainfall at a particular place are termed the rainfall regime (American Meteorological Society 2019). Rainfall regimes are influenced by large-scale climatic features, such as the ITCZ, and also by regional ones such as mountains and lakes. They vary in space and time depending on the climatic region and on the season. The rainfall regimes influence the performance of the rainfall products. Hence, their performance can differ over two regions adjacent to each other but with different rainfall regimes.

Some comparison studies took the different rainfall regimes into account. For instance, to compare six satellite-based products over East Africa, Cattani et al. (2016) divided this large area in eight smaller areas, each characterized by a specific precipitation seasonality. Areas with higher precipitation intensity showed a bigger standard deviation and mean average errors. The standard deviation also depends on the season since precipitation patterns change over the year. Some areas had an overall better correlation and NS efficiency for the different products than others. These differences between the areas show the influence of rainfall regimes on the performance of the products; a product can perform differently over two geographically close areas but having different rainfall regimes. Similarly,
Romilly and Gebremichael (2011) compared the bias of three satellite-based products over six river basins in Ethiopia that were divided in four regions based on similar rainfall annual cycles and topography. They showed that the bias of these three products depended on the rainfall regime, that is, the bias was different from one region to another but could also vary according to the season.

The variation in time of the rainfall products' performance was also shown by Ali et al. (2005), who compared three satellite-based products and one gaugeonly product over the Sahel. The monthly mean statistics were better in the core of the rainy season for CMAP while GPCP and GPCC had better statistics in its margins. Dinku et al. (2008b) evaluated five gauge-only products over Ethiopia and found that they performed better (i.e., higher correlation and NS efficiency) during the wettest season (June-August) and worse during the dry season (December-February). They showed that these seasonal differences were more important when the comparison was done at higher spatial resolution. The poor performance during the dry season was attributed to the fact that rainfall during this season is local in both time and space, and thus a denser network of gauges would be needed to reproduce the rainfall patterns. On the contrary, reanalyses perform more poorly during the monsoon season due to the convective nature of the rainfall. In general, the satellite-based estimates are expected to perform better in summers and in the tropics while models are expected to be better in winters and high latitudes because the satellite estimates tend to reproduce convective rainfall more accurately (Ebert et al. 2007). The reanalyses and global models, in general, have been shown to perform more poorly over the tropics and to fail to reproduce some regional-scale features. Thus, it is not surprising that the reanalyses are outperformed by satellitebased products over Africa and especially during the monsoon season.

Some climates are more difficult than others to represent, which is the case for arid areas by satellite-based products, for example. Jobard et al. (2011) compared 10 satellite-based products over the Sahel and showed that they all had higher RMSE ratios in the northern part where rainfalls had low intensities. On the contrary, in Cattani et al. (2016), the six rainfall products had low RMSE and mean average error over arid areas. However, it has to be taken relatively since the monthly rainfall amount was also very low over these areas. Dinku et al. (2010) and Dinku et al. (2011a) had specifically studied the limitations of satellite-based precipitation estimates over arid areas. Dinku et al. (2011a) evaluated the skills of four rainfall products over an arid 
region in Ethiopia while Dinku et al. (2010) compared seven products over different arid and semiarid regions. They both concurred on the poor performance of the different satellite products over such regions, especially the drier ones. The products overestimated the frequency of rainfall despite a low probability of detection (POD). The low detection skill and the high overestimation were attributed to several possible reasons. First, the subcloud evaporation can play an important role in this overestimation. These regions have a dry atmosphere so the rainfall detected aloft by the satellite might evaporate before reaching the ground. Second, a limitation specific to PMW algorithms is that they can mistakenly identify desert surfaces as raining, because desert and snow cover have spectral characteristic close to rainfall (Wang et al. 2009). Finally, the coarse resolution of the rainfall products can also be an explanation factor for the low POD, especially since they are compared to point data. Indeed, a pixel might cover both rain and nonrainy (warm) surface, but the pixel represents the averaged values that may not be identified as rain. As mentioned above, gauge-only products can also have difficulties over dry areas, when the rainfall is localized.

\section{b. Use cases}

The "best" rainfall products depend on the intended use cases. Sometimes, requirements on the spatial and/or temporal resolution can limit the possible choices (see Tables 1-3 for the resolution of the different products). Depending on the application, some characteristics are more important than others. The important characteristics of seven use cases are discussed below. Recommendations about the rainfall products for these cases are given in Table 8 .

\section{1) Drought MONITORING}

Droughts have a high economic cost, because of their possible large spatial and temporal scale. With the agriculture in sub-Saharan Africa being mainly rain-fed, the population is vulnerable to such a natural disaster. It can also impact the food and water security; for example, the drought of the Horn of Africa in 2011 caused famine in several regions, and large population movement (Sheffield et al. 2014). Hence, drought monitoring and early warning systems are important in this region. These applications need precipitation data, in general 1-10-day accumulations. One should avoid rainfall products that overestimate the occurrence or the amount of rainfall events. The good representation of the low-intensity rainfall events is more important than the high ones. In terms of criteria, this translates to
- low false alarm rate (FAR; no overestimation of occurrence),

- low or dry frequency bias (no overestimation of occurrence),

- dry bias preferred (no overestimation of amount),

- low or negative ME (no overestimation of amount), and

- distribution representing well the low precipitation values (representation of low rainfall events).

\section{2) Agriculture/Crop MODEling}

In sub-Saharan Africa, agriculture is mainly rain-fed, making the population highly vulnerable to rainfall variability. Rainfall information is therefore valuable for farmers, and an important input for crop modeling. Rainfall data are also used to derive rainfall indices for crop insurance. Such insurance helps the smallholder farmer to be more climate resilient. For these types of application, the chosen rainfall product should correctly represent the precipitation distribution over time and estimate accurately the amount per events. The good representation of dry spells is also important since they are influencing the vegetation growth. The most important criteria for these types of application are

- low RMSE and MAE (accurate amount at pentadal and dekadal scales),

- high coefficient of determination $R^{2}$ or correlation coefficient, and

- good representation of dry spell occurrence.

This application is probably the most demanding in terms of accuracy and rainfall distribution.

\section{3) FlOOD MONITORING/EXTREME EVENTS}

Sub-Saharan Africa is also vulnerable to floods. The number of deaths and the economic loss due to floods have increased in the last decades (Thiemig et al. 2011). The fast urbanization has increased the population vulnerability to such natural disasters. In this context, flood monitoring and early warning system are needed to reduce the human and economic losses (Thiemig et al. 2011). Good estimation of flood events relies on precipitation data representing well the high-intensity rainfalls. For such applications, rainfall products underestimating the occurrence and amount should be avoided. In terms of criteria, this translates to

- high POD (no underestimation of occurrence),

- low or wet frequency bias (no underestimation of occurrence),

- wet bias preferred (no underestimation of amount),

- low or positive ME (no underestimation of amount), and 
TABLE 8. Recommendations depending on the use cases (based on literature, see Table 5).

\begin{tabular}{|c|c|}
\hline Use cases & Recommendations \\
\hline Drought monitoring & $\begin{array}{l}\text { TARCAT, RFE2, ARC2 recommended } \\
\text { Avoid RFE2 and ARC2 over mountainous areas } \\
\text { Avoid RT products which have a large wet bias } \\
\text { CHIRPS developed for drought monitoring, but advised for flood monitoring by Dembélé and } \\
\text { Zwart (2016) and Toté et al. (2015) }\end{array}$ \\
\hline Agriculture/crop modeling & $\begin{array}{l}\text { Not many comparison studies [only Pierre et al. (2011) looks at vegetation modeling] } \\
\text { Depends on the region } \\
\text { RFE2 over the Sahel (both good for occurrence and amount) } \\
\text { CMORPH has good rain-no-rain discrimination, but need bias correction (large wet bias) }\end{array}$ \\
\hline Flood monitoring & $\begin{array}{l}\text { Avoid TARCAT, RFE2, and ARC2 } \\
\text { CHIRPS: developed for drought, but recommended for flood over Burkina Faso and Mozambique } \\
\text { by Dembélé and Zwart (2016) and Toté et al. (2015) } \\
\text { CMORPH: good detection skill, and (large) wet bias (except over Zimbabwe) } \\
\text { PERSIANN: high POD and positive bias, but very large bias and do not represent well distribution } \\
\text { of high precipitation values (over the Sahel). To be used with caution. } \\
\text { Other possibilities: GPCC-1DD, TMPA 3B42, GSMaP (but can have dry bias for some } \\
\text { years/locations) }\end{array}$ \\
\hline $\begin{array}{l}\text { Hydrological modeling/reservoir } \\
\text { management }\end{array}$ & $\begin{array}{l}\text { Need to account for the bias of rainfall products (especially RT, which have large bias) } \\
\text { Possible improvement by calibrating the model } \\
\text { (Gosset et al. 2013; Thiemig et al. 2013) }\end{array}$ \\
\hline Climatology/general & $\begin{array}{l}\text { Depends on the regions } \\
\text { General good agreement at monthly scale } \\
\text { PERSIANN-CDR, ARC2 (and CHIRPS) developed for climatology } \\
\text { Gauge-only products: long time period, but accuracy varies in time } \\
\text { Over the Sahel: regional products (except TARCAT over Burkina Faso), and CMAP at monthly } \\
\text { scale (Ali et al. 2005) } \\
\text { CHIRPS: good results, but only two studies (Dembélé and Zwart 2016; Toté et al. 2015) } \\
\text { CMORPH: the algorithm has been modified during production of version v0.x, prefer v1.0 for } \\
\text { climatology (for more consistency in time). Be aware of its relatively large wet bias. } \\
\text { TMPA: in general reasonable performance }\end{array}$ \\
\hline Mountainous areas & $\begin{array}{l}\text { CMORPH and TARCAT recommended } \\
\text { Avoid RFE2, ARC2, and PERSIANN }\end{array}$ \\
\hline Diurnal cycle & $\begin{array}{l}\text { Only few studies at subdaily scale } \\
\text { Only studied over Niamey, Ouémé, and Dakar } \\
\text { (Pfeifroth et al. 2016; Roca et al. 2010) }\end{array}$ \\
\hline
\end{tabular}

${ }^{a}$ Performance of rainfall product increases for coarser resolution.

${ }^{\mathrm{b}}$ Version 1.0 has been reprocessed with consistent input/algorithm.

- distribution representing well the high precipitation values (representation of intense rainfall events).

\section{4) HydrologicAl MODELING/RESERVOIR MANAGEMENT}

Hydrological modeling is used for many applications linked to water management, such as reservoir management. Decisions made based on the results of such models can have an impact on the population, the economy, or the environment (Thiemig et al. 2013). Precipitation data are one of the main inputs, and so influence the accuracy of the output. The temporal resolution needed depends on the exact application; it can range from subdaily to monthly. In general, a good estimation of both the occurrence and the amount of rainfall is needed. Bias correction as a preprocessing step can improve the model results. This is especially true when using real-time products that have in general large bias. The results are also influenced by the model parameters. These parameters can be specifically calibrated for the chosen rainfall product, in order to improve the result's accuracy.

\section{5) General/Climatology}

Climatological applications need long data records in order to study trends and variations. Most of the studies are focused on a small number of years. Studies over longer time periods would be interesting. For these types of applications, rainfall products need consistent performance in time. This can be an issue. Gauge-only products have long time coverage, but their performance varies with the gauge density. Similarly, more observations are available for reanalysis in more recent years, improving their performance. The sensors and 
sometimes the algorithms used for satellite-based products change in time, making them less consistent. The rainfall products should cover a long time period and be able to represent the yearly and seasonal variability. Thus, the important criteria to look at are

- high correlation or coefficient of determination (good representation of the trend, little dispersion),

- high NS efficiency (good fit, low relative residual variance), and

- low RMSE (good fit, general low misfit).

\section{6) Mountainous AREAS}

Complex orography is a well-known difficulty for rainfall products (see section 5a). Their accuracy is lower than over flatter areas, and they tend to underestimate rainfall. However, some products have been shown to perform relatively better, while some others are more inadequate for mountainous areas.

\section{7) DiURnAL CYCLE}

Most of the well-known rainfall products are available at subdaily scale. However, very few comparison and validation studies considered this scale. The diurnal cycle represents a large precipitation variation within a day, and has been specifically studied by Pfeifroth et al. (2016) over the two sites of Niamey (Niger) and Ouémé (Benin). The diurnal cycle varies within the rainy season, but also from year to year. It can be characterized by the number of rainy peaks, their timing, and their size.

The recommendations given in Table 8 focused on the satellite-based products because more literature was available for them. The most used of them are described in more detail in appendix B. The reanalyses and gaugeonly products also have some strengths.

The main advantage of the gauge-only products is their long record period that goes back to 1901 (while the satellite-based products do not start before 1979). However, the quality of the products varies in time with the gauge network density, which is particularly sparse in some African regions. The product using the highest number of records is GPCC-FDR, and it has to be noted, however, that this number varies a lot in time (Becker et al. 2013). A drawback of some gauge-only products (GPCC-FDR, CRU-TS, and UDEL) is their irregular updates, making them unavailable for recent years' studies. CRU-TS and UDEL also include other variables, such as the temperature, in a consistent format. Having a consistent dataset for both precipitation and temperature can be an advantage for some applications that need these two measurements.

The reanalysis have a higher temporal resolution than the gauge-only products, but also cover a shorter time period. They include many atmospheric variables. This can be useful for climatological applications that do not focus exclusively on precipitation, for example. They can also be used to understand better the mechanisms producing rainfall.

\section{Conclusions}

In this paper, we have reviewed the most-used rainfall products and their relative performances. The choice of products will depend on the intended application. However, different use cases have different requirements that can guide us toward the best choice. Users also have to consider some factors influencing the accuracy of the products and thus the results of their applications. These factors include the gauge density, the orography, and the rainfall regime.

Various methods have been developed to derive rainfall from different types of data. Some of the most recent products build upon older ones. The algorithm of NASA's newest rainfall product, IMERG, is based on the methods of previously existing products: (i) TMPA for the intercalibration and merging of the PMW estimates and for the bias adjustment, (ii) PERSIANN-CCS for the PMW-calibrated IR estimates, and (iii) CMORPHKalman filter for the merging of PMW and IR estimates. Similarly, the recent MSWEP product (first release in 2016 and version 2 in 2017) is not using a new algorithm to derive rainfall estimates from measurements. Instead, it uses already existing gauge-only (non-gauge-adjusted), satellite-based rainfall products and reanalyses to derive anomalies while a corrected version of CHPclim is used for the long-term mean precipitation.

It is important to understand the method behind a rainfall product in order to understand its strengths and its limitations, or, in other words, to know how robust it is and to which extent one can trust it. The diagrams in appendix B are meant to facilitate such understanding across products. When choosing one rainfall product among all the existing ones, one should not only look at validation studies but at the description of the algorithm (C. Kummerow 2017, meeting presentation). Comparing fairly different products is difficult, and the results depend on the reference dataset, on the method, and on resolution. Moreover, the conclusion of a study might not hold for another region or rainfall regime. The algorithm's description will give an idea of the robustness of a product and of its limits. Finally, we agree with Kummerow's plea to only build new rainfall products with a clear use case in mind, one that has not yet been catered to by existing products (C. Kummerow 2017, meeting presentation). 
Acknowledgments. This work is part of the project "Straight as rain: Africa's rainfall measured, modelled, mapped and analyzed" funded by TU Delft|Global Initiative, a program of the Delft University of Technology to boost Science and Technology for Global Development. The authors wish to acknowledge the TWIGA project (project ID: 776691) funded under the EU H2020 (Greening the Economy) program. The authors thank Marie-Claire ten Veldhuis for her many helpful comments and discussions.

AMMA

AMMA-MIP AMMA-Model Intercomparison Project

ARC2

BLD

CAMS-OPI

CDF

CFSR

CFSv2

CHIRPS

CHPclim

CMAP

CMORPH

CORDEX

CPC

CRT

CRU-TS

CSI

ENSEMBLES

EPSAT

ERA

ETS

FAR

FB

GCM

GPCC

GPCC-clim

GPCC-FDD

GPCC-FDR

GPCP

\section{APPENDIX A}

\section{List of Acronyms}

African Monsoon Multidisciplinary Analyses

GPCP-SG

GPI

GPM

GSMaP

GTS

HK

HSS

IMERG

IPWG

IR

ITCZ

JRA

MAE

$M E$

MERRA

Africa Rainfall Climatology version 2

Blended

Climate Anomaly Monitoring SystemOutgoing Longwave Radiation Precipitation Index

Cumulative density function

Climate Forecast System Reanalysis

Climate Forecast System version 2

Climate Hazards Group Infrared Precipitation with Station Data

Climate Hazards Group's Precipitation Climatology

CPC Merged Analysis of Precipitation

CPC morphing technique

Coordinated Regional Climate Downscaling Experiment

Climate Prediction Center

Corrected

Climatic Research Unit-Time Series

Critical success index

Ensembles-Based Predictions of Climate Changes and Their Impacts

Estimation of Precipitation by Satellites

European Centre for Medium-Range Weather Forecasts (ECMWF) Reanalysis

Equitable threat score

False alarm ratio

Frequency bias

Global circulation model

Global Precipitation Climatology Centre

GPCC Climatology

GPCC-Full Data Daily

GPCC-Full Data Reanalysis

Global Precipitation Climatology Project

SPARC
MSWEP

NS

OR

PERSIANN

PERSIANN-

CCS

PERSIANN-

CDR

PMW

POD

POFD

PR

PREC/L

R1

$\mathrm{R} 2$

$\mathrm{RCM}$

RFE2

RMSE

$\mathrm{SD}$

SM2RAIN

S-RIP

TAMSAT

TARCAT

TMPA

TRMM
GPCP-Satellite and Gauge

GOES precipitation index

Global Precipitation Measurement

Global Satellite Mapping of Precipitation

Global Telecommunication System

Hanssen and Kuiper discriminant

Heidke skill score

Integrated Multisatellite Retrievals for GPM

International Precipitation Working Group

Infrared

Intertropical convergence zone

Japanese Meteorological Agency (JMA) Reanalysis

Mean average error

Mean error

Modern-Era Retrospective Analysis for Research and Applications

Multi-Source Weighted-Ensemble Precipitation

Nash-Sutcliffe

Odds ratio

Precipitation Estimation from Remotely Sensed Information using Artificial Neural Networks

PERSIANN-Cloud Classification System

PERSIANN-Climate Data Record

Passive microwave

Probability of detection

Probability of false detection

Precipitation radar

Precipitation Reconstruction over Land

NCEP-NCAR Reanalysis

NCEP-DOE Reanalysis

Regional circulation model

Rainfall Estimate version 2

Root-mean-square error

Standard deviation

Soil Moisture to Rainfall

SARC Reanalysis Intercomparison Project

Stratosphere-Troposphere Processes and Their Role in Climate

Tropical Applications of Meteorology Using Satellite Data and GroundBased Observations

TAMSAT African Rainfall Climatology and Time Series

TRMM Multisatellite Precipitation Analysis

Tropical Rainfall Measuring Mission 
UDEL

WAM

WAMME
University of Delaware dataset

West African monsoon

West African Monsoon Modeling and Evaluation project

\section{APPENDIX B}

\section{Satellite-Based Products: Description and Performance}

\section{a. Climate Anomaly Monitoring System-outgoing longwave radiation precipitation index (CAMS-OPI)}

The CAMS-OPI product provides monthly mean and anomaly precipitation on a $2.5^{\circ} \times 2.5^{\circ}$ grid resolution from 1979 up to present. This product has two types of inputs: 1) monthly rain gauge totals from the Climate Anomaly Data Base (CADB) (initially rain gauges from CAMS were used), and 2) satellite-based estimates derived from outgoing longwave radiation (OLR) observations from NOAA polar-orbiting satellites. These two inputs are merged, such that over the oceans the final estimates are the same as the satellite-based estimates and that over the land the final estimates take the values of the gauge-based estimates where available; everywhere else the gauge and the satellite estimates are blended. Figure B1 represents a flowchart of CAMSOPI's algorithm. A more detailed description of the CAMS-OPI product and a comparison with GPCP and CMAP is given in Janowiak and Xie (1999).

CAMS-OPI has the advantage of being a near-realtime product, so it is useful for real-time precipitation monitoring. However, for other purposes, it is advised to use other monthly global precipitation products such as GPCP or CMAP. They are not real-time products, but they include more observations and use better quality controls for the rain gauge data.

\section{b. Global Precipitation Climatology Project $(G P C P)-$ Satellite and Gauge ( $S G)$}

GPCP-SG gives global monthly precipitation estimates, and associated error estimates, on a $2.5^{\circ} \times$ $2.5^{\circ}$ lat/lon grid from 1979 to a delayed present. Precipitation estimates from different sources of observations are merged to create the GPCP-SG final estimates. GPCP-SG is based on 1) PMW information from SSMI and SSMIS, 2) IR data from geostationary and polar-orbiting satellites, 3) rain gauges data from GPCC, 4$)$ sounding data from the Television and Infrared Observation Satellite Program (TIROS) Operational Vertical Sounder (TOVS) and the Atmospheric Infrared
Sounder (AIRS), and 5) OLR precipitation index (OPI) from NOAA. Some of these input data are not available for the entire period: there are no geo-IR estimates before December 1987 and no PMW estimates from SSMI before December 1985. The algorithm is different before and after these dates, in order to adapt to the data availability. This product is thus not consistent in time. The algorithm is shown in Fig. B2 for the period from 1987 to present, in Fig. B3 for 1986-87, and in Fig. B4 for 1979-85.

The merging method as well as more details about the dataset is given in Adler et al. (2003) for version 2, Huffman et al. (2009) for version 2.1, and Huffman and Bolvin (2013) for version 2.2. A newer version (2.3) recently became available, and its differences with the previous version 2.2 are described in Adler et al. (2018). The intermediate estimates and their associate errors are also available; there is a total of 27 datasets associated to this product (e.g., long term monthly means from 1981 to 2010).

\section{c. CPC Merged Analysis of Precipitation (CMAP)}

\section{1) DESCRIPTION}

The CMAP product gives pentadal (5 days) and monthly global precipitation estimates from 1979 to near present on a $2.5^{\circ} \times 2.5^{\circ}$ lat/lon grid. The estimates are obtained by merging observations from rain gauges with five different satellite-derived precipitation estimates. The "enhanced" version of CMAP uses the precipitation estimate from NCEP-NCAR reanalysis (R1) as an additional input data. Its resolution and coverage (both spatial and temporal) are otherwise the same as for the original CMAP dataset. The satellite and reanalysis estimates are compared to the gauge analysis and weighted accordingly. In this way, the reanalysis is filling the gaps in the satellite coverage. The amount and the type of data used for the estimation vary in space and time which can be an inconvenient since the quality of the estimates depends on them. A flowchart describing CMAP's algorithm is given in Fig. B5. The CMAP product is described in Xie and Arkin (1997) and Xie and Arkin (1996).

\section{2) Performance}

CMAP's performance seems consistent across different regions. It showed similar good results (i.e., low bias and RMSE and high NS efficiency and correlation coefficient) in estimating rainfall amount at monthly time scale over Ethiopia (Dinku et al. 2007, 2011b) and over the Sahel (Ali et al. 2005). Its bias remained low despite its tendency to underestimate high rainfall values (the same was observed for the other monthly products compared in these studies). Over the Sahel, Ali et al. (2005) noticed an overestimation of low rainfall which led to an underestimation of the low rainfall frequency 


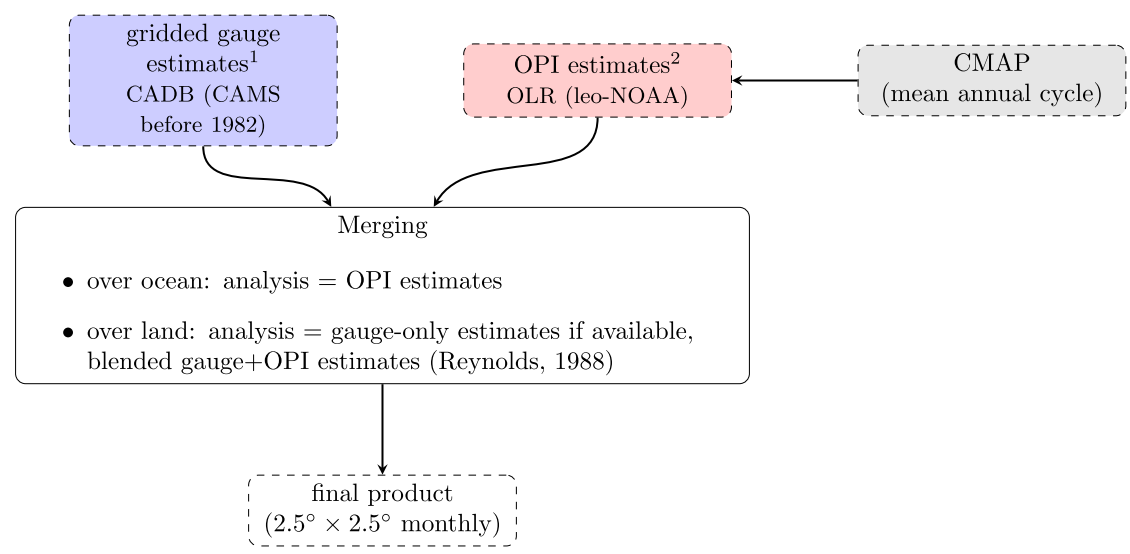

Notes

${ }^{1}$ Gridding method: modified spherical version of Shepard (1968)

${ }^{2}$ OPI algorithm: Xie and Arkin (1998)

FIG. B1. CAMS-OPI algorithm.

and an overestimation of the medium events frequency. According to Okoro et al. (2014), CMAP represented well the interannual and spatial variability over the Niger Delta. This result was confirmed over the Sahelian region by Ali et al. (2005), who also showed that CMAP had better performance in the core of the rainy season than at its edges.

\section{d. Global Precipitation Climatology Project $(G P C P)-1 D D$}

\section{1) DESCRIPTION}

GPCP produces a global daily product on a $1.0^{\circ} \times 1.0^{\circ}$ lat/lon grid (GPCP-1DD) that covers the period from October 1996 to a delayed present. The GPCP-1DD product is consistent with GPCP-SG in the way that it approximately sums to the monthly estimates of GPCPSG. GPCP-1DD is mainly based on IR data, but it also used PMW data, sounding data from TOVS and AIRS, and GPCP-SG. The 3-hourly infrared brightness temperatures from geosynchronous Earth-orbiting (GEO) satellites are compared to a threshold defined from SSMIbased precipitation frequency, and then the "cold" pixels are given a precipitation rate (the conditional rain rates are set locally by month from the GPCP-SG monthly product). LEO satellite GPI estimates are adjusted to GPCP-SG and used to fill the gap when and where the abovementioned geo-IR estimates are missing. The resulting estimates [threshold-match precipitation index (TMPI)] are used between $40^{\circ} \mathrm{N}$ and $40^{\circ} \mathrm{S}$. Outside these latitudes, daily TOVS and AIRS precipitation estimates are used. The rainfall occurrence and amount of the TOVS/AIRS-based estimates are rescaled such that the occurrence matches the occurrence of TMPI at the boundaries and that the amounts sum locally to the monthly value of GPCP-SG. The flowchart in Fig. B6 represents the algorithm of GPCP-1DD. The method and the data used to derive GPCP-1DD product are described in Huffman et al. (2001) and Adler et al. (2017).

\section{2) PERFORMANCE}

Over the Sahel, GPCP-1DD performed relatively well, despite a small overestimation almost everywhere. It performed better than TMPA 3B42 over Burkina Faso and the West coast, but worse than regional products like EPSAT-SG, RFE2, or TARCAT. It tended to underestimate weaker rainfall events and overestimate large one (Jobard et al. 2011). Gosset et al. (2013) evaluated GPCP-1DD along seven other rainfall products over the two sites of Niamey (Niger) and Ouémé (Benin). They showed that GPCP-1DD had a very low bias over both sites (especially in Benin), but different behaviors. Its performance was better over Benin where it represented well the intensity distribution despite a relatively high FAR. Over Niger, its behavior was closer to its behavior over the Sahel, with an underestimation of low rainfall values and an overestimation of high rainfall values. Its tendency to underestimate rainfall frequency and overestimate rainfall amounts (similar to TMPA 3B43v6) could be due to the adjustment of daily estimates to the monthly GPCP-SG product. This adjustment method only modifies the precipitation amounts: rainfall amounts are increased during the rainy days to compensate the underestimation of rainy days occurrence (Gosset et al. 2013). Over West Africa, the performance of GPCP-1DD seemed to be different over the coastal regions (like Benin) and the ones more north (the Sahel, Niger). 


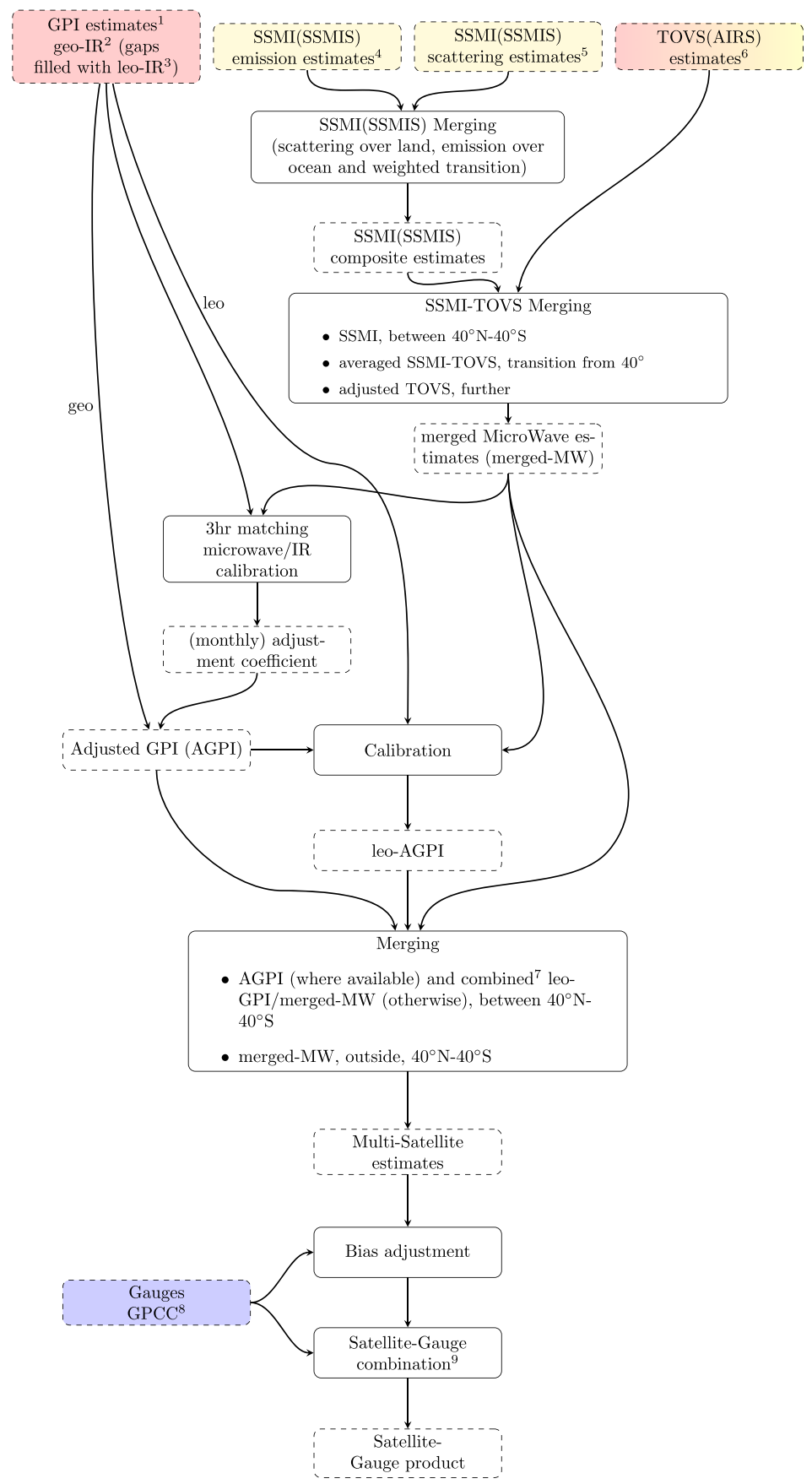

\section{Notes}

${ }^{1}$ GPI algorithm: Arkin and Meisner (1987)

${ }^{2}$ GOES, GMS, MTSat, Meteosat

${ }^{3}$ NOAA series of polar orbiting satellites

${ }^{4}$ Produced the GPCP Polar Satellite Precipitation Data Centre using Wilheit et al. (1991)

${ }^{5}$ Produced the GPCP Polar Satellite Precipitation Data Centre using the Grody Scattering Index (Grody, 1991; Weng and Grody 1994)

TOVS algorithm: Susskind et al. (1997)

${ }^{7}$ weighted combination, the weights being the inversed estimared error variances of the respective estimate

${ }^{8}$ GPCC-FDR7 (v7) for the period 1979-2013, and GPCC-monitoring (v5) Product after

FIG. B2. GPCP-SG algorithm for the period 1987-present. 


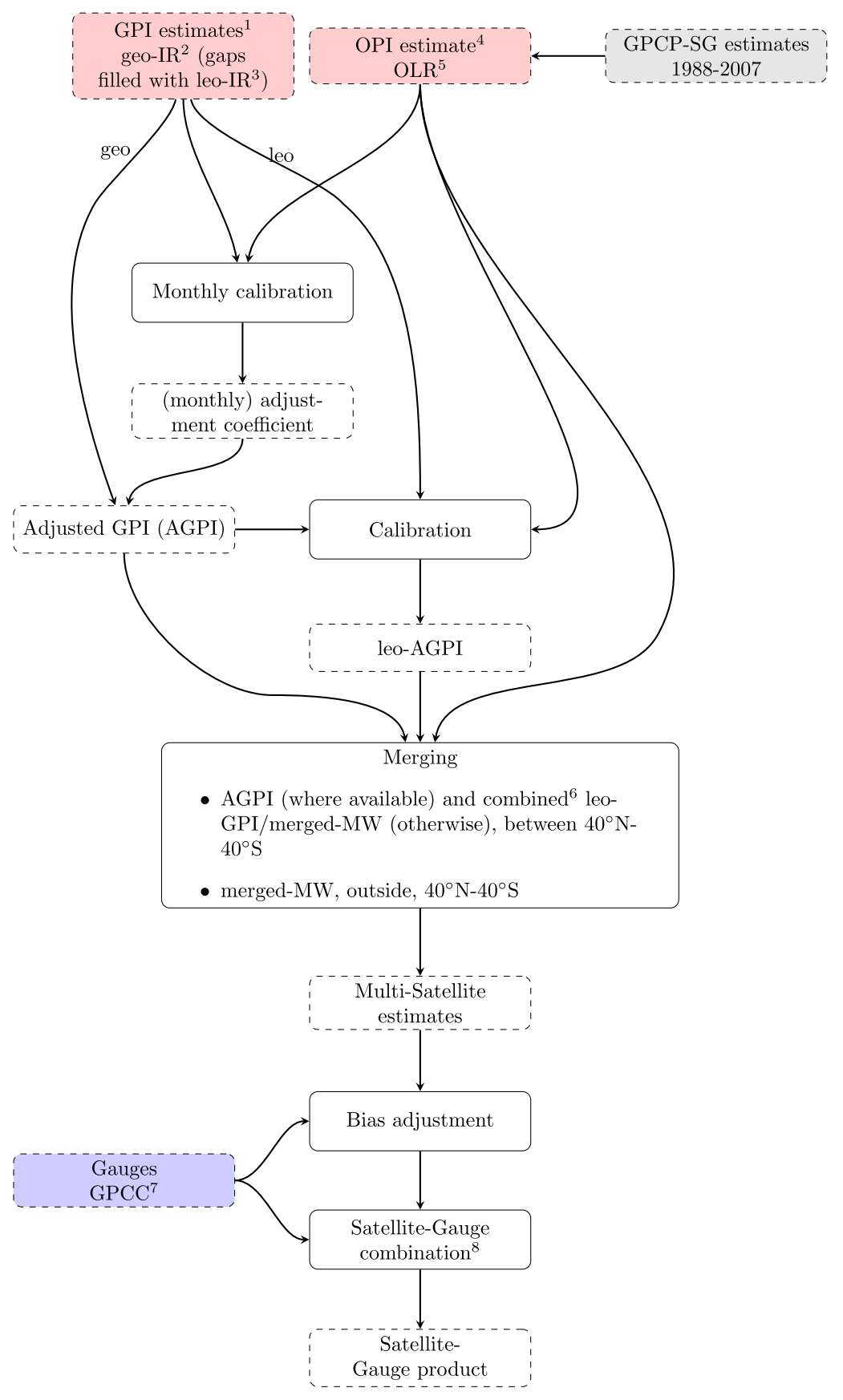

\section{Notes}

${ }^{1}$ GPI algorithm: Arkin and Meisner (1987)

${ }^{2}$ GOES, GMS, MTSat, Meteosat

${ }^{3}$ NOAA series of polar orbiting satellites

${ }^{4}$ Xie and Arkin (1998)

${ }^{5}$ form AVHRR aboard the polar orbiting NOAA series of satellites

${ }^{6}$ weighted combination, the weights being the inversed estimared error variances of the respective estimates

${ }^{7}$ GPCC-FDR7 (v7) for the period 1979-2013, and GPCC-monitoring (v5) Product after

8 weighted average, the weight being the inverse estimated error variance

FIG. B3. GPCP-SG algorithm for the period 1986-87. 


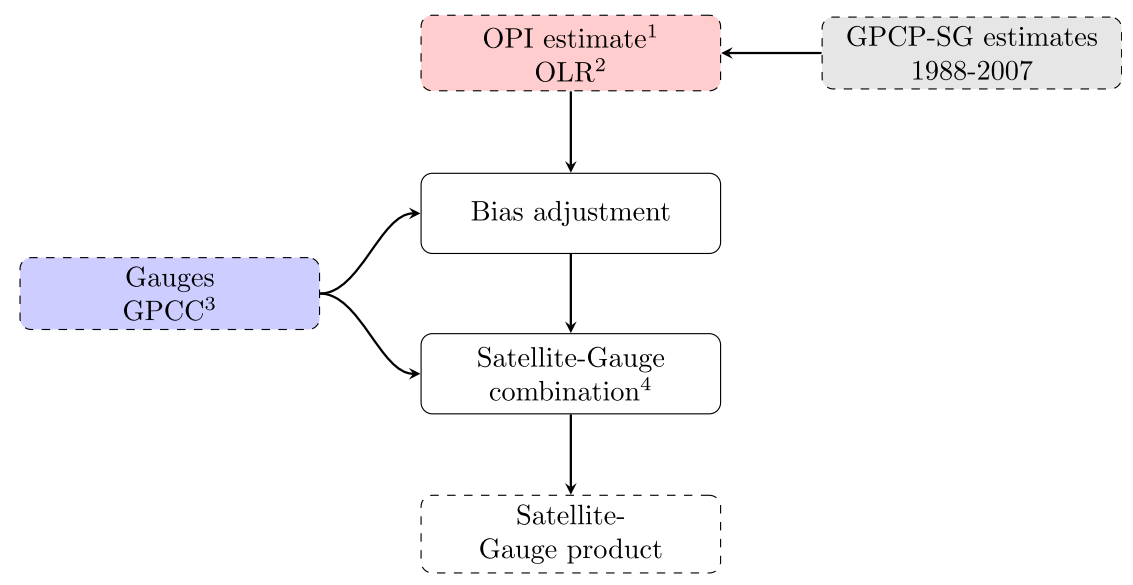

Notes

${ }^{1}$ Xie and Arkin (1998)
${ }^{2}$ form AVHRR aboard the polar orbiting NOAA series of satellites
${ }^{3}$ GPCC-FDR7 (v7) for the period 1979-2013, and GPCC-monitoring (v5) Product after
${ }^{4}$ weighted average, the weight being the inverse estimated error variance

FIG. B4. GPCP-SG algorithm for the period 1979-85.

In East Africa, GPCP-1DD has been evaluated over Ethiopia by Dinku et al. (2007) and over Uganda by Maidment et al. (2013). Over Ethiopia, GPCP-1DD had a limited performance and was outperformed by TMPA 3B42 and CMORPH. It overestimated rainfall at all range. However, it performed better over Uganda with a low bias and good correlation to the gauge data. GPCP-1DD has been known to miss warm orographic rain [for instance, over India in Joshi et al. (2012)], this could explain the difference of performance since Ethiopia has a complex topography compared to Uganda. The underestimation of orographic precipitation could be due to the fact that GPCP-1DD is mainly based on IR data (PMW and gauge data are not used directly).

\section{e. CPC morphing technique (CMORPH)}

\section{1) DESCRIPTION}

CMORPH is a high-resolution global precipitation product. It takes advantages of the higher temporal resolution of the IR data and the higher accuracy of the PMW precipitation estimates. LEO satellite PMW observations are used to estimate the precipitation fields, which are then propagated by motion vectors derived from geostationary satellite IR data. Half-hourly global precipitation estimates are computed on a $0.07277^{\circ}(\approx 8 \mathrm{~km})$ lat/lon grid and are also available as 3 -hourly or as daily estimates on a $0.25^{\circ}$ lat/lon grid about $18 \mathrm{~h}$ after real time. The (half-hourly) 8 -km estimates are obtained by interpolation since the satellite-derived estimates have a coarser resolution (around 12 or $15 \mathrm{~km}$ ).
CMORPH exists in two versions. The original one, CMORPHv0.x, covers the period from December 2002 to present. However, the algorithm and the version of the inputs have evolved in time. That is why the CMORPH product has been reprocessed and extended to January 1998, using a fixed algorithm and the same versions for the input data. The reprocessed CMORPH is called CMORPHv1.0. CMORPHv1.0 includes a satellite-only product (CMORPH-RAW, similar to CMORPHv0.x), a bias-corrected product (CMORPHCRT), and a gauge-satellite blended product (CMORPHBLD). Flowcharts representing the algorithms of CMORPH-RAW and CMORPH-CRT are shown in Figs. B7 and B8 . For more information about the CMORPH products, see Joyce et al. (2004) for version v0.x and Xie et al. (2017) for version 1.0. Among the articles cited below only Cattani et al. (2016) and Pfeifroth et al. (2016) used CMORPHv1.0 (CRT and RAW, respectively).

\section{2) Performance}

CMORPH had poor performance over the Sahel despite a good discrimination of the rain and no-rain events (Novella and Thiaw 2010; Pierre et al. 2011). It strongly overestimated rainfall amounts, especially the high rainfall values (Pierre et al. 2011; Jobard et al. 2011; Dinku et al. 2015). Over the two sites of Niamey (Niger) and Ouémé (Benin), CMORPH also overestimated, but showed a good correlation with the gauges data (Gosset et al. 2013) and represented well the diurnal cycle (Pfeifroth et al. 2016). Thus, CMORPH seemed to have different performances over different parts of West Africa, but overestimated rainfall amount on the whole region. 


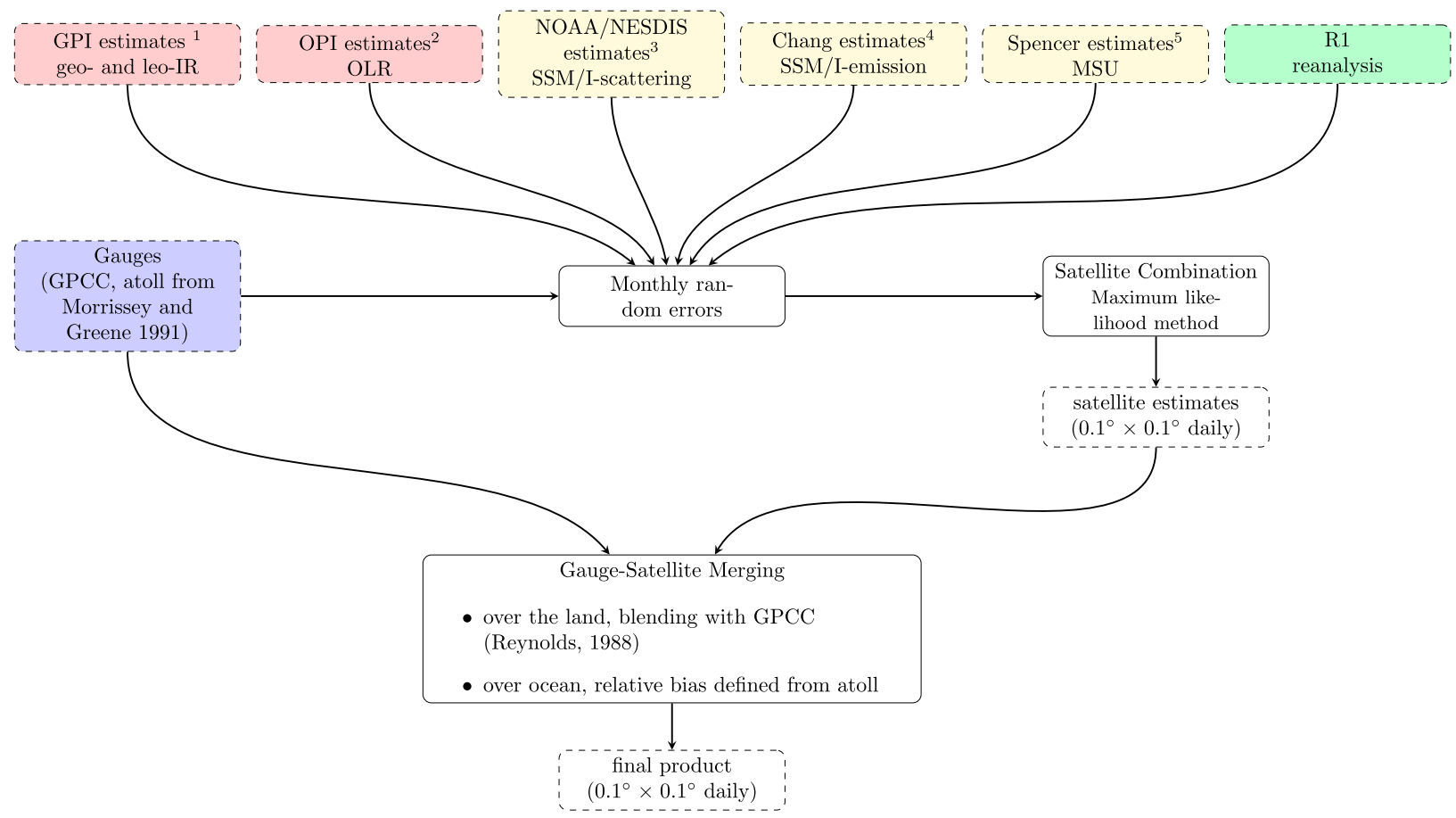

\section{Notes}

${ }^{1}$ GPI algorithm: Arkin and Meisner (1987)

${ }^{2}$ OPI algorithm: Xie and Arkin (1998)

${ }^{3}$ Grosdy algorithm: Grody (1991)

${ }^{4}$ Chang algorithm: Wilheit et al. (1991)

${ }^{5}$ Spencer algorithm: Spencer (1993)

FIG. B5. CMAP algorithm.

On the other hand, CMORPH performed very well over Ethiopia (Dinku et al. 2007; Romilly and Gebremichael 2011). It tended to underestimate rainfall amount but had a good detection of rainfall occurrence (Dinku et al. 2008a, 2011b, 2015; Bitew and Gebremichael 2010). The performance of CMORPH over East Africa varied depending of the regions (Cattani et al. 2016). It has been shown to have good performance over Ethiopia and Zimbabwe by Dinku et al. (2008a) and over Uganda by Asadullah et al. (2008). CMORPH tended to underestimate orographic rain (Cattani et al. 2016; Haile et al. 2013; Thiemig et al. 2012; Dinku et al. 2011a); however, its performance remained good over mountainous areas, especially compared to other products.

\section{f. Tropical Rainfall Measuring Mission (TRMM) Multisatellite Precipitation Analysis (TMPA)}

\section{1) DESCRIPTION}

TRMM is a joint mission between the National Aeronautics and Space Administration (NASA) and the Japan Aerospace Exploration Agency (JAXA) to study rainfall for weather and climate research. The
TRMM satellite, launched in November 1997, is equipped with different types of instruments: Precipitation Radar (PR), TRMM Microwave Imager (TMI), Visible and Infrared Scanner (VIRS), Clouds and Earth Radiant Energy System (CERES), and Lightning Imaging Sensor (LSI). Several products are derived from the TRMM data including quasi-global $\left(50^{\circ} \mathrm{N}-50^{\circ} \mathrm{S}\right)$ precipitation estimates: the TRMM Multisatellite Precipitation Analysis (TMPA) products. They cover the period from 1998 to near present on a $0.25^{\circ} \times 0.25^{\circ}$ lat/lon grid at 3-hourly (TMPA 3B42), daily (TMPA 3B42 derived), and monthly (TMPA3B43) temporal resolution.

The inputs use to derive these products are 1) PMW data from different LEO satellites (including TMI on TRMM), 2) IR data from the international constellation of GEO satellites, 3) TRMM Combined Instrument (TCI, TRMM2B31) based on TMI and TRMM PR (for calibration), and 4) GPCC monthly rainfall estimates. The algorithm for TMPA 3B42 (and TMPA3B43) is shown in Fig. B9. More details about the input datasets and the algorithm can be found in Huffman et al. (2007) for version 6 and in Huffman and Bolvin (2018) for version 7. A real-time version of TMPA 3B42 (TMPA 3B42RT) is also available; it is based on calibration by the TMI 


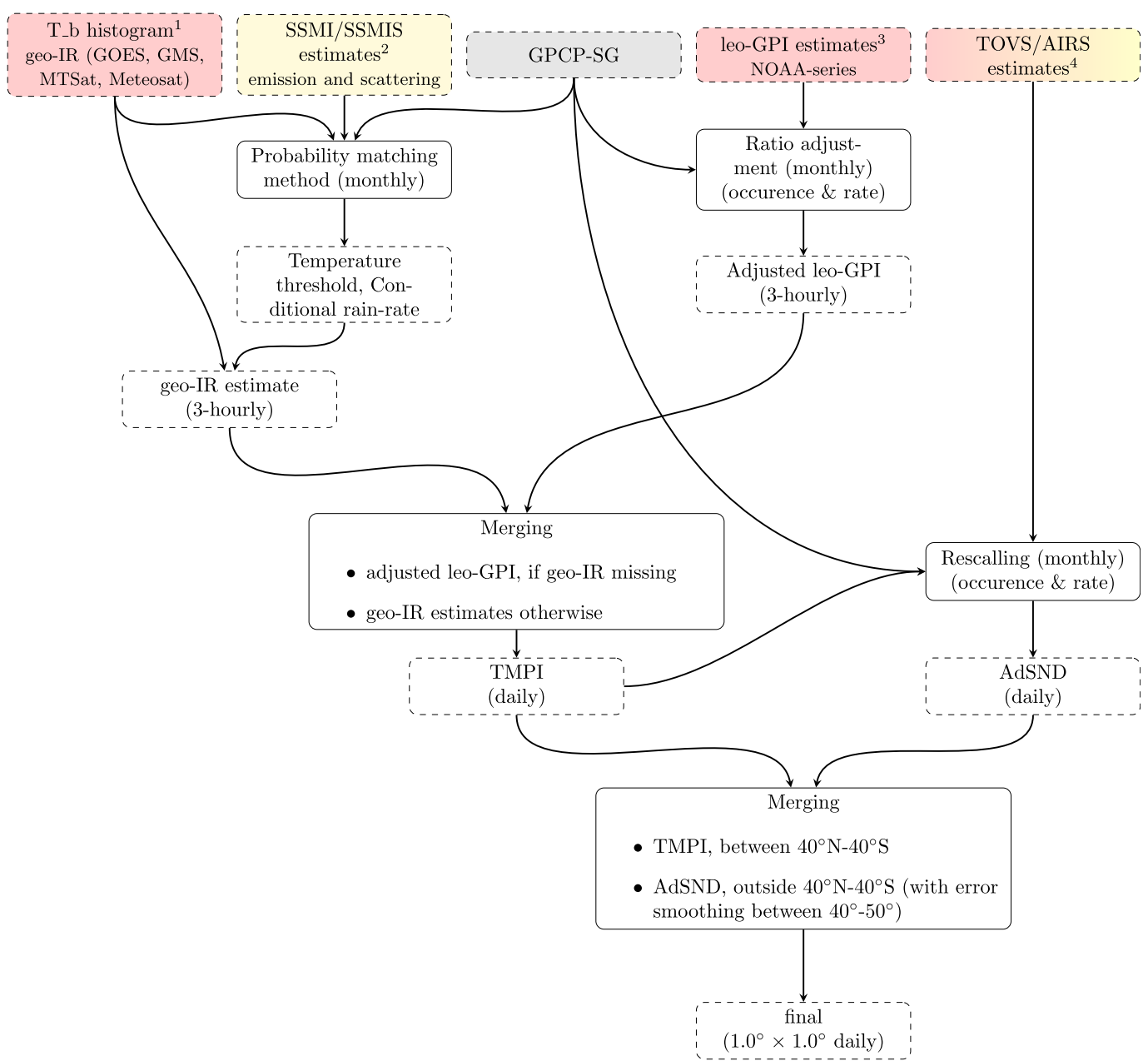

\section{Notes}

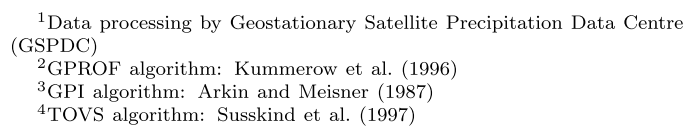

FIG. B6. GPCP-1DD algorithm.

precipitation product instead of TCI and does not incorporate gauge data.

\section{2) Performance}

Overall, the TMPA 3B42 product performed well over different parts of Africa (Sahel, Benin, Niger, Ethiopia, Uganda, Zimbabwe). Over the Sahel, version 6 underestimated the number of rainy days and the high rainfall values (Pierre et al. 2011; Jobard et al. 2011). Its performance was lower over the west coast and Burkina Faso (Jobard et al. 2011). This lower performance over Burkina Faso has also been noticed for version 7 by Dembélé and Zwart (2016). These two studies showed that both version of TMPA underestimated high rainfall value, while Dinku et al. (2015) found that version 7 overestimated high rainfall rates over the Sahel. Over Benin and Niger, the version 6 underestimated the number of rainy days as over the Sahel but overestimated the high rain rates (Roca et al. 2010; Gosset et al. 2013). Pfeifroth et al. (2016) showed that TMPA version 7 was able to reproduce the diurnal cycle and its variability, for two sites in Benin and Niger. However, if the size of the peaks were very close to the gauge data, they were delayed up to two hours. The two versions were quickly compared in Gosset et al. (2013), and version 7 showed a general improvement (depending on the statistics).

Over Ethiopia, TMPA had more difficulties and was often outperformed by CMORPH (Dinku et al. 2007, 2008a, 2011b, 2015), particularly over Lake Tana. This can be due to the fact that no gauges were available near 


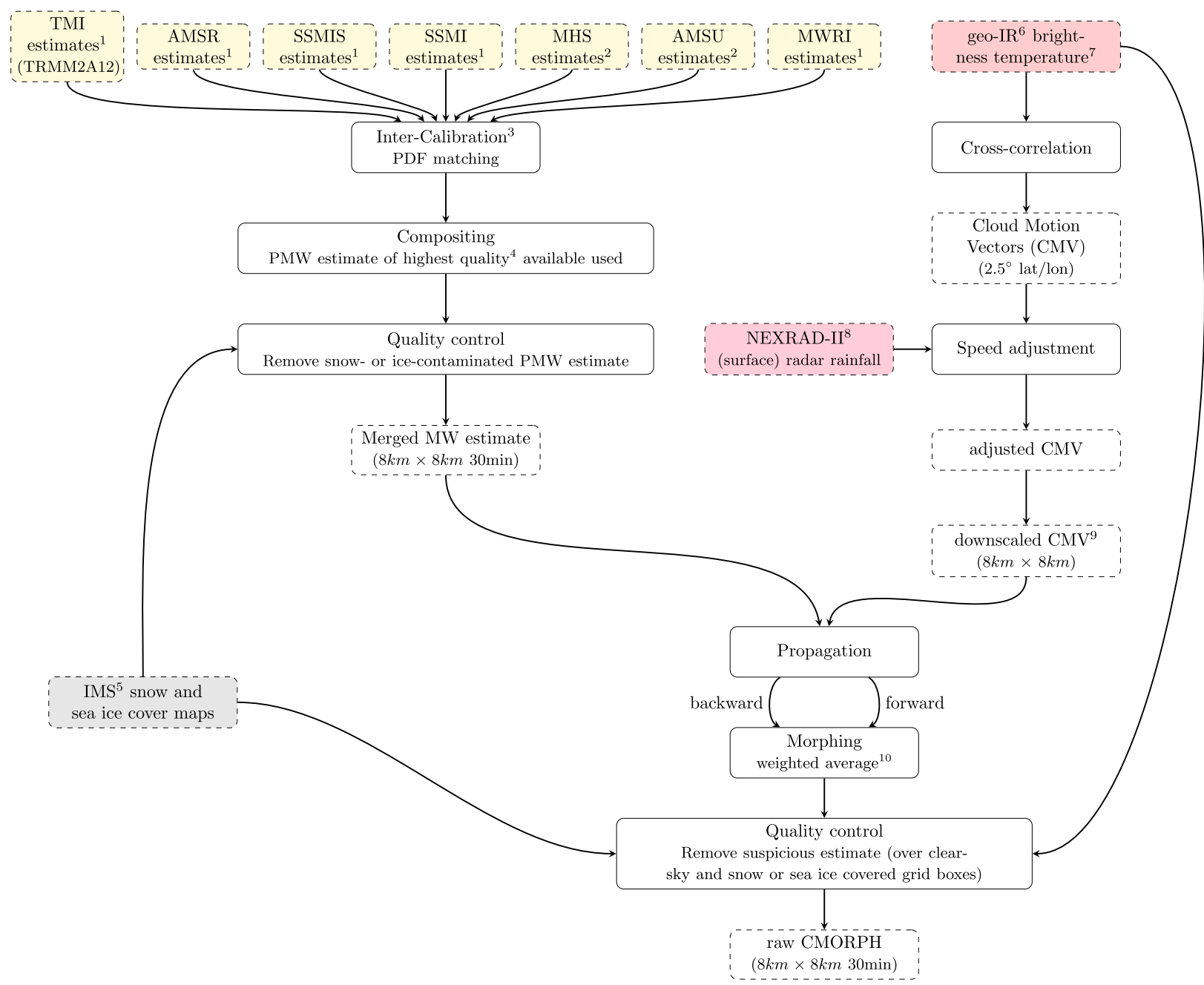

\section{Notes}

${ }^{1}$ generated using the Goddard Profiling Algorithm (GPROF v2004,Kummerow et al. (2001))

2 generated using Microwave Surface and Precipitation Product System (MSPPS): Ferraro et al. (2005)

3 calibrated to TMI estimate, after April (when TMI stopped) PDF table from historical data are used

${ }^{4}$ the ranking being: TMI, AMSR, MWRI, SSMIS, SSM/I, MHS and AMSU

${ }^{5}$ NOAA/NESDID Interactive Multi-sensor Snow and Ice mapping System (daily 4km). IMS maps are based on satellite and in-situ measurement (nsidc.org/

data/docs/noaa/g02156_ims_snow_ice_analysis/)

${ }^{6}$ from GOES, GMS, MTSat and Meteosat

${ }^{7}$ from the CPC (NCEP/NWS/NOAA) Merged 4km Global IR Dataset (Janowiak et al., 2001)

${ }^{8}$ U.S. NextGeneration Weather Radar - stage II (surface precipitation radar)

${ }^{9}$ using bilinear interpolation

${ }^{10}$ the weight being inversely proportional to the temporal lenght of the (backward or forward) propagation

FIG. B7. CMORPH-RAW algorithm.

this lake for the bias adjustment (Worqlul et al. 2014; Haile et al. 2013). However, both versions showed satisfactory results over other regions of East Africa such as Uganda (Asadullah et al. 2008; Diem et al. 2014), Lake Victoria (Haile et al. 2013), or Zimbabwe (Dinku et al. 2008a). Cattani et al. (2016) compared TMPA with other rainfall products over the entire East Africa. TMPA had overall the best performance over the entire region (but it was not independent from the reference data in this study). The performance of TMPA was lower over complex orography where it tended to underestimate rainfall amount (Thiemig et al. 2012; Dinku et al. 2011a; Diem et al. 2014). This could explain why it performed less well over Ethiopia, which has a complex orography.

\section{3) Integrated Multisatellite Retrievals FOR GPM (IMERG)}

The TRMM satellite stopped collecting data in 2015. The TMPA products will continue until 2018, with some modification in the algorithm due to the data no longer being available. The Global Precipitation Measurement (GPM) mission is built upon and will replace the TRMM 


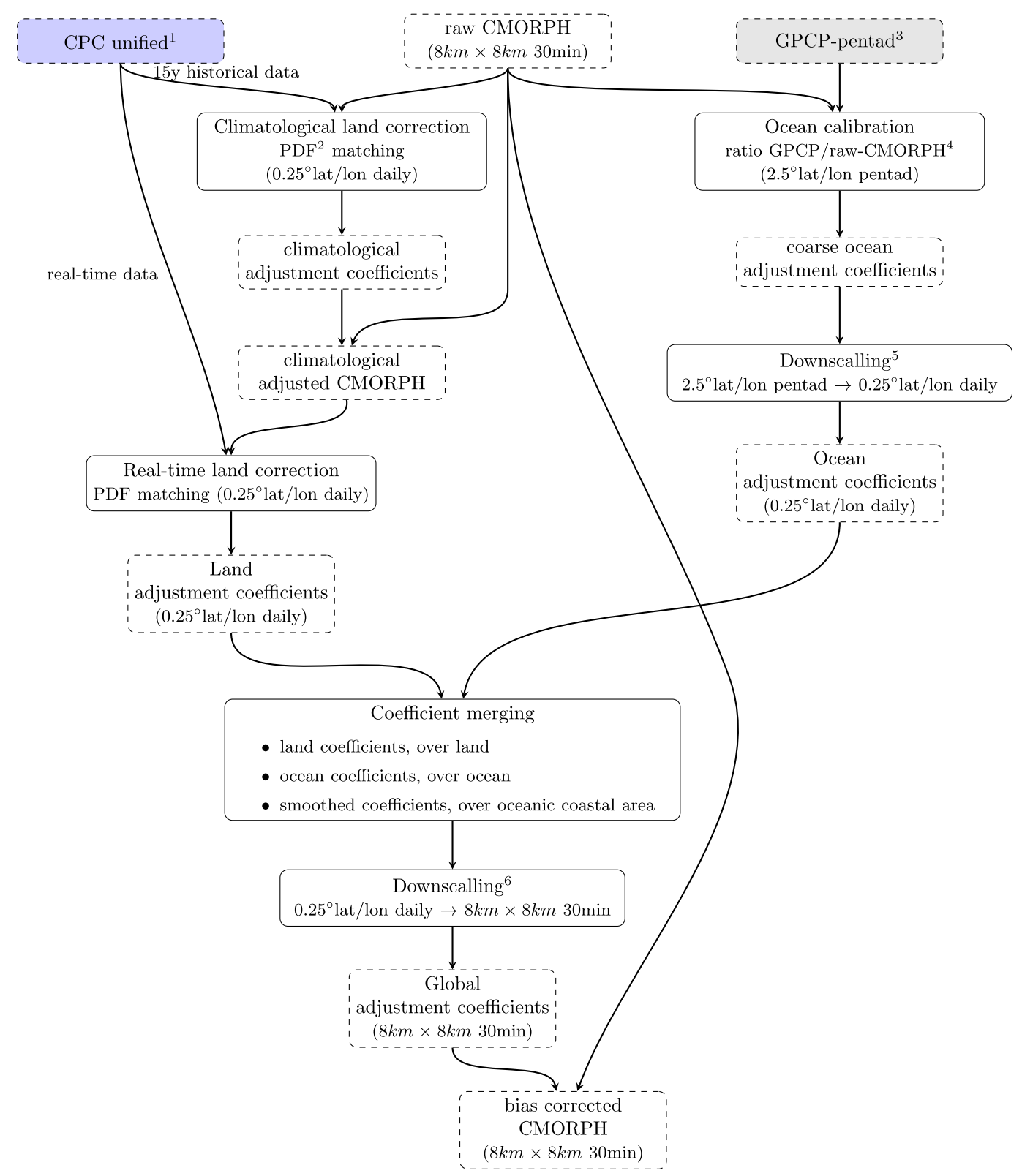

\section{Notes}

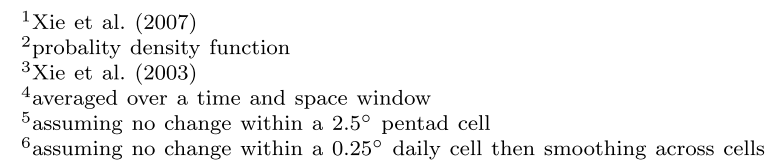

FIG. B8. CMORPH-CRT algorithm.

mission. The GPM Core Observatory satellite was launched in February 2017 and a new product, the Integrated Multisatellite Retrievals for GPM (IMERG), will supersede TMPA (the transition is planned through 2019).

The IMERG product gives half-hourly quasi-global $\left(60^{\circ} \mathrm{N}-60^{\circ} \mathrm{S}\right)$ precipitation estimates on a $0.1^{\circ} \times 0.1^{\circ}$ lat $/ \mathrm{lon}$ grid. It covers the period from March 204 to present with a latency of respectively $4,12 \mathrm{~h}$ and 2.5 months after the end of the month for the Early, Late and Final runs. The inputs are similar to the ones use for TMPA: 1) PMW data from different LEO satellites (including TMI and GMI on TRMM and GPM), 2) IR data from the 


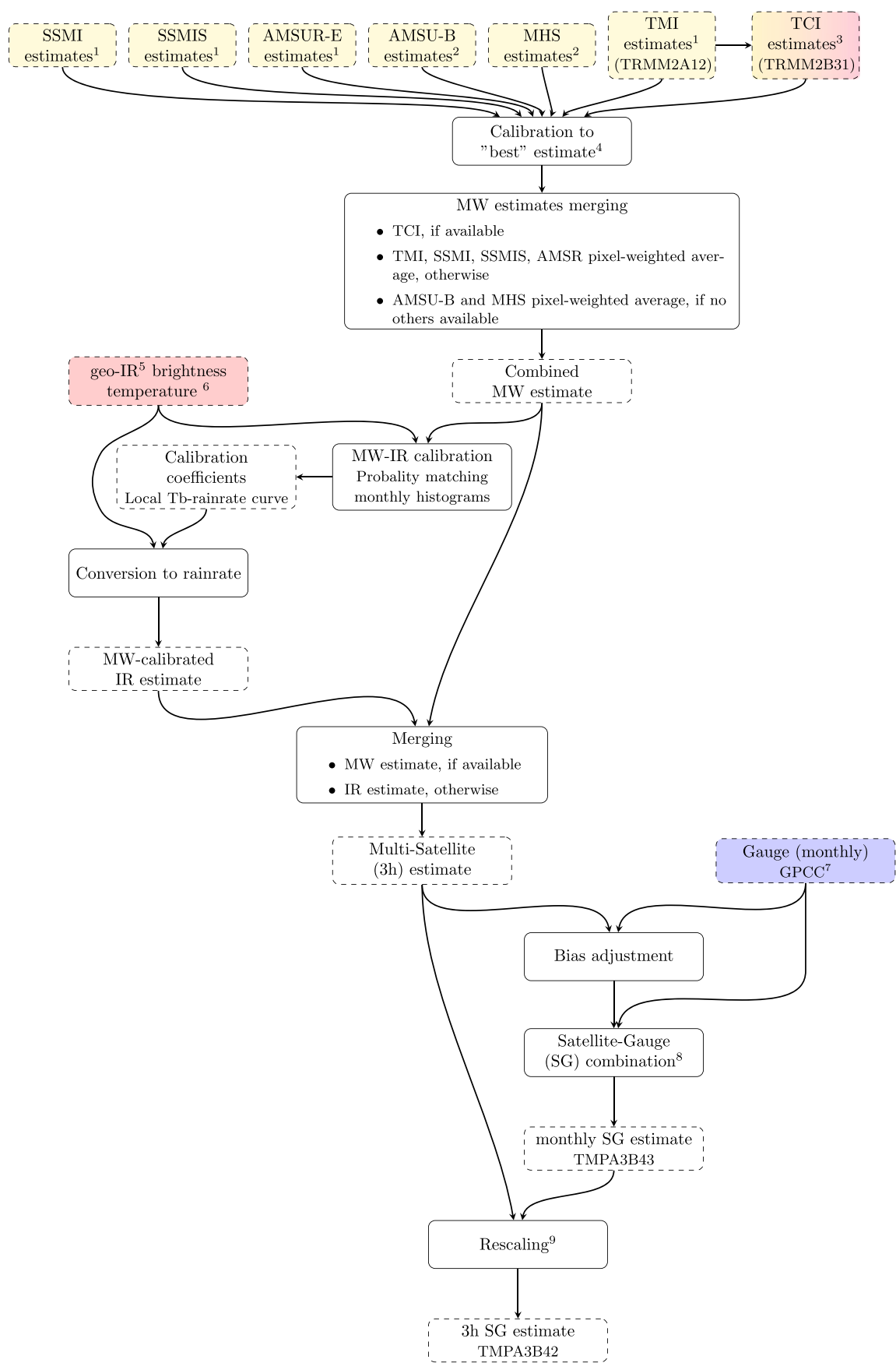

\section{Notes}

${ }^{1}$ computed using a sensor-specific versionof the Goddard Profiling Algorithm (GPROF, Kummerow et al., 2001) ${ }^{2}$ NESDIS/MSPPS algorithm: Zhao and Weng (2002); Weng et al. (2003)

${ }^{4}$ First, SSMI, SSMIS, AMSUR, AMSU-B and MHS estimates are first climatologically matched to TMI estimate. Then, they are, as well as TMI ${ }^{4}$ First, SSMI, SSMIS, AMSUR, AMSU-B and MHS estimates are first climatologically
stimate, calibrated to TCI using probability matching of precipitation rate histograms

estimate, calibrated to TCI using probability
${ }^{5}$ from GOES, GMS, MTSat and MeteoSat

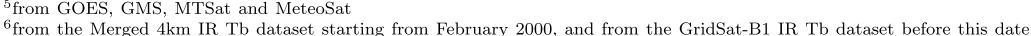
${ }^{7}$ GPCC-FDR for the period 1979-2010, and GPCC-monitoring Product after ${ }^{8}$ GPCC-FDR for the period 1979-2010,

using inverse error variance weighting

FIG. B9. TMPA algorithm. 
international constellation of GEO satellites, 3) GPM Combined Instrument (GCI, 2B-CMB) based on GMI and GPM Dual Precipitation Radar (DPR) (for calibration), and 4) GPCC monthly product. In addition, IMERG uses the monthly GPCP-SG product to calibrate the PMW-based rainfall estimates. IMERG's algorithm (shown in Fig. B10) differs from TMPA's algorithm. It uses a similar intercalibration and merging method for the PMW estimates, and the same bias adjustment and satellite-gauge combination as TMPA. But, the MW-calibrated IR estimates are derived by the PERSIANN-CCS algorithm, and they are combined to the merge-MW estimates using the CMORPH-Kalman Filter (CMORPH-KF) method. More details about the input datasets and a description of the algorithm can be found in Huffman et al. (2018).

With IMERG being a recent product, only few studies have evaluated its performance over Africa. It has been compared to its predecessor TMPA by Dezfuli et al. (2017a) over two regions having different rainy season characteristics, one in West Africa and one in East Africa. They showed that IMERG was closer to the gauge data than TMPA, especially for the extreme events. In a follow-up article, Dezfuli et al. (2017b) compared IMERG and TMPA with three rain gauges at three locations having different rainfall's characteristics. They showed that the performance of both products depended of the season, the region and the evaluation statistics. Both TMPA and IMERG performed better in East Africa and southern West African than in the southern Sahel. This can be expected since the latter has a more arid climate and arid areas are known to be challenging for satellite-based rainfall products. The diurnal cycle was better represented by IMERG, probably because of its higher resolution. However, TMPA represented better the annual cycle for two out of the three rain gauges.

\section{g. Precipitation Estimation from Remote Sensing Information Using Artificial Neural Network (PERSIANN)}

\section{1) DESCRIPTION}

The PERSIANN product was developed in 1997 at the University of Arizona. Quasi-global $\left(60^{\circ} \mathrm{N}-60^{\circ} \mathrm{S}\right)$ up to hourly precipitation estimates at $0.25^{\circ}$ lat/lon resolution are available from 2000 to present with 2 days latency.

PERSIANN is based on an artificial neural network that is applied to IR data from geostationary satellites (CPC/NCEP Merged 4-km IR dataset; Janowiak et al. 2001) to obtain an intermediate precipitation product at $4-\mathrm{km}$ resolution every $30 \mathrm{~min}$. The intermediate product is then aggregated to form the final precipitation product.
The neural network can be trained with different types of data, such as satellite measurements, gauges, groundbased radar data, and ground-surface topographic information. For the operational product, the neural network is trained and updated with PMW data only. The algorithm for the operational product is shown in Fig. B11.

PERSIANN-Cloud Classification System (PERSIANNCCS), another PERSIANN product with higher spatial and temporal resolution, was developed at the Center for Hydrometeorology and Remote Sensing (CHRS) at the University of California, Irvine. The method is similar to the one of PERSIANN, the main difference being the introduction of a Cloud Classification System (CCS). In PERSIANN, the fitting of infrared cloud images to rain rate is done pixel-to-pixel while PERSIANN-CCS uses cloud-patch regions. The cloud-patch features are categorized and the fitting of infrared images to rain rate is unique for each cloud-patch group. The parameters defining the fitting are calibrated through a neural network (Hong et al. 2004). Contrary to PERSIANN, the neural network is not updated but was initially trained with PMW data. The resulting quasi-global $\left(60^{\circ} \mathrm{N}-60^{\circ} \mathrm{S}\right)$ rain estimates are given on a $0.04^{\circ}$ lat/lon grid every hour and cover the period from January 2003 to present.

The PERSIANN-Climate Data Record (PERSIANNCDR) product has been developed for climate and variability studies. It covers a longer period, from 1983 to a delayed present (2015), and is available as daily estimates at $0.25^{\circ}$ resolution. PERSIANN-CDR is based on the same algorithm as PERSIANN. The two main differences are that 1) the neural network in PERSIANN-CDR is not updated, and 2) PERSIANN-CDR uses a different IR dataset, namely, GridSat-B1. Moreover, PERSIANNCDR is bias adjusted with the monthly GPCP.v2.2 product. More detailed descriptions of this product can be found in Ashouri et al. (2015) and Hsu et al. (2014).

The evolution of PERSIANN products from 2000 to 2009 is described in Hsu and Sorooshian (2008).

\section{2) Performance}

PERSIANN tended to overestimate rainfall, especially high rainfall values, except over mountainous areas where it tended to underestimate.

Over the Sahel, PERSIANN performed well in detecting rainfall occurrence (i.e., high POD), but also tended to estimate rain when there was no rain event (i.e., high FAR) (Jobard et al. (2011), and Dembélé and Zwart (2016) over Burkina Faso). It had a strong wet bias and showed overall poor performance over the region (Jobard et al. 2011; Novella and Thiaw 2010; Dembélé and Zwart 2016). This high bias was also observed in Niger and to a lesser extent in Benin; however, PERSIANN had a better correlation over Niger 


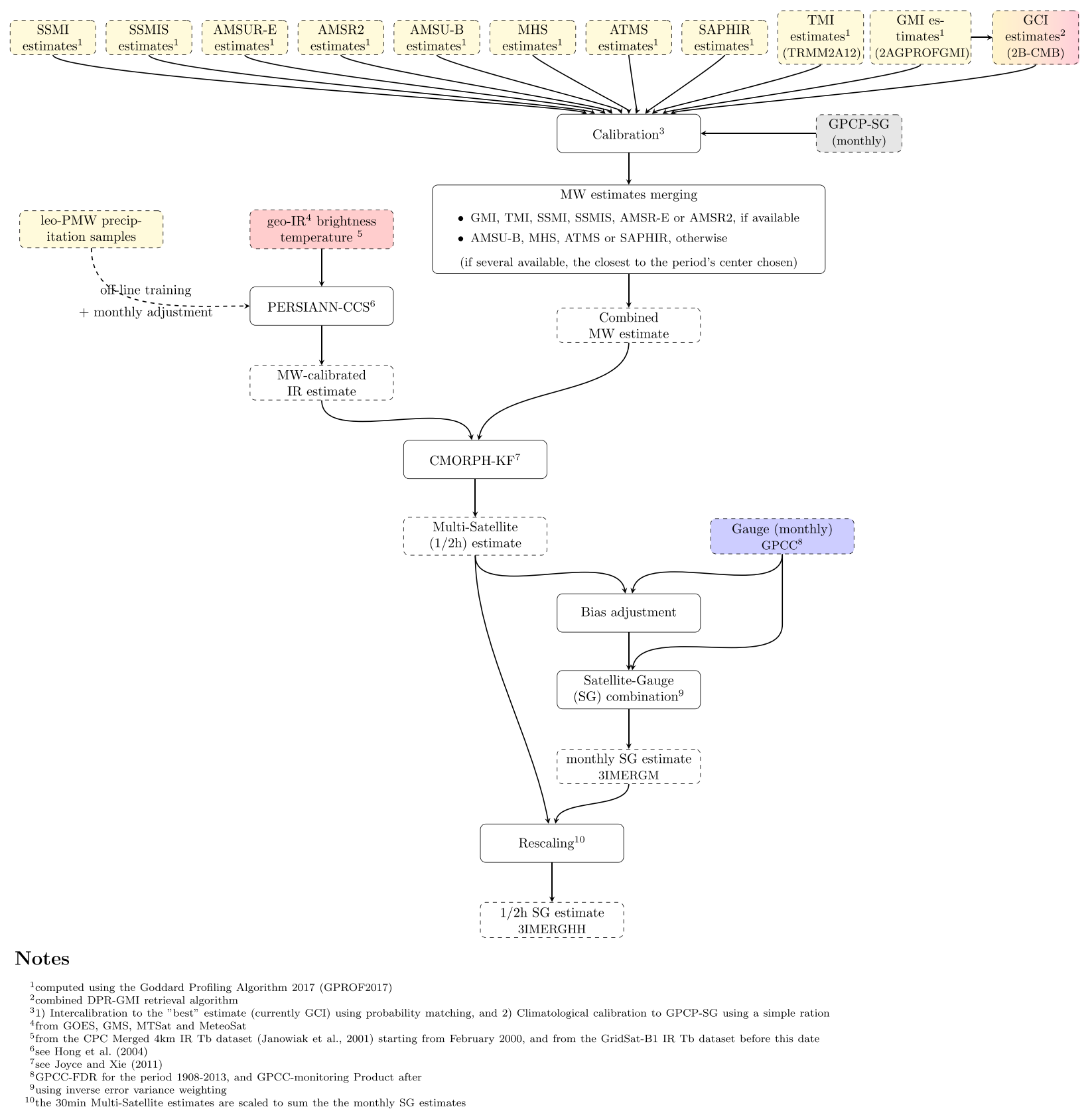

FIG. B10. IMERG algorithm.

than Benin (Gosset et al. 2013). PERSIANN was able to reproduce the diurnal cycle with reasonable timing (e.g., the peak in Ouémé, Benin, was delayed by around $2 \mathrm{~h}$ ) according to Pfeifroth et al. (2016).

Dinku et al. (2008a) found that PERSIANN had a large overestimation and generally poor performance over Ethiopia. However, Hirpa et al. (2010) and Romilly and Gebremichael (2011) studied the performance of PERSIANN at the scale of river basins (located in Ethiopia) and found that PERSIANN substantially underestimated rainfall at high elevation while it performed reasonably well at low elevation. PERSIANN, unlike TMPA 3B42RT and CMORPH, did not show an elevation-dependent trend, which led to this severe underestimation at high elevation (Hirpa et al. 2010). These results were consistent with other studies over other mountainous area such as the Tibetan Plateau (Gao and Liu 2013) or Chile (Zambrano-Bigiarini et al. 2017). This trend was also present over Uganda where PERSIANN overestimated at low elevation and 


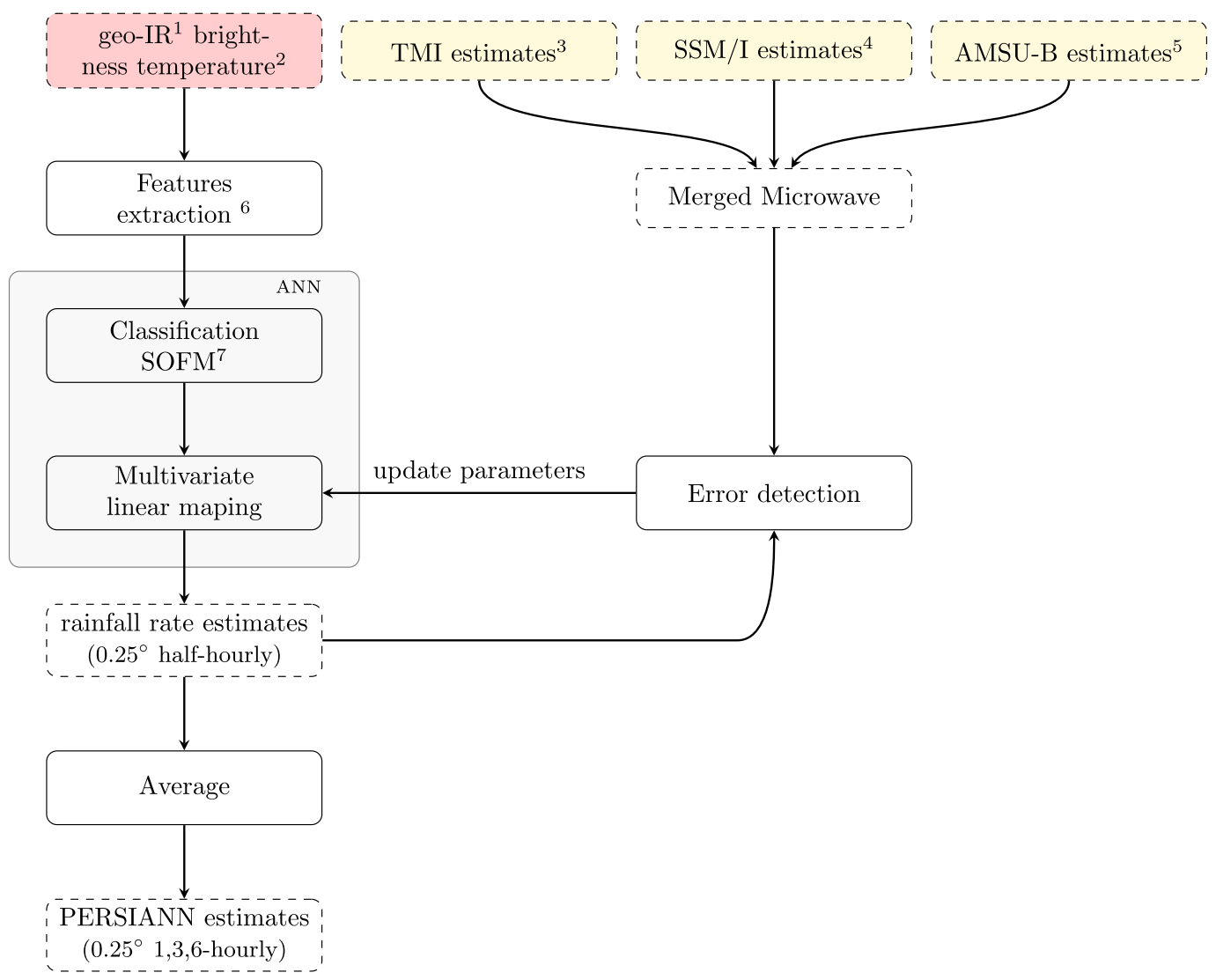

\section{Notes}

${ }^{1}$ from GOES, GMS, MTSat and Meteosat

${ }^{2}$ from the CPC/NCEP Merged $4 \mathrm{~km} \mathrm{IR} \mathrm{Tb} \mathrm{dataset} \mathrm{(Janowiak} \mathrm{et} \mathrm{al.,} \mathrm{2001)}$

${ }^{3}$ generated using the Goddard Profiling Algorithm Kummerow et al. (2001)

4 generated using the algorithm descrribed in Ferraro and Marks (1995)

5 generated using the algorithm described in Weng et al. (2003)

${ }^{6}$ from $5 \times 5$ moving window

${ }^{7}$ Self-Organizing Feature Map (SOFM) algorithm, a neural network-based classification scheme

FIG. B11. PERSIANN algorithm.

underestimated at high one according to Asadullah et al. (2008). The poor performance of PERSIANN and its underestimation at high elevation were also confirmed over East Africa by Cattani et al. (2016) and over four African river basins by Thiemig et al. (2012). This underestimation at high elevation could be explained by the fact that PERSIANN is based on IR data and that orographic precipitation is a warm-cloud process. It has been suggested by Hirpa et al. (2010) and Thiemig et al. (2012) that the underestimation could come from the poor detection of light rain or underestimation of total precipitation at high elevation linked to the thermal IR threshold used to discriminate between raining and nonraining clouds.

PERSIANN-CCS showed a similar trend in underestimating light and moderate rainfall at high elevation and overestimating rainfall, especially heavy events, at low latitude (Hong et al. 2007; Bitew and Gebremichael 2010).

\section{h. Rainfall Estimate version 2 (RFE2)}

\section{1) DESCRIPTION}

RFE2 is the second version of the Rainfall Estimate (RFE) product. It was implemented in 2001 based on the method of Xie and Arkin (1996), and replaced the previous version (RFE 1.0, Herman et al. 1997) operational from 1995 to 2000 . RFE2 produces daily rainfall estimates on a $0.1^{\circ} \times 0.1^{\circ} \mathrm{lat} / \mathrm{lon}$ grid for Africa $\left(20^{\circ} \mathrm{W}-55^{\circ} \mathrm{E}\right.$ and $40^{\circ} \mathrm{S}-40^{\circ} \mathrm{N}$ ) from January 2001 to present. RFE2 computes rainfall estimates based on four operational sources of data: 1) daily GTS rain gauge data, 2) the Geostationary Operational Environmental Satellite 


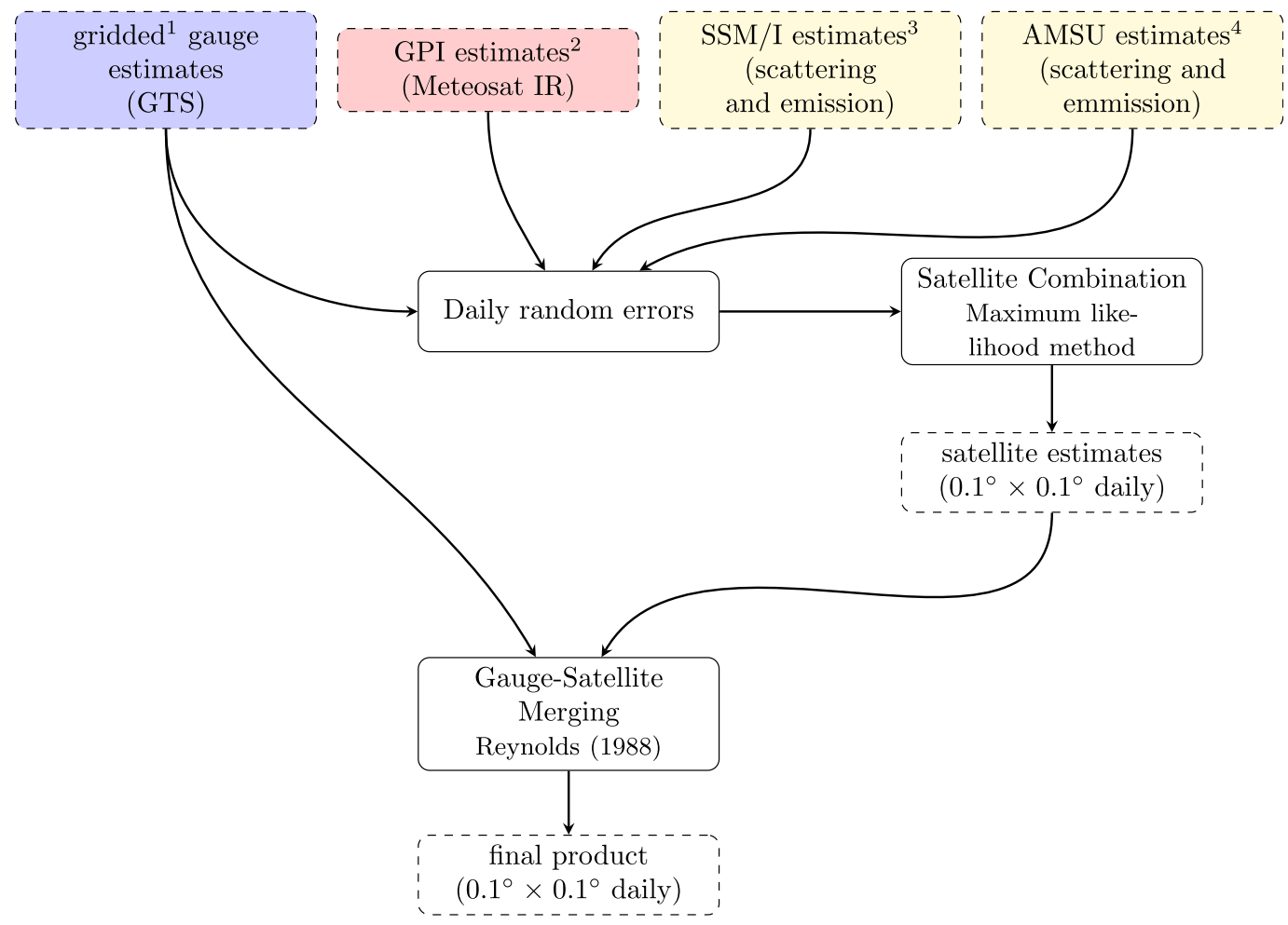

\title{
Notes
}

\author{
${ }^{1}$ Gridding method of Shepard (1968) \\ ${ }^{2}$ GPI algorithm: Arkin and Meisner (1987) \\ ${ }^{3}$ NOAA algorithm: Ferraro and Marks (1995), Ferraro et al. (1996) \\ ${ }^{4}$ NOAA algorithm: Zhao et al. (2000)
}

FIG. B12. RFE2 algorithm.

(GOES) precipitation index (GPI) calculated from cloudtop IR temperatures on a half-hourly basis, 3) Special Sensor Microwave Imager (SSM/I)-based rainfall estimates, and 4) Advanced Microwave Sounding Unit (AMSU)-based rainfall estimates. The last two inputs are new in RFE2. The thermal IR (input 2) and the passive microwaves (inputs 3 and 4 ) are compared to the gauge data (input 1), then linearly combined through the maximum likelihood method and finally merged with gauge data (input 1). This process is illustrated in Fig. B12, representing the RFE2 algorithm. More information is given in NOAA/CPC (2001).

\section{2) Performance}

The performance of RFE2 varied from region to region, but it overall tended to underestimate (i.e., dry bias).

Over the Sahel, RFE2 had good skill at separating rain and no-rain events and showed good performance at estimating dekadal rainfall amount, despite its tendency to underestimate (Novella and Thiaw 2010; Pierre et al.
2011; Jobard et al. 2011; Dembélé and Zwart 2016). Gosset et al. (2013) showed that RFE2 also underestimated rainfall amount over Benin and Niger by overestimating occurrence of low rainfall events and underestimating the high ones. Thiemig et al. (2012) found that, despite a small underestimation, RFE2 performed well over the Volta basin in Ghana. Thus, RFE2 appeared to perform well over West Africa but presented a dry bias.

Over Ethiopia, RFE2 has been reported as having poor performance, at both daily and dekadal time scale, with severe underestimation (Dinku et al. 2007, 2008a, 2011b, 2015). However, RFE2 still performed reasonably well at detecting rainfall occurrence (Dinku et al. 2008a, 2011b). Its performance over Uganda seemed also limited (including a dry bias), especially during boreal summer rainfall, even if it showed some skill in reproducing spatial patterns (Asadullah et al. 2008; Diem et al. 2014; Maidment et al. 2013). Over East Africa, RFE2 was outperformed by CMORPH and TMPA 3B42, but outperformed GSMaP and PERSIANN 
(Cattani et al. 2016). RFE2 showed good performance with a good detection of rainfall occurrence over Zimbabwe (Dinku et al. 2008a), and very poor one over the desert locust recession region, especially over the Sahara (as the other products studied over this region by Dinku et al. (2010)).

A problem of RFE2 product is its underestimation of orographic precipitation (which explains its poor performance over Ethiopian highland) noticed by Cattani et al. (2016), Thiemig et al. (2012), Dinku et al. (2011a), Dinku et al. (2011b), and Diem et al. (2014). This version of RFE (2.0), unlike the first version (RFE 1.0), does not include orographic effects. The algorithm uses a fixed temperature threshold, and thus has difficulty to capture warmcloud precipitation, due to orographic effect for instance.

\section{i. Africa Rainfall Climatology version 2 (ARC2)}

\section{1) DESCRIPTION}

RFE2 temporal coverage is too short for climate studies. Thus, another rainfall product based on the same algorithm was developed for climatology in 2004: the Africa Rainfall Climatology (ARC) product. ARC uses only two of the four inputs of RFE2: the gauges and the IR data because of their availability and consistency over time. However, large biases are present in ARC (due to inconsistencies in the original reprocessing) and a longer temporal coverage was needed for climatology. In 2012, the version 2 of ARC (ARC2) has been developed, and the production of ARC stopped. The main differences with ARC are the time period extended back to 1983, and the recalibration of the IR data between 1983 and 2005 .

The inputs used in ARC2 are the quality-controlled GTS gauge observations and the 3-hourly geostationary IR data (instead of half-hourly for RFE2). The algorithm is the same as for RFE2. ARC2 estimates rainfall daily (from 0600 to 0600 UTC) on the same grid as RFE2, that is, $0.1^{\circ} \times 0.1^{\circ}$ lat/lon grid from $20^{\circ} \mathrm{W}$ to $55^{\circ} \mathrm{E}$ and from $40^{\circ} \mathrm{S}$ to $40^{\circ} \mathrm{N}$. It covers the time period from 1983 to present and is updated on a daily basis. ARC2 shows an improvement compare to ARC and is consistent with RFE2, GPCP, and CMAP (Novella and Thiaw 2013). The ARC2 product is described in Novella and Thiaw (2013), and a flowchart representing its algorithm is given in Fig. B13.

\section{2) Performance}

$\mathrm{ARC} 2$ has been created to fix some of the problems in the first version of ARC, such as the large dry bias from 1998 to 2000 (that does not appear anymore in ARC2). ARC2 was an improvement compared to ARC but still has some systematic errors such as a dry bias during Northern Hemisphere summer as noticed in Novella and Thiaw (2013) and Maidment et al. (2014).

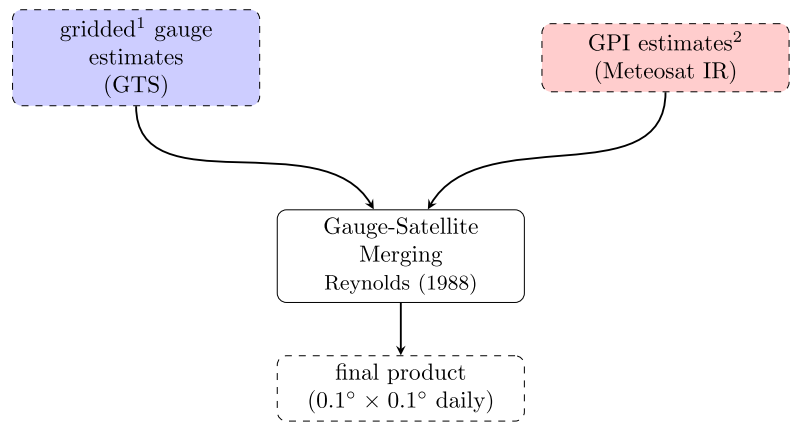

\section{Notes}

${ }^{1}$ Gridding method of Shepard (1968)

${ }^{2}$ GPI algorithm: Arkin and Meisner (1987)

FIG. B13. ARC2 algorithm.

According to Novella and Thiaw (2013), ARC2 had an overall good performance over Africa, but with some variations depending on the regions. They found that ARC2 outperformed TMPA 3B42 and CMORPH at daily scale over the Sahel, but performed poorly over Ethiopia and the Gulf of Guinea. Over Burkina Faso (which is part of the Sahel), ARC2 was found to have only weak correlation with gauge data at daily scale, but to perform well at dekadal time scale, by Dembélé and Zwart (2016). Diem et al. (2014) showed that ARC2 overestimated the number of rainy day for six stations in west Uganda. It could estimate well seasonal totals in the northern part, but had difficulties over the more mountainous South.

ARC presented the same region dependency: good performance over the Sahel (Novella and Thiaw 2010), and poor one over Ethiopia (Dinku et al. 2007). It was also noticed that ARC2 was performing worse over mountainous terrain such as the Ethiopian highlands (Novella and Thiaw 2013) or southwest Uganda (Diem et al. 2014). This poor result can be explained by the low amount of available gauge records (GTS data) in the Ethiopian highlands and the Gulf of Guinea and the inability of IR-based estimates to capture warm-cloud precipitation over coastal and orographic regions (Dinku et al. 2011a; Novella and Thiaw 2013; Maidment et al. 2014; Dinku et al. 2007).

ARC2 and RFE2 use similar algorithms; the main difference is that ARC2 uses less input data. Thus, some similarities in their performances are visible, such as the regions over which they perform well or poorly, or their difficulties over mountainous areas, for example.

\section{j. Global Satellite Mapping of Precipitation (GSMaP)}

\section{1) DESCRIPTION}

The GSMaP project produces several hourly quasiglobal $\left(60^{\circ} \mathrm{S}-60^{\circ} \mathrm{N}\right)$ precipitation products with different 
latencies going from $0 \mathrm{~h}$ for the real-time product to 3 days for the standard version. All these precipitation estimates are given hourly on a $0.1^{\circ} \times 0.1^{\circ}$ lat/lon grid. The near-real-time version has a latency of $4 \mathrm{~h}$ and goes from 2008 to present while the standard version (with or without gauge calibration) goes from 2000 to present. These products are based on PMW data from TMI, AMSR(-E), and SSM/I, and on IR data from several geostationary satellites provided by CPC [GOES-8/GOES-10, Meteosat-7/Meteosat-5, and Geostationary Meteorological Satellite (GMS)].

The method developed by the GSMaP project has three main steps: 1) retrieval of the rainfall measurements (from microwave imagers and microwave sounders); 2) combination of microwave and infrared data (GSMaPMKV); and, if wanted, 3 ) the gauge calibration (GSMaPGauge). The merging method is similar to the one of CMORPH described in Joyce et al. (2004): the PMW estimates are propagated using IR-based advection vectors. Then, the estimates are refined to obtain the final estimate (GSMaP-MKV) using the correlation between geo-IR measurements (cloud-top height) and surface rainfall rate via a Kalman filter. A detailed description of the method can be found in Ushio et al. (2009) and Aonashi et al. (2009).

A gauge-calibrated version (GSMaP-Gauge) of GSMaP exists. It is based on GSMaP-MKV, and has the same temporal and spatial resolution. The GSMaP-MKV estimates are adjusted, over land, with the global gauge analysis from CPC Unified. The gauge-adjustment method is described in Mega et al. (2014). The algorithm used for both GSMaP-Gauge and GSMaP-MKV is shown in Fig. B14.

\section{2) Performance}

Over the Sahel, GSMaP has a dry bias, and it especially underestimates high precipitation values (Jobard et al. 2011; Roca et al. 2010). Both Roca et al. (2010) and Gosset et al. (2013) evaluated this product over Niamey (Niger) and Ouémé (Benin). According to Roca et al. (2010), GSMaP underestimated high rainfall values, while Gosset et al. (2013) noticed an overestimation of the high rates and an underestimation of the lower ones. This could be due to the fact that they considered different time scales, and that the second study took a longer period into account while the first only considered the rainy season 2006. Moreover, Thiemig et al. (2012) also noticed the same behavior over the Volta basin, that is, underestimation of low rain rates and extreme overestimation of high ones. Over the south of West Africa, TMPA seemed to perform better than GSMaP according to these three studies. Gosset et al. (2013) found that, in general, regional products perform better than global ones for this region.
Cattani et al. (2016) evaluated six rainfall products, including GSMaP, over East Africa. They showed that GSMaP was able to reproduce the annual rainfall patterns of the different climates. They found that CMORPHv1 performs slightly better than GSMaP, while they both use a similar morphing approach. This result can be partially explained by the bias correction used in CMORPH and not in GSMaP. GSMaP also underestimates orographic precipitation, more than CMORPH and RFE2.

As the other rainfall products tested over the desert locust recession regions by Dinku et al. (2010), GSMaP had poor performance over these regions.

\section{k. Climate Hazards Group Infrared Precipitation (CHIRP) with Station Data (CHIRPS)}

CHIRPS (version 2, since 2015) gives daily, pentadal, and monthly quasi-global $\left(50^{\circ} \mathrm{S}-50^{\circ} \mathrm{N}\right)$ precipitation estimates from 1981 to near present. The estimates are available on a high resolution $0.05^{\circ} \times 0.05^{\circ}$ lat/lon grid, or on a coarser $0.25^{\circ} \times 0.25^{\circ}$ lat/lon grid. It was created by the U.S. Geological Survey (USGS) Earth Resources Observation and Science (EROS) Center and collaborators at the University of California, Santa Barbara, Climate Hazards Group. It was developed for drought early warning and environmental monitoring to support the Famine Early Warning Systems Network (FEWS-NET).

Different types of inputs are used in CHIRPS 1) global $0.05^{\circ} \times 0.05^{\circ}$ precipitation climatologies from the Climate Hazards group Precipitation climatology, referred to as CHPclim; 2) satellite-based precipitation estimates from the TMPA 3B42 product; 3 ) thermal infrared observations from geostationary satellites; 4 ) gauge observations from public dataset [GHCN monthly, GHCN daily, Global Summary of the Day (GSOD), GTS, and Southern African Science Service Centre for Climate Change and Adaptive Land Management (SASSCAL)] and several private archives (from national meteorological agencies, for example); and 5) the atmospheric model rainfall fields from the NOAA Climate Forecast System, version 2 (CFSv2), which is used to fill the gap in satellite coverage. Cold cloud duration $(\mathrm{CCD})$ derived from the IR data (input 3 ) is calibrated against the TMPA 3B42 product (input 2) to obtain precipitation estimates. These estimates are converted to fraction of normal precipitation, and multiplied to the precipitation climatology from CHPclim (input 1). The model CFSv2 (input 5 ) is used when and where IR data are missing. The new estimates are then bias adjusted to gauges data (input 4).

The description of the method can be found in Funk et al. (2014, 2015b). The latter also validated and compared CHIRPS with other gridded products, namely, GPCC, TMPA 3B42 v7 real-time, CFSv2, ECMWF 


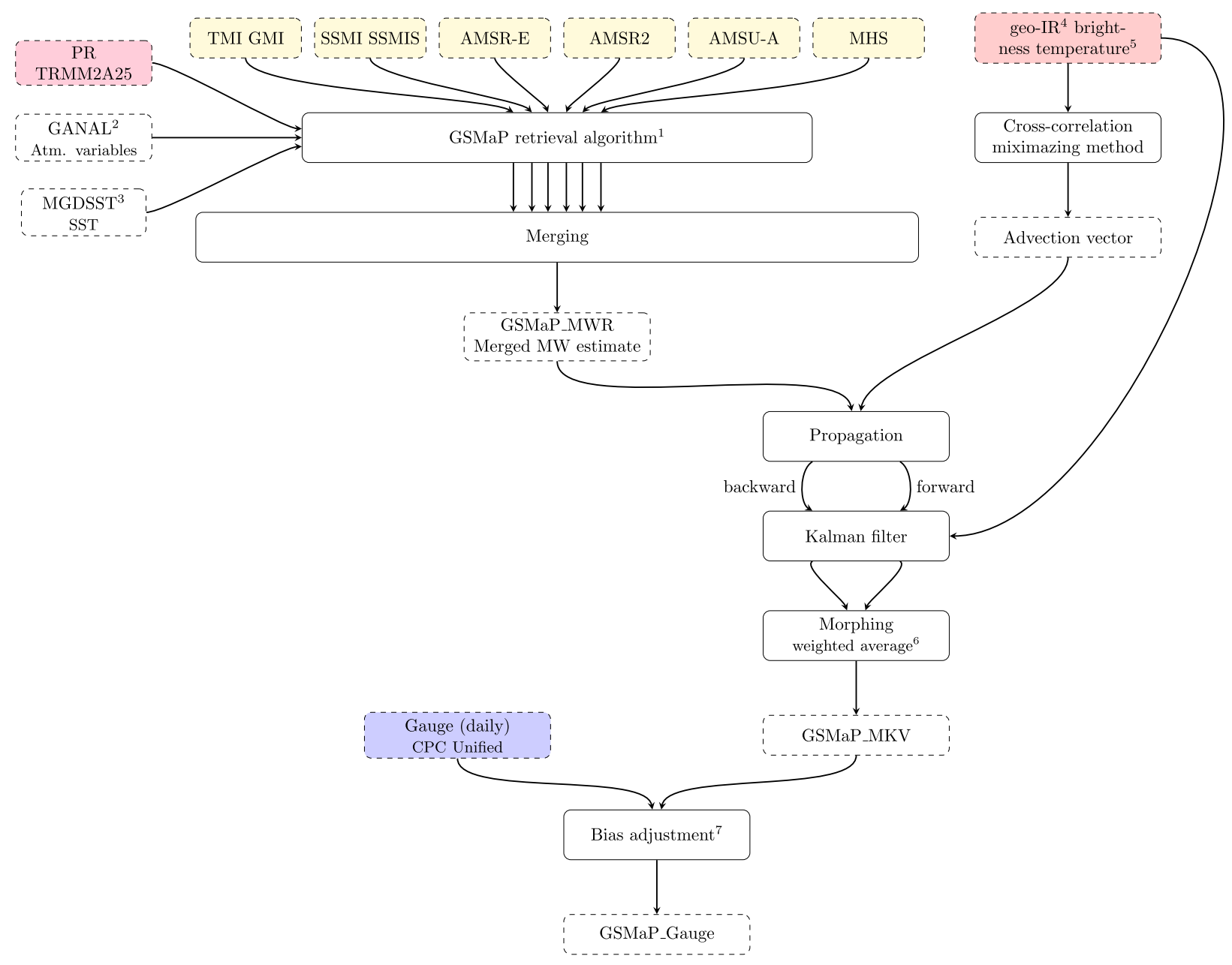

\section{Notes}

Kubota et al. (2006); Aonashi et al. (2009)

${ }^{2}$ Japan Meteorological Agency (JMA) Global Analysis (GANAL) and Forecast data set

${ }^{3}$ JMA Merged satellite and in situ data Global Daily Sea Surface Temperatures

${ }^{4}$ from GOES, GMS, MTSat and Meteosat

${ }^{5}$ from the CPC Merged 4km Global IR Dataset (Janowiak et al., 2001)

${ }^{6}$ based on the root-mean-square uncertainty in the estimate after the forward/backward propogation

FIG. B14. GSMaP algorithm.

reanalysis, and CPC Unified). The method is also described by a flowchart in Fig. B15.

\section{l. Tropical Applications of Meteorology Using} Satellite Data and Ground Based Observations (TAMSAT) African Rainfall Climatology and Time Series (TARCAT)

\section{1) DESCRIPTION}

The TAMSAT Research Group, based at the Meteorology Department of the University of Reading (United Kingdom), started in the mid-1980s. They produce different rainfall products updated in near-real time as part of the TARCAT dataset. TARCAT was developed for drought monitoring. Rainfall estimates, climatologies, and anomalies are available at pentadal, dekadal, monthly, and seasonal time resolution on a $0.0375^{\circ} \times 0.0375^{\circ}$ lat/lon grid $(\approx 4 \mathrm{~km})$ for Africa. In January 2014 , a daily rainfall estimate product was released for the same time period. The particularity of TARCAT is that it is only based on IR data. It does not use any bias adjustment from gauge data, but this is compensated by regional and monthly calibration parameters (derived from historical IR and gauges data).

The TARCAT product is based on Meteosat thermal infrared imagery provided by EUMETSAT, and on historical gauges observations (from African National Meteorological and Hydrological Centers, for the majority 


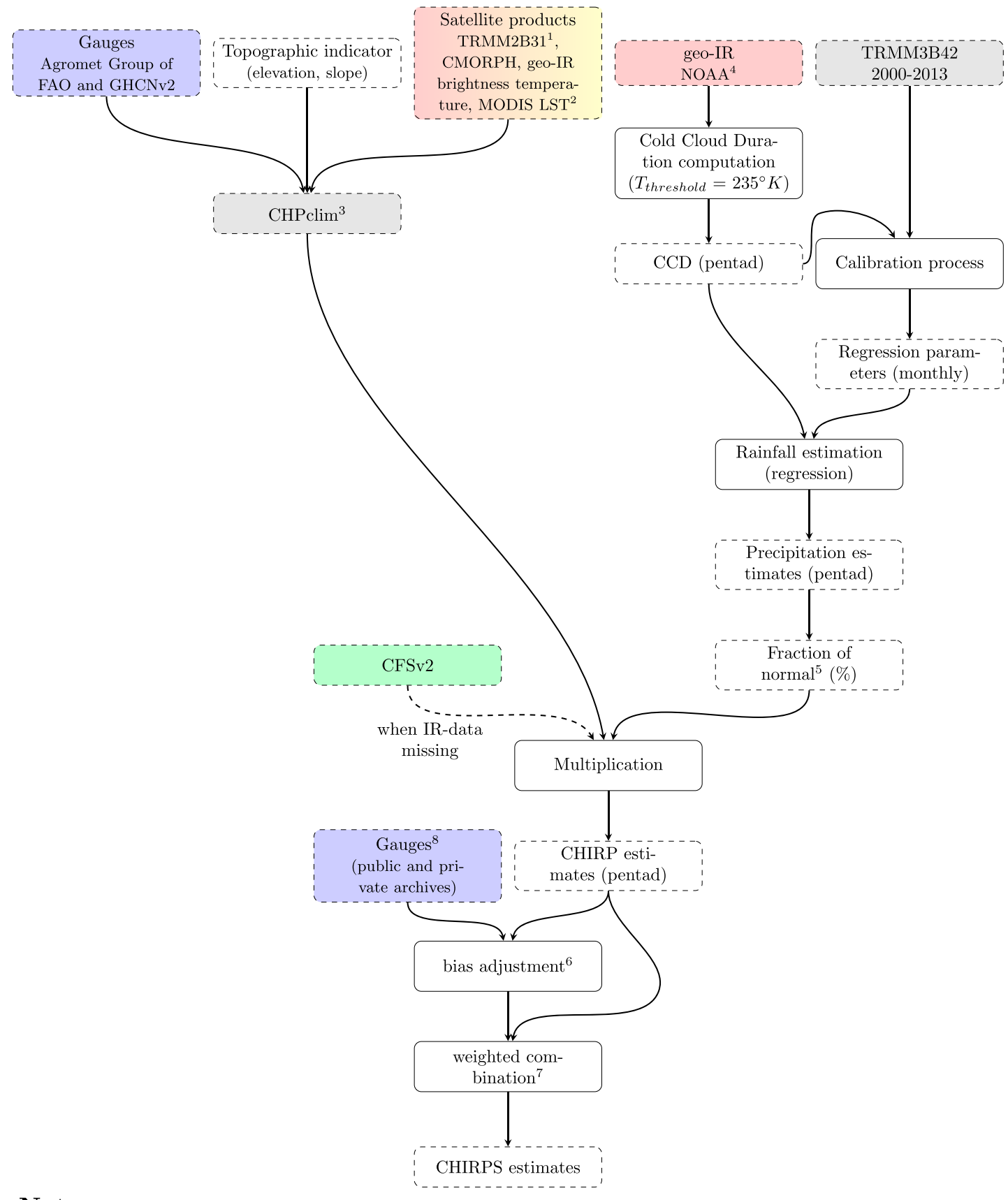

\section{Notes}

${ }^{1}$ MicroWave precipitation estimates

${ }^{2}$ Land Surface Temprature

${ }^{3}$ CHPclim is described in Funk et al. (2015)

${ }^{4}$ GriSat-B1 archive (1981-2008) and CPC TIR dataset (2000-present)

${ }^{5}$ each grid cell's value is divided by the grid cell's 1981-2013 mean precipitation estimate

${ }^{6}$ the bias is computed from the five closest stations with a modified inverse distance weighting algorithm

7the weights are based on the expected correlation with the nearest station and the expected correlation between the 'truth' and the CHIRP estimates

${ }^{8}$ GHCN monthly, GHCN daily, Global Summary of the Day(GSOD), GTS, Southern African Science Service Center for Climate Change and Adaptive Land Management(SASSCAL) and different national meteorological agencies

FIG. B15. CHIRPS algorithm. 


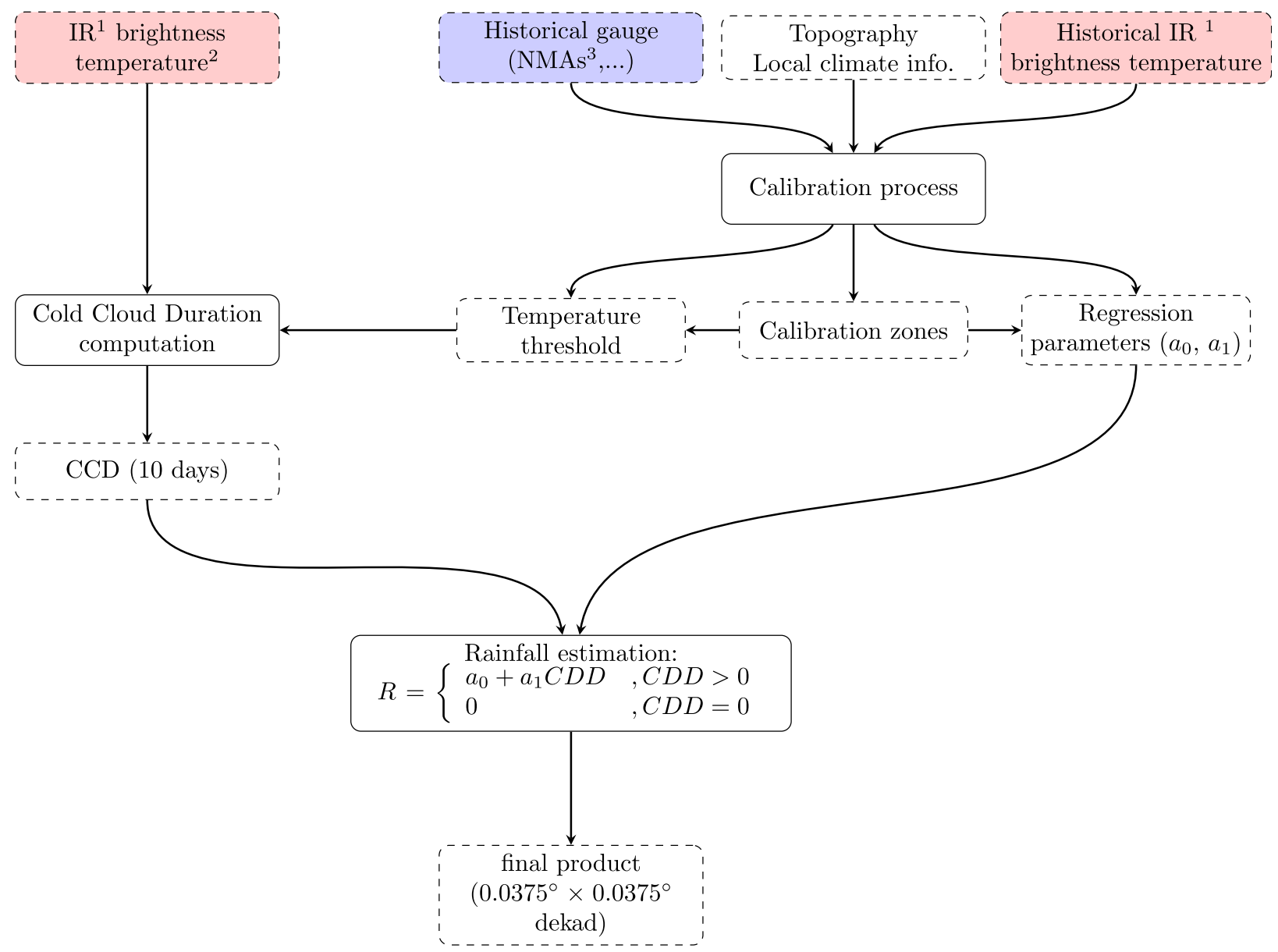

\section{Notes}

\footnotetext{
${ }^{1}$ from Meteosat

2 produced by EUMETSAT

${ }^{3}$ National Meteorological Agencies
}

FIG. B16. TARCAT algorithm.

of them). CCD is derived from the IR data and is then used to estimate dekadal precipitation through linear regression. The temperature threshold used to compute the CCD and the regression parameters are calibrated locally (Africa is divided in several smaller regions) using historical IR and gauge data. The gauge data covers the period from 1983 to 2010 and are only used for calibration. Thus, TARCAT product is not influenced by current changes in gauge coverage. The daily rainfall is derived from the dekadal estimates and daily CCD. The TARCAT algorithm is described in Tarnavsky et al. (2014) and Maidment et al. (2014). A flowchart representing this algorithm is shown in Fig. B16.

A version 3 of TARCAT was released in January 2017 and is described in Maidment et al. (2017) and TAMSAT Group (2016). The algorithm is similar but the calibration differs from version 2 . Indeed, the calibration is not done on rectangular areas anymore but on $1.0^{\circ}$ grid boxes where the gauge density is sufficient, and then interpolated. The temperature threshold is derived at daily scale and the calibration parameters at pentadal scale, instead of dekadal scale in version 2 . In version 3, a bias adjustment based on CHPclim is applied on the calibration parameters. With version 3 being recent, no studies evaluating it against other rainfall products have been found. Thus, below, we are only looking at the performance of the previous version.

\section{2) Performance}

TARCAT showed good performance over Sahel (Novella and Thiaw 2010; Jobard et al. 2011; Dinku et al. 2015), Ethiopia (Dinku et al. 2007, 2015), Uganda 
(Asadullah et al. 2008; Maidment et al. 2013), and East Africa (Cattani et al. 2016). TARCAT tended to underestimate precipitation amount. This dry bias was large over Ethiopia, and relatively low over Sahel. Dembélé and Zwart (2016) found contradictory results over Burkina Faso (part of the Sahel). In their study, TARCAT showed low performance. The main problem of TARCAT, mentioned in most of the studies above, was that it missed high rainfall values.

Dinku et al. (2007) showed that RFE2 also underestimated rainfall over Ethiopia. They attributed the underestimation of these two products to the information content of IR data in general, and to the warm orographic process in their case. However, this dry bias was recognized later by Maidment et al. (2014) when evaluating the performance of TARCAT over Africa, and was attributed to the calibration approach optimized for drought monitoring. Low-intensity rainfall events are more important than the high-intensity ones for drought monitoring.

\section{REFERENCES}

Adler, R. F., and Coauthors, 2003: The version-2 Global Precipitation Climatology Project (GPCP) monthly precipitation analysis (1979-present). J. Hydrometeor., 4, 1147-1167, https://doi.org/ 10.1175/1525-7541(2003)004<1147:TVGPCP $>2.0 . C O ; 2$.

, and Coauthors, 2018: The Global Precipitation Climatology Project (GPCP) monthly analysis (new version 2.3 ) and a review of 2017 global precipitation. Atmosphere, 9, 138, https:// doi.org/10.3390/atmos9040138.

M. Sapiano, and J.-J. Wang, 2017: Global Precipitation Climatology Project (GPCP) daily analysis. Climate Algorithm Theoretical Basis Document CDRP-ATBD-0913, NOAA Climate Data Record, $21 \mathrm{pp}$.

Ali, A., A. Amani, A. Diedhiou, and T. Lebel, 2005: Rainfall estimation in the Sahel. Part II: Evaluation of rain gauge networks in the CILSS countries and objective intercomparison of rainfall products. J. Appl. Meteor., 44, 1707-1722, https:// doi.org/10.1175/JAM2305.1.

American Meteorological Society, 2019: Precipitation regime. Glossary of Meteorology, http://glossary.ametsoc.org/wiki/ Precipitation_regime.

Aonashi, K., and Coauthors, 2009: GSMaP passive microwave precipitation retrieval algorithm: Algorithm description and validation. J. Meteor. Soc. Japan Ser. II, 87A, 119-136, https:// doi.org/10.2151/jmsj.87A.119.

Asadullah, A., N. Mcintyre, and M. Kigobe, 2008: Evaluation of five satellite products for estimation of rainfall over Uganda / Evaluation de cinq produits satellitaires pour l'estimation des précipitations en Ouganda. Hydrol. Sci. J., 53, 1137-1150, https://doi.org/10.1623/hysj.53.6.1137.

Ashouri, H., K.-L. Hsu, S. Sorooshian, D. K. Braithwaite, K. R. Knapp, L. D. Cecil, B. R. Nelson, and O. P. Prat, 2015: PERSIANN-CDR: Daily precipitation climate data record from multisatellite observations for hydrological and climate studies. Bull. Amer. Meteor. Soc., 96, 69-83, https://doi.org/ 10.1175/BAMS-D-13-00068.1.

Beck, H. E., A. I. J. M. van Dijk, V. Levizzani, J. Schellekens, D. G. Miralles, B. Martens, and A. de Roo, 2017a: MSWEP: 3-hourly $0.25^{\circ}$ global gridded precipitation (1979-2015) by merging gauge, satellite, and reanalysis data. Hydrol. Earth Syst. Sci., 21, 589-615, https://doi.org/10.5194/hess-21-589-2017.

— , and Coauthors, 2017b: Global-scale evaluation of 22 precipitation datasets using gauge observations and hydrological modeling. Hydrol. Earth Syst. Sci., 21, 6201-6217, https:// doi.org/10.5194/hess-21-6201-2017.

, E. F. Wood, M. Pan, C. K. Fisher, D. G. Miralles, A. I. J. M. van Dijk, T. R. McVicar, and R. F. Adler, 2019: MSWEP v2 global 3-hourly $0.1^{\circ}$ precipitation: Methodology and quantitative assessment. Bull. Amer. Meteor. Soc., 100, 473-500, https://doi.org/10.1175/BAMS-D-17-0138.1.

Becker, A., P. Finger, A. Meyer-Christoffer, B. Rudolf, K. Schamm, U. Schneider, and M. Ziese, 2013: A description of the global land-surface precipitation data products of the Global Precipitation Climatology Centre with sample applications including centennial (trend) analysis from 1901present. Earth Syst. Sci. Data, 5, 71-99, https://doi.org/ 10.5194/essd-5-71-2013.

Bitew, M. M., and M. Gebremichael, 2010: Evaluation through independent measurements: Complex terrain and humid tropical region in Ethiopia. Satellite Rainfall Applications for Surface Hydrology, M. Gebremichael and F. Hossain, Eds., Springer, 205-214.

Bosilovich, M. G., J. Chen, F. R. Robertson, and R. F. Adler, 2008: Evaluation of global precipitation in reanalyses. J. Appl. Meteor. Climatol., 47, 2279-2299, https://doi.org/ 10.1175/2008JAMC1921.1.

— , and Coauthors, 2015: MERRA-2: Initial evaluation of the climate. NASA Tech. Memo. NASA/TM-2015-104606/Vol. 43, 145 pp., https://gmao.gsfc.nasa.gov/pubs/docs/Bosilovich803.pdf.

Brocca, L., and Coauthors, 2014: Soil as a natural rain gauge: Estimating global rainfall from satellite soil moisture data. J. Geophys. Res. Atmos., 119, 5128-5141, https://doi.org/ 10.1002/2014JD021489.

—, T. Moramarco, F. Melone, and W. Wagner, 2013: A new method for rainfall estimation through soil moisture observations. Geophys. Res. Lett., 40, 853-858, https://doi.org/ 10.1002/grl.50173.

— , and Coauthors, 2019: SM2RAIN-ASCAT (2007-2018): Global daily satellite rainfall from ASCAT soil moisture. Earth Syst. Sci. Data, 11, 1583-1601, https://doi.org/10.5194/ essd-11-1583-2019.

Cattani, E., A. Merino, and V. Levizzani, 2016: Evaluation of monthly satellite-derived precipitation products over East Africa. J. Hydrometeor., 17, 2555-2573, https://doi.org/10.1175/ JHM-D-15-0042.1.

Chen, M., P. Xie, J. E. Janowiak, and P. A. Arkin, 2002: Global land precipitation: A 50-yr monthly analysis based on gauge observations. J. Hydrometeor., 3, 249-266, https://doi.org/ 10.1175/1525-7541(2002)003<0249:GLPAYM>2.0.CO;2.

—, W. Shi, P. Xie, V. B. S. Silva, V. E. Kousky, R. W. Higgins, and J. E. Janowiak, 2008: Assessing objective techniques for gauge-based analyses of global daily precipitation. J. Geophys. Res., 113, D04110, https://doi.org/10.1029/2007JD009132.

Crétat, J., E. K. Vizy, and K. H. Cook, 2014: How well are daily intense rainfall events captured by current climate models over Africa? Climate Dyn., 42, 2691-2711, https://doi.org/ 10.1007/s00382-013-1796-7.

Dee, D. P., and Coauthors, 2011: The ERA-Interim reanalysis: Configuration and performance of the data assimilation system. Quart. J. Roy. Meteor. Soc., 137, 553-597, https://doi.org/ 10.1002/qj.828. 
Dembélé, M., and S. J. Zwart, 2016: Evaluation and comparison of satellite-based rainfall products in Burkina Faso, West Africa. Int. J. Remote Sens., 37, 3995-4014, https://doi.org/10.1080/ 01431161.2016.1207258.

Dezfuli, A. K., C. M. Ichoku, G. J. Huffman, K. I. Mohr, J. S. Selker, N. van de Giesen, R. Hochreutener, and F. O. Annor, 2017a: Validation of IMERG precipitation in Africa. J. Hydrometeor., 18, 2817-2825, https://doi.org/10.1175/JHM-D-17-0139.1.

-, , K. I. Mohr, and G. J. Huffman, 2017b: Precipitation characteristics in West and East Africa from satellite and in situ observations. J. Hydrometeor., 18, 1799-1805, https:// doi.org/10.1175/JHM-D-17-0068.1.

Diem, J. E., J. Hartter, S. J. Ryan, and M. W. Palace, 2014: Validation of satellite rainfall products for western Uganda. J. Hydrometeor., 15, 2030-2038, https://doi.org/10.1175/JHM-D-13-0193.1.

Dinku, T., P. Ceccato, E. Grover-Kopec, M. Lemma, S. J. Connor, and C. F. Ropelewski, 2007: Validation of satellite rainfall products over East Africa's complex topography. Int. J. Remote Sens., 28, 1503-1526, https://doi.org/10.1080/01431160600954688. , S. Chidzambwa, P. Ceccato, S. J. Connor, and C. F. Ropelewski, 2008a: Validation of high-resolution satellite rainfall products over complex terrain. Int. J. Remote Sens., 29, 4097-4110, https://doi.org/10.1080/01431160701772526.

— S. J. Connor, P. Ceccato, and C. F. Ropelewski, 2008b: Comparison of global gridded precipitation products over a mountainous region of Africa. Int. J. Climatol., 28, 1627-1638, https://doi.org/10.1002/joc.1669.

_, P. Ceccato, K. Cressman, and S. J. Connor, 2010: Evaluating detection skills of satellite rainfall estimates over Desert Locust recession regions. J. Appl. Meteor. Climatol., 49, 13221332, https://doi.org/10.1175/2010JAMC2281.1.

$\_,-$_ estimation over mountainous and arid parts of East Africa. Int. J. Remote Sens., 32, 5965-5979, https://doi.org/10.1080/ 01431161.2010.499381.

— - S. Connor, and P. Ceccato, 2011b: Evaluation of satellite rainfall estimates and gridded gauge products over the Upper Blue Nile region. Nile River Basin: Hydrology, Climate and Water Use, A. M. Melesse, Ed., Springer, 109-127.

_- S. Alessandrini, M. Evangelisti, and O. Rojas, 2015: A description and evaluation of FAO satellite rainfall estimation algorithm. Atmos. Res., 163, 48-60, https://doi.org/10.1016/ j.atmosres.2015.01.020.

Druyan, L. M., and Coauthors, 2010: The WAMME regional model intercomparison study. Climate Dyn., 35, 175-192, https://doi.org/10.1007/s00382-009-0676-7.

_- , and M. Fulakeza, 2013: Downscaling reanalysis over continental Africa with a regional model: NCEP versus ERA Interim forcing. Climate Res., 56, 181-196, https://doi.org/ 10.3354/cr01152.

Ebert, E. E., J. E. Janowiak, and C. Kidd, 2007: Comparison of near-real-time precipitation estimates from satellite observations and numerical models. Bull. Amer. Meteor. Soc., 88, $47-$ 64, https://doi.org/10.1175/BAMS-88-1-47.

FAO, 2016: The state of food and agriculture 2016: Climate change, agriculture and food security. Food and Agriculture Organization, 173 pp., http://www.fao.org/3/a-i6030e.pdf.

Fujiwara, M., and Coauthors, 2017: Introduction to the SPARC Reanalysis Intercomparison Project (S-RIP) and overview of the reanalysis systems. Atmos. Chem. Phys., 17, 1417-1452, https://doi.org/10.5194/acp-17-1417-2017.

Funk, C., and J. Verdin, 2003: Comparing satellite rainfall estimates and reanalysis precipitation fields with station data for
Western Kenya. Extended Abstract, JRC-FAO Int. Workshop on Crop Monitoring for Food Security in Africa, Nairobi, Kenya, JRC-FAO, 89-95.

- , and Coauthors, 2014: A quasi-global precipitation time series for drought monitoring. USGS Data Series 832.4 pp., https:// doi.org/10.3133/ds832.

- , A. Verdin, J. Michaelsen, P. Peterson, D. Pedreros, and G. Husak, 2015a: A global satellite-assisted precipitation climatology. Earth Syst. Sci. Data, 7, 275-287, https://doi.org/ 10.5194/essd-7-275-2015.

, and Coauthors, 2015b: The climate hazards infrared precipitation with stations-A new environmental record for monitoring extremes. Sci. Data, 2, 150066, https://doi.org/10.1038/ sdata.2015.66.

Gao, Y. C., and M. F. Liu, 2013: Evaluation of high-resolution satellite precipitation products using rain gauge observations over the Tibetan Plateau. Hydrol. Earth Syst. Sci., 17, 837-849, https://doi.org/10.5194/hess-17-837-2013.

Gebrechorkos, S. H., S. Hülsmann, and C. Bernhofer, 2019: Statistically downscaled climate dataset for East Africa. Sci. Data, 6, 31, https://doi.org/10.1038/s41597-019-0038-1.

Gelaro, R., and Coauthors, 2017: The Modern-Era Retrospective Analysis for Research and Applications, version 2 (MERRA-2). J. Climate, 30, 5419-5454, https://doi.org/10.1175/JCLI-D-160758.1 .

Gosset, M., J. Viarre, G. Quantin, and M. Alcoba, 2013: Evaluation of several rainfall products used for hydrological applications over West Africa using two high-resolution gauge networks. Quart. J. Roy. Meteor. Soc., 139, 923-940, https://doi.org/10.1002/qj.2130.

Haiden, T., M. J. Rodwell, D. S. Richardson, A. Okagaki, T. Robinson, and T. Hewson, 2012: Intercomparison of global model precipitation forecast skill in 2010/11 using the SEEPS score. Mon. Wea. Rev., 140, 2720-2733, https://doi.org/10.1175/ MWR-D-11-00301.1.

Haile, A. T., E. Habib, M. Elsaadani, and T. Rientjes, 2013: Intercomparison of satellite rainfall products for representing rainfall diurnal cycle over the Nile basin. Int. J. Appl. Earth Obs. Geoinf., 21, 230-240, https://doi.org/10.1016/j.jag.2012.08.012.

Harris, I., P. Jones, T. Osborn, and D. Lister, 2014: Updated highresolution grids of monthly climatic observations - The CRU TS3.10 Dataset. Int. J. Climatol., 34, 623-642, https://doi.org/ 10.1002/joc.3711.

Hennermann, K., 2019: ERA5 data documentation. ECMWF, https:// confluence.ecmwf.int/display/CKB/ERA5+data+documentation.

Herman, A., V. B. Kumar, P. A. Arkin, and J. V. Kousky, 1997: Objectively determined 10-day African rainfall estimates created for famine early warning systems. Int. J. Remote Sens., 18, 2147-2159, https://doi.org/10.1080/014311697217800.

Hersbach, H., and Coauthors, 2018: Operational global reanalysis: Progress, future directions and synergies with NWP. ERA Rep. Series 27, 63 pp., https://doi.org/10.21957/tkic6g3wm.

Hirpa, F. A., M. Gebremichael, and T. Hopson, 2010: Evaluation of high-resolution satellite precipitation products over very complex terrain in Ethiopia. J. Appl. Meteor. Climatol., 49, 1044-1051, https://doi.org/10.1175/2009JAMC2298.1.

Hong, Y., K.-L. Hsu, S. Sorooshian, and X. Gao, 2004: Precipitation Estimation from Remotely Sensed Imagery using an Artificial Neural Network Cloud Classification System. J. Appl. Meteor., 43, 1834-1853, https://doi.org/10.1175/JAM2173.1.

D. Gochis, J. Cheng, K. Hsu, and S. Sorooshian, 2007: Evaluation of PERSIANN-CCS rainfall measurement using the NAME event rain gauge network. J. Hydrometeor., 8, 469482, https://doi.org/10.1175/JHM574.1. 
Hourdin, F., and Coauthors, 2010: AMMA-Model Intercomparison Project. Bull. Amer. Meteor. Soc., 91, 95-104, https://doi.org/ 10.1175/2009BAMS2791.1.

Hsu, K.-L., and S. Sorooshian, 2008: Satellite-based precipitation measurement using PERSIANN system. Hydrological Modelling and the Water Cycle: Coupling the Atmospheric and Hydrological Models, S. Sorooshian et al., Eds., Springer, 27-48.

—- H. Ashouri, D. Braithwaite, and S. Sorooshian, 2014: Precipitation - PERSIANN-CDR. Climate Algorithm Theoretical Basis Doc. CDRP-ATBD-0286, NOAA, 30 pp., https://www.ncdc.noaa.gov/sites/default/files/cdr-documentation/ CDRP_ATBD_01B-16_05122014.pdf.

Huffman, G. J., and D. T. Bolvin, 2013: GPCP version 2.2 SG combined precipitation data set documentation. NASA GSFC Doc., 46 pp., ftp://precip.gsfc.nasa.gov/pub/gpcp-v2.2/ doc/V2.2 doc.pdf.

_, and _- 2018: TRMM and other data precipitation data set documentation. NASA TRMM Doc., 46 pp., https:// pmm.nasa.gov/sites/default/files/document_files/3B42_3B43_ doc_V7_180426.pdf.

— , R. F. Adler, M. M. Morrissey, D. T. Bolvin, S. Curtis, R. Joyce, B. McGavock, and J. Susskind, 2001: Global precipitation at one-degree daily resolution from multisatellite observations. J. Hydrometeor., 2, 36-50, https://doi.org/ 10.1175/1525-7541(2001)002<0036:GPAODD>2.0.CO;2.

— , and Coauthors, 2007: The TRMM Multisatellite Precipitation Analysis (TMPA): Quasi-global, multiyear, combined-sensor precipitation estimates at fine scales. J. Hydrometeor., 8, 38-55, https://doi.org/10.1175/JHM560.1.

— R. F. Adler, D. T. Bolvin, and G. Gu, 2009: Improving the global precipitation record: GPCP version 2.1. Geophys. Res. Lett., 36, L17808, https://doi.org/10.1029/2009GL040000.

— , and Coauthors, 2018: NASA Global Precipitation Measurement (GPM) Integrated Multi-satellitE Retrievals for GPM (IMERG). Algorithm Theoretical Basis Doc., version 5.2, 35 pp., https://pmm.nasa.gov/sites/default/files/document_ files/IMERG_ATBD_V5.2_0.pdf.

Janowiak, J. E., and P. Xie, 1999: CAMS-OPI: A global satelliterain gauge merged product for real-time precipitation monitoring applications. J. Climate, 12, 3335-3342, https://doi.org/ 10.1175/1520-0442(1999)012<3335:COAGSR >2.0.CO;2.

— - R. J. Joyce, and Y. Yarosh, 2001: A real-time global halfhourly pixel-resolution infrared dataset and its applications. Bull. Amer. Meteor. Soc., 82, 205-218, https://doi.org/10.1175/ 1520-0477(2001)082<0205:ARTGHH>2.3.CO;2.

Jobard, I., F. Chopin, J. C. Berges, and R. Roca, 2011: An intercomparison of 10-day satellite precipitation products during West African monsoon. Int. J. Remote Sens., 32, 2353-2376, https://doi.org/10.1080/01431161003698286.

Joshi, M. K., A. Rai, and A. C. Pandey, 2012: Validation of TMPA and GPCP 1DD against the ground truth rain-gauge data for Indian region. Int. J. Climatol., 33, 2633-2648, https://doi.org/ 10.1002/joc.3612.

Joyce, R. J., J. E. Janowiak, P. A. Arkin, and P. Xie, 2004: CMORPH: A method that produces global precipitation estimates from passive microwave and infrared data at high spatial and temporal resolution. J. Hydrometeor., 5, 487-503, https://doi.org/10.1175/ 1525-7541(2004)005<0487:CAMTPG > 2.0.CO;2.

Kalnay, E., and Coauthors, 1996: The NCEP/NCAR 40-Year Reanalysis Project. Bull. Amer. Meteor. Soc., 77, 437-471, https://doi.org/10.1175/1520-0477(1996)077<0437:TNYRP> 2.0.CO;2.
Kanamitsu, M., W. Ebisuzaki, J. Woollen, S.-K. Yang, J. J. Hnilo, M. Fiorino, and G. L. Potter, 2002: NCEP-DOE AMIP-II Reanalysis (R-2). Bull. Amer. Meteor. Soc., 83, 1631-1643, https://doi.org/10.1175/BAMS-83-11-1631.

Kidd, C., and G. Huffman, 2011: Global precipitation measurement. Meteor. Appl., 18, 334-353, https://doi.org/10.1002/ met.284.

— trievals. Hydrol. Earth Syst. Sci., 15, 1109-1116, https://doi.org/ 10.5194/hess-15-1109-2011.

Kim, J.-E., and M. J. Alexander, 2013: Tropical precipitation variability and convectively coupled equatorial waves on submonthly time scales in reanalyses and TRMM. J. Climate, 26, 3013-3030, https://doi.org/10.1175/JCLI-D-12-00353.1.

Kobayashi, S., and Coauthors, 2015: The JRA-55 reanalysis General specifications and basic characteristics. J. Meteor Soc. Japan Ser. II, 93, 5-48, https://doi.org/10.2151/jmsj.2015001.

Koutsouris, A. J., D. Chen, and S. W. Lyon, 2016: Comparing global precipitation data sets in eastern Africa: A case study of Kilombero Valley, Tanzania. Int. J. Climatol., 36, 2000-2014, https://doi.org/10.1002/joc.4476.

Lorenz, C., and H. Kunstmann, 2012: The hydrological cycle in three state-of-the-art reanalyses: Intercomparison and performance analysis. J. Hydrometeor., 13, 1397-1420, https:// doi.org/10.1175/JHM-D-11-088.1.

Maggioni, V., P. C. Meyers, and M. D. Robinson, 2016: A review of merged high-resolution satellite precipitation product accuracy during the Tropical Rainfall Measuring Mission (TRMM) era. J. Hydrometeor., 17, 1101-1117, https://doi.org/10.1175/ JHM-D-15-0190.1.

Maidment, R. I., D. I. F. Grimes, R. P. Allan, H. Greatrex, O. Rojas, and O. Leo, 2013: Evaluation of satellite-based and model re-analysis rainfall estimates for Uganda. Meteor. Appl., 20, 308-317, https://doi.org/10.1002/met.1283.

- , D. Grimes, R. P. Allan, E. Tarnavsky, M. Stringer, T. Hewison, R. Roebeling, and E. Black, 2014: The 30 year TAMSAT African Rainfall Climatology and Time Series (TARCAT) data set. J. Geophys. Res. Atmos., 119, 10619 10 644, https://doi.org/10.1002/2014JD021927.

_ - and Coauthors, 2017: Data descriptor: A new, long-term daily satellite-based rainfall dataset for operational monitoring in Africa. Sci. Data, 4, 170063, https://doi.org/10.1038/ sdata.2017.63.

Matsuura, K., and C. J. Willmott, 2015: Terrestrial precipitation: 1900-2014 gridded monthly time series (version 4.01). University of Delaware, http://climate.geog.udel.edu/ climate/ html_pages/Global2014/README.GlobalTsP2014.html.

Mega, T., T. Ushio, T. Kubota, M. Kachi, K. Aonashi, and S. Shige, 2014: Gauge adjusted global satellite mapping of precipitation (GSMaP Gauge). XXXIth URSI General Assembly and Scientific Symp., Beijing, China, IEEE, 1-4, https://doi.org/ 10.1109/URSIGASS.2014.6929683.

Nikulin, G., and Coauthors, 2012: Precipitation climatology in an ensemble of CORDEX-Africa regional climate simulations. J. Climate, 25, 6057-6078, https://doi.org/10.1175/ JCLI-D-11-00375.1.

_ - and Coauthors, 2018: Dynamical and statistical downscaling of a global seasonal hindcast in Eastern Africa. Climate Serv., 9, 72-85, https://doi.org/10.1016/j.cliser.2017.11.003.

Nkiaka, E., N. R. Nawaz, and J. C. Lovett, 2017: Evaluating global reanalysis precipitation datasets with rain gauge measurements in the Sudano-Sahel region: Case study of the Logone 
catchment, Lake Chad Basin. Meteor. Appl., 24, 9-18, https:// doi.org/10.1002/met.1600.

NOAA/CPC, 2001: The NOAA climate prediction center African rainfall estimation algorithm version 2.0. NOAA/CPC Tech. Doc., 4 pp., https://www.cpc.ncep.noaa.gov/products/fews/ RFE2.0_tech.pdf.

Novella, N. S., and W. M. Thiaw, 2010: Validation of satellitederived rainfall products over the Sahel. NOAA/CPC Tech. Doc., 9 pp., https://pdfs.semanticscholar.org/c826/ 2ff005dc7d2c79e1c60e205076ba1a8f8821.pdf.

— , and _ 2013: African Rainfall Climatology version 2 for famine early warning systems. J. Appl. Meteor. Climatol., 52, 588-606, https://doi.org/10.1175/JAMC-D-11-0238.1.

Okoro, U. K., W. Chen, C. Chineke, and O. Nwofor, 2014: Comparative analysis of gridded datasets and gauge measurements of rainfall in the Niger Delta region. Res. J. Environ. Sci., 8, 373-390, https://doi.org/10.3923/rjes.2014.373.390.

Onogi, K., and Coauthors, 2007: The JRA-25 reanalysis. J. Meteor. Soc. Japan Ser. II, 85, 369-432, https://doi.org/ 10.2151/jmsj.85.369.

Paeth, H., and Coauthors, 2011: Progress in regional downscaling of West African precipitation. Atmos. Sci. Lett., 12, 75-82, https://doi.org/10.1002/asl.306.

Pfeifroth, U., J. Trentmann, A. H. Fink, and B. Ahrens, 2016: Evaluating satellite-based diurnal cycles of precipitation in the African tropics. J. Appl. Meteor. Climatol., 55, 23-39, https:// doi.org/10.1175/JAMC-D-15-0065.1.

Pierre, C., G. Bergametti, B. Marticorena, E. Mougin, T. Lebel, and A. Ali, 2011: Pluriannual comparisons of satellite-based rainfall products over the Sahelian belt for seasonal vegetation modeling. J. Geophys. Res., 116, D18201, https://doi.org/ 10.1029/2011JD016115.

Rienecker, M. M., and Coauthors, 2011: MERRA: NASA's Modern-Era Retrospective Analysis for Research and Applications. J. Climate, 24, 3624-3648, https://doi.org/ 10.1175/JCLI-D-11-00015.1.

Roca, R., P. Chambon, I. Jobard, P.-E. Kirstetter, M. Gosset, and J. C. Bergès, 2010: Comparing satellite and surface rainfall products over West Africa at meteorologically relevant scales during the AMMA campaign using error estimates J. Appl. Meteor. Climatol., 49, 715-731, https://doi.org/ 10.1175/2009JAMC2318.1.

Romilly, T. G., and M. Gebremichael, 2011: Evaluation of satellite rainfall estimates over Ethiopian river basins. Hydrol. Earth Syst. Sci., 15, 1505-1514, https://doi.org/ 10.5194/hess-15-1505-2011.

Saha, S., and Coauthors, 2010: The NCEP Climate Forecast System Reanalysis. Bull. Amer. Meteor. Soc., 91, 1015-1058, https:// doi.org/10.1175/2010BAMS3001.1.

— - and Coauthors, 2014: The NCEP Climate Forecast System version 2. J. Climate, 27, 2185-2208, https://doi.org/10.1175/ JCLI-D-12-00823.1.

Schneider, U., A. Becker, P. Finger, A. Meyer-Christoffer, M. Ziese, and B. Rudolf, 2014: GPCC's new land surface precipitation climatology based on quality-controlled in situ data and its role in quantifying the global water cycle. Theor. Appl. Climatol., 115, 15-40, https://doi.org/10.1007/s00704-013-0860-x.

Serrat-Capdevila, A., J. B. Valdes, and E. Z. Stakhiv, 2014: Water management applications for satellite precipitation products: Synthesis and recommendations. J. Amer. Water Resour. Assoc., 50, 509-525, https://doi.org/10.1111/jawr.12140.

Sheffield, J., and Coauthors, 2014: A drought monitoring and forecasting system for sub-Sahara African water resources and food security. Bull. Amer. Meteor. Soc., 95, 861-882, https:// doi.org/10.1175/BAMS-D-12-00124.1.

Sorooshian, S., K.-L. Hsu, X. Gao, H. V. Gupta, B. Imam, and D. Braithwaite, 2000: Evaluation of PERSIANN system satellite-based estimates of tropical rainfall. Bull. Amer. Meteor. Soc., 81, 2035-2046, https://doi.org/10.1175/15200477(2000)081<2035:EOPSSE > 2.3.CO;2.

Sun, Q., C. Miao, Q. Duan, H. Ashouri, S. Sorooshian, and K.-L. Hsu, 2018: A review of global precipitation data sets: Data sources, estimation, and intercomparisons. Rev. Geophys., 56, 79-107, https://doi.org/10.1002/2017RG000574.

Sylla, M. B., I. Diallo, and J. S. Pal, 2013: West African monsoon in state-of-the-science regional climate models. Climate Variability-Regional and Thematic Patterns, A. Tarhule, Ed., InTechOpen, 3-36, https://doi.org/10.5772/55140.

TAMSAT Group, 2016: TAMSAT version 3 calibration methodology. Draft TAMSAT Tech. Rep., University of Reading, Reading, 63 pp., http://www.met.reading.ac.uk/ emily/ TAMSAT_technical_report.pdf.

Tarnavsky, E., D. Grimes, R. Maidment, E. Black, R. P. Allan, M. Stringer, R. Chadwick, and F. Kayitakire, 2014: Extension of the TAMSAT satellite-based rainfall monitoring over Africa and from 1983 to present. J. Appl. Meteor. Climatol., 53, 2805-2822, https://doi.org/10.1175/JAMC-D-14-0016.1.

Thiemig, V., A. de Roo, and H. Gadain, 2011: Current status on flood forecasting and early warning in Africa. Int. J. River Basin Manage., 9, 63-78, https://doi.org/10.1080/ 15715124.2011.555082.

, R. Rojas, M. Zambrano-Bigiarini, V. Levizzani, and A. De Roo, 2012: Validation of satellite-based precipitation products over sparsely gauged African river basins. J. Hydrometeor., 13, 1760-1783, https://doi.org/10.1175/JHM-D-12-032.1.

,,$-- \ldots$, and A. D. Roo, 2013: Hydrological evaluation of satellite-based rainfall estimates over the Volta and BaroAkobo Basin. J. Hydrol., 499, 324-338, https://doi.org/10.1016/ j.jhydrol.2013.07.012.

Toté, C., D. Patricio, H. Boogaard, R. Van der Wijngaart, E. Tarnavsky, and C. Funk, 2015: Evaluation of satellite rainfall estimates for drought and flood monitoring in Mozambique. Remote Sens., 7, 1758-1776, https://doi.org/ $10.3390 /$ rs 70201758 .

Ushio, T., and Coauthors, 2009: A Kalman filter approach to the global satellite mapping of precipitation (GSMaP) from combined passive microwave and infrared radiometric data. J. Meteor. Soc. Japan Ser. II, 87A, 137-151, https://doi.org/ 10.2151/jmsj.87A.137.

van de Giesen, N., R. Hut, and J. Selker, 2014: The TransAfrican Hydro-Meteorological Observatory (TAHMO). Wiley Interdiscip. Rev.: Water, 1, 341-348, https://doi.org/ 10.1002/wat2.1034.

Wang, N.-Y., C. Liu, R. Ferraro, D. Wolff, E. Zipser, and C. Kummerow, 2009: TRMM 2A12 land precipitation product - Status and future plans. J. Meteor. Soc. Japan Ser. II, 87A , 237-253, https://doi.org/10.2151/jmsj.87A.237.

Worqlul, A. W., B. Maathuis, A. A. Adem, S. S. Demissie, S. Langan, and T. S. Steenhuis, 2014: Comparison of rainfall estimations by TRMM 3B42, MPEG and CFSR with groundobserved data for the Lake Tana basin in Ethiopia. Hydrol. Earth Syst. Sci., 18, 4871-4881, https://doi.org/10.5194/hess-184871-2014.

Xie, P., and P. A. Arkin, 1996: Analyses of global monthly precipitation using gauge observations, satellite estimates, and numerical model predictions. J. Climate, 9, 840-858, 
https://doi.org/10.1175/1520-0442(1996)009<0840:AOGMPU> 2.0.CO;2.

_ and _ 1997: Global precipitation: A 17-year monthly analysis based on gauge observations, satellite estimates, and numerical model outputs. Bull. Amer. Meteor. Soc., 78, 2539-2558, https:// doi.org/10.1175/1520-0477(1997)078<2539:GPAYMA>2.0.CO;2.

, J. E. Janowiak, P. A. Arkin, R. Adler, A. Gruber, R. Ferraro, G. J. Huffman, and S. Curtis, 2003: GPCP pentad precipitation analyses: An experimental dataset based on gauge observations and satellite estimates. J. Climate, 16, 2197-2214, https:// doi.org/10.1175/2769.1.

_- M. Chen, S. Yang, A. Yatagai, T. Hayasaka, Y. Fukushima, and C. Liu, 2007: A gauge-based analysis of daily precipitation over East Asia. J. Hydrometeor., 8, 607-626, https://doi.org/ 10.1175/JHM583.1.

, R. Joyce, S. Wu, S.-H. Yoo, Y. Yarosh, F. Sun, and R. Lin, 2017: Reprocessed, bias-corrected CMORPH global highresolution precipitation estimates from 1998. J. Hydrometeor., 18, 1617-1641, https://doi.org/10.1175/JHM-D-16-0168.1.
Xu, W., R. F. Adler, and N.-Y. Wang, 2013: Improving geostationary satellite rainfall estimates using lightning observations: Underlying lightning-rainfall-cloud relationships. J. Appl. Meteor. Climatol., 52, 213-229, https://doi.org/10.1175/ JAMC-D-12-040.1.

— — $—$, and — 2014: Combining satellite infrared and lightning information to estimate warm-season convective and stratiform rainfall. J. Appl. Meteor. Climatol., 53, 180-199, https://doi.org/10.1175/JAMC-D-13-069.1.

Xue, Y., and Coauthors, 2010: Intercomparison and analyses of the climatology of the West African Monsoon in the West African Monsoon Modeling and Evaluation project (WAMME) first model intercomparison experiment. Climate Dyn., 35, 3-27, https://doi.org/10.1007/s00382-010-0778-2.

Zambrano-Bigiarini, M., A. Nauditt, C. Birkel, K. Verbist, and L. Ribbe, 2017: Temporal and spatial evaluation of satellitebased rainfall estimates across the complex topographical and climatic gradients of Chile. Hydrol. Earth Syst. Sci., 21, 12951320, https://doi.org/10.5194/hess-21-1295-2017. 